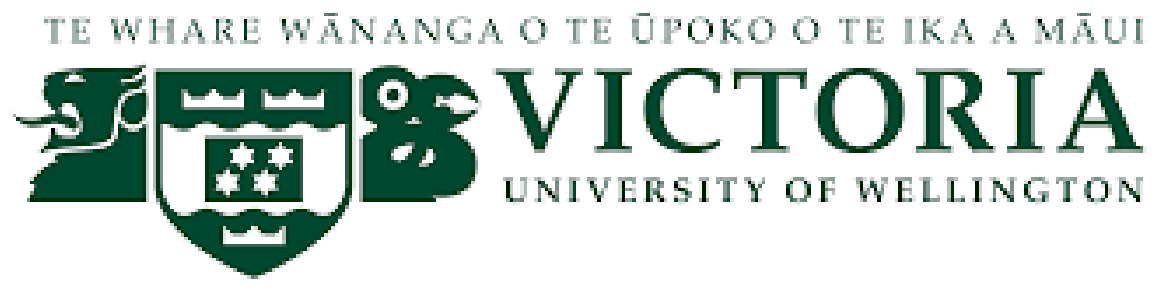

School of Geography, Environment, and Earth Science

Victoria University of Wellington

New Zealand

Understanding the urban livelihoods and wellbeing of migrant women working in garment factories in

\author{
Vientiane, Laos
}

\title{
Chanmala Homesana
}

Thesis submitted to Victoria University of Wellington in partial fulfilment of the requirements for the degree of Master of Development Studies 


\section{Abstract}

Rural-urban migrants are the major contributions to the labour force that drives the manufacturing sector in Laos. Migrants, particularly young women, contribute abundant cheap labour to garment industries. Despite their hard work and contribution, the living and working conditions for migrants are often overlooked. This thesis explores the migration, livelihoods and wellbeing of migrant women working in the garment factories in Vientiane, the capital city of Laos. This thesis focuses particularly on how working in the factories and living in the city affects the wellbeing of women

The field research was conducted in three garment factories in Vientiane where most garment factories are located. The data was obtained mainly from ten individual interviews and four focus group sessions with women workers. Additionally, ten officials from public and private sector were interviewed to bring additional perspectives into this research.

The theoretical framework of the study derives from the sustainable livelihood framework to explore the main aspects of women's livelihoods. Also, Marxist, radical and post-structural feminist theories are incorporated into the framework to analyse the issues facing migrant women. This research pays attention to how women are oppressed as a subordinated class and gender, as well as to how women individually and collectively use their agency to improve their conditions.

This thesis claims that working in the factory and living in the city have both positive and negative consequences for women workers. It has increased the human, social and financial capital of women workers. However, women were oppressed in many forms by their capitalist employers as well as by men inside and outside the factory. However, although women workers experience exploitation and oppression, they are able to construct their new identities and develop strategies to cope in their everyday lives. 


\section{Acknowledgement}

This thesis would not have been possible without the contributions of numerous people and institutions. First and foremost, I would like to express my sincere gratitude to my supervisor Professor John Overton for his continuous support, patience, motivation, and immense knowledge. His guidance helped me in all the time of research and writing of this thesis.

I would like to express my sincere thanks to the New Zealand government for granting me a scholarship through the New Zealand Aid Programme. This scholarship has provided me with financial support which enables me to pursue a Master's Degree in Development Studies at Victoria University of Wellington. Also, many thanks to the Victoria Scholarship Team for their support which made my academic journey in New Zealand so smooth.

I am indebted to the women workers in three factories where I conducted research. These women welcomed me into their dormitories with kindness. Importantly, their life stories and experiences are the foundation of this research. I hope that this research can show my respects and my thanks to these women by sharing their struggles and their experiences, as well as by showing that their voices have been heard.

I would like to thank my best tutor, Alex Hill, for her knowledge and generosity in supporting me with the writing of this thesis. Her suggestions and encouragement give me confidence and positive energy. Also, many thanks to my friends, classmates and office mates for fruitful discussion, for all experiences we shared and for the joy we have had in the last two years. Without them, my academic and personal life would not be this interesting.

Finally, I would like to thank the most important people in my life, my beloved family in Laos. I would like to thank my parents for raising me with the important value of education and for supporting me whatever choices I choose in life. Without their support, I would not come this far. I also would like to thank my younger brother and younger sister for their encouragement. Having them make me want to be a better sister and a good role model. 


\section{Abbreviation}

$\begin{array}{ll}\text { NSEDPS } & \text { National Socio-Economic Development Plans } \\ \text { MPI } & \text { Ministry of Planning and Investment } \\ \text { GDP } & \text { Gross domestic product } \\ \text { OECD } & \text { Organisation for Economic Co-operation and Development } \\ \text { GSP } & \text { Generalised Scheme of Preferences } \\ \text { UNDP } & \text { United Nations Development Programme } \\ \text { GRID } & \text { Gender Resource Information and Development Centre } \\ \text { FDI } & \text { Foreign Direct Investment } \\ \text { LAGF } & \text { Lao Association of Garment Factories } \\ \text { LSB } & \text { Lao Statistics Bureau } \\ \text { LAGF } & \text { Lao Association of Garment Factory } \\ \text { ASEAN } & \text { Association of Southeast Asian Nations } \\ \text { MOIC } & \text { Department for International Development } \\ & \end{array}$




\section{Table of Contents}

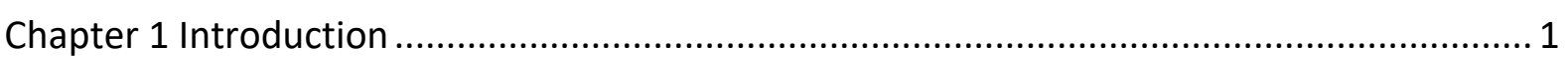

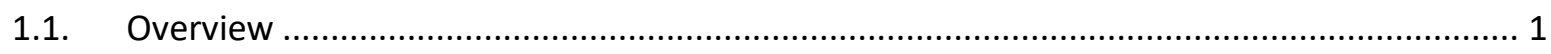

1.2. Research objective and research questions.................................................................. 2

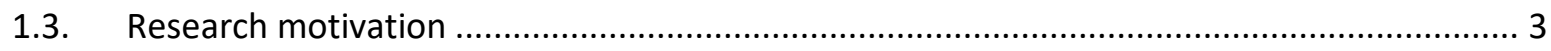

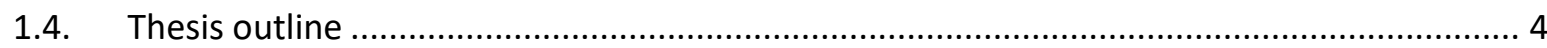

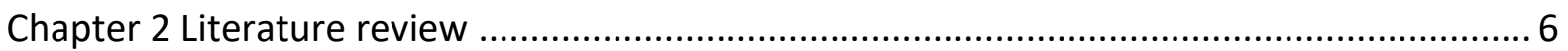

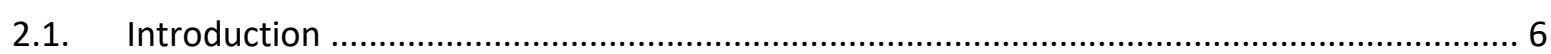

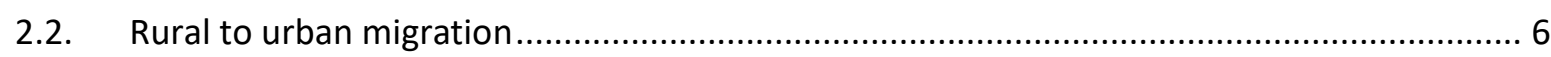

2.3. Patriarchy, gender norms and women's position in the labour force ................................. 7

2.4. Working and living conditions in the factories............................................................ 10

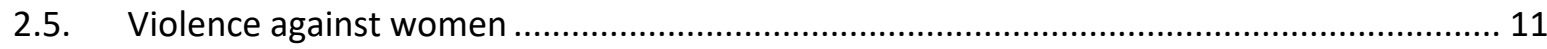

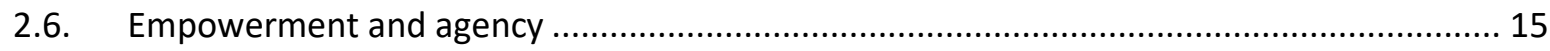

2.6.1. Concept of empowerment and agency ............................................................................ 15

2.6.2. Factory work and empowerment …………................................................................... 17

2.6.3. Women's agency, coping and resistance strategies........................................................ 19

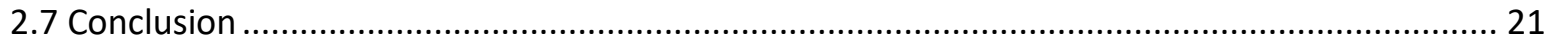

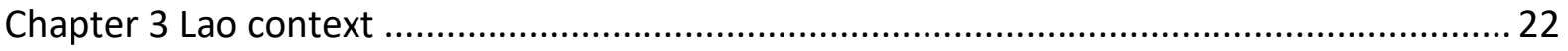

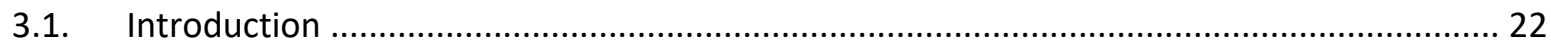

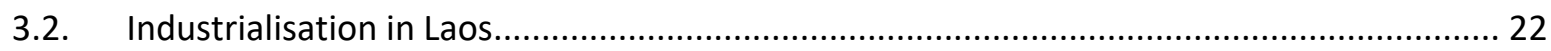

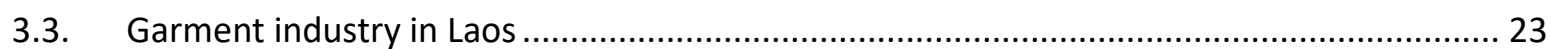

3.4. Human development and Garment labour force in Laos ................................................. 24

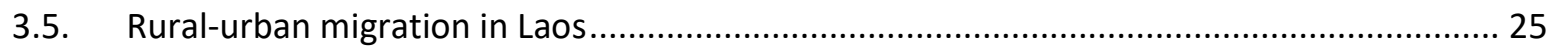

3.6. Working condition of garment factory workers in Vientiane .............................................. 26

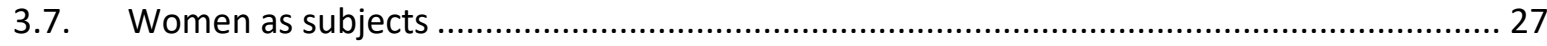

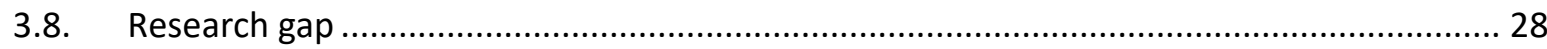

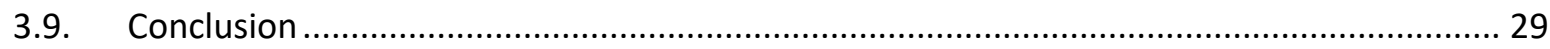

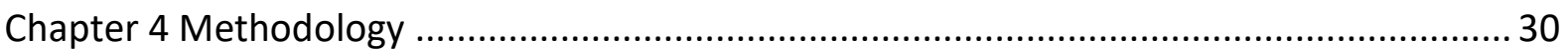

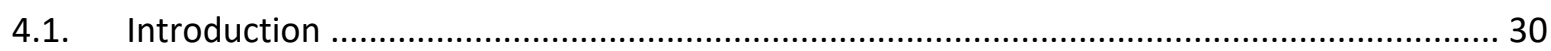

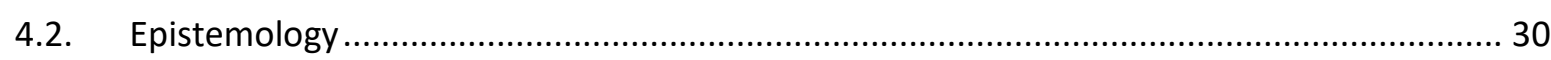

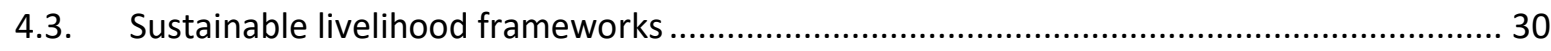

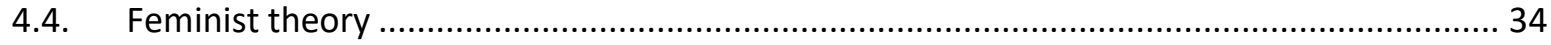

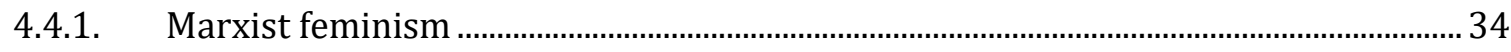

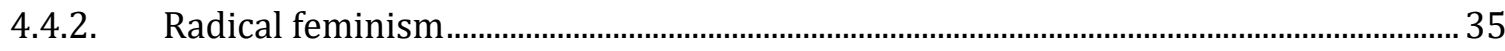

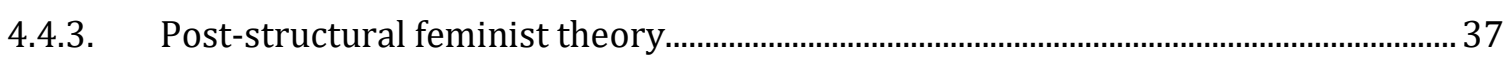




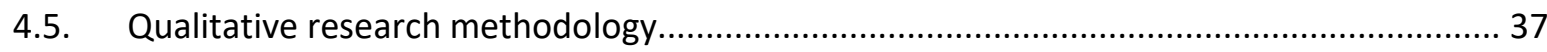

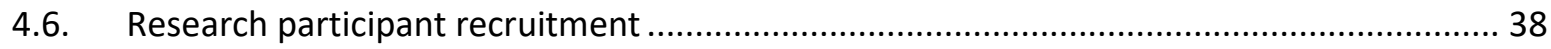

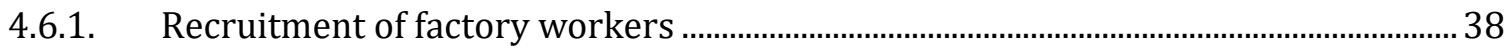

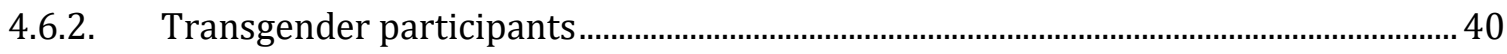

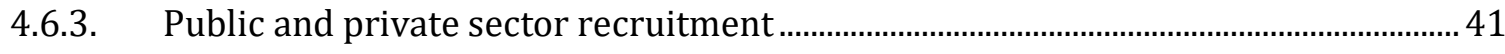

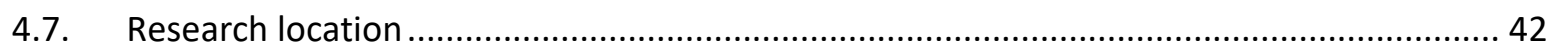

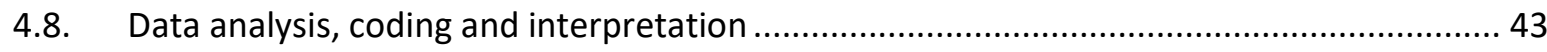

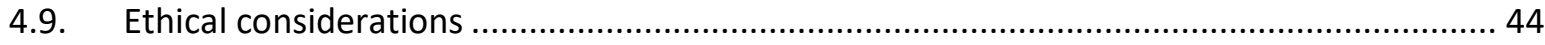

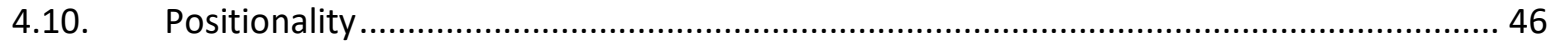

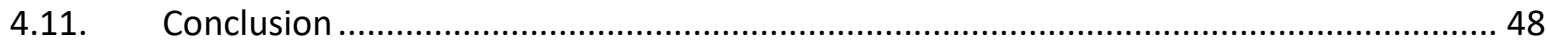

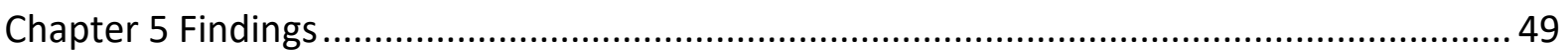

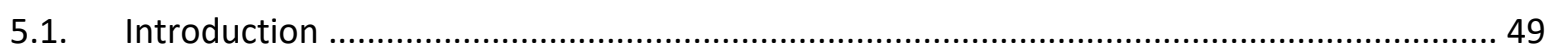

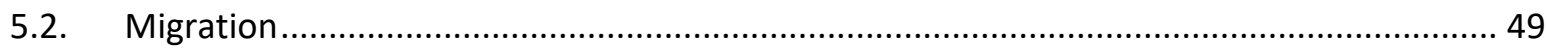

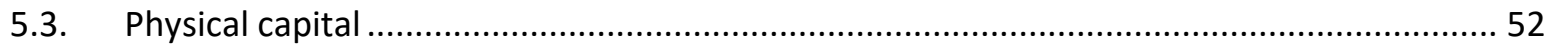

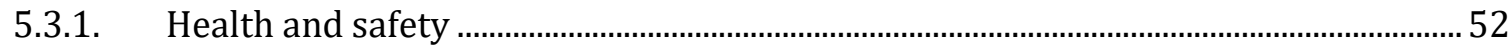

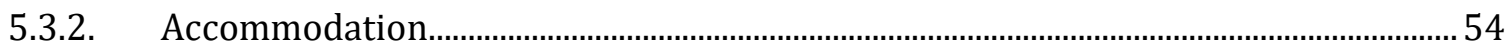

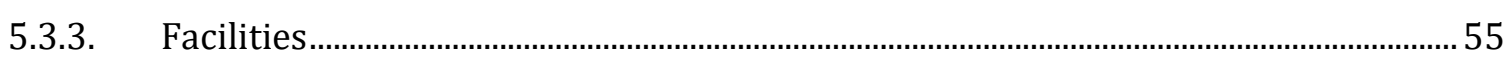

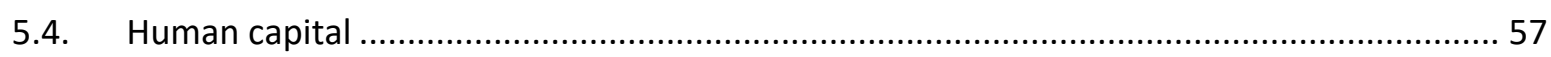

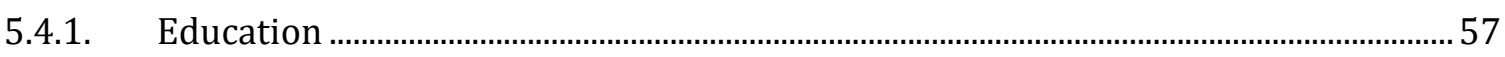

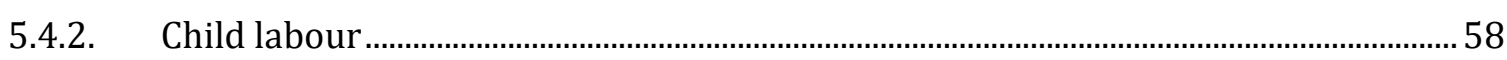

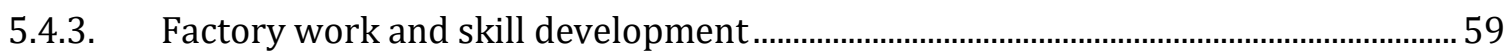

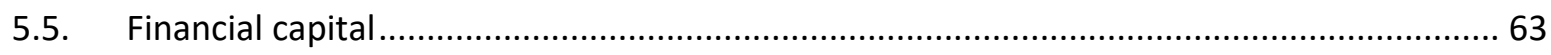

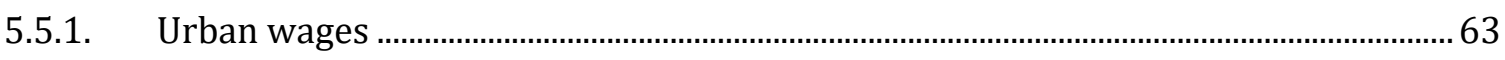

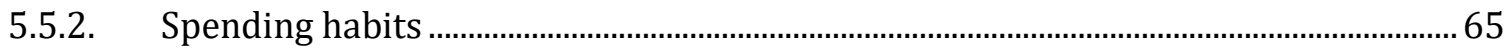

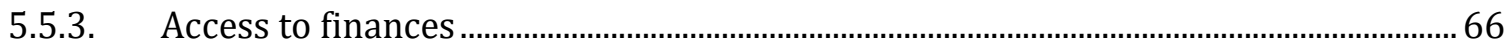

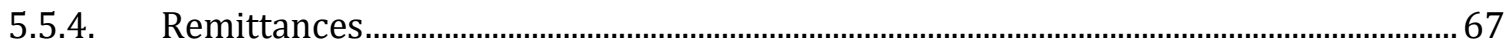

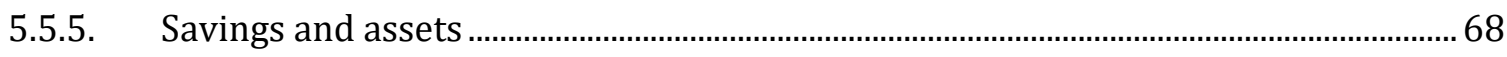

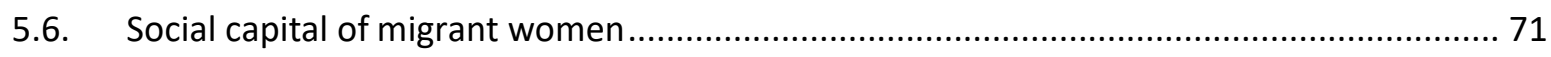

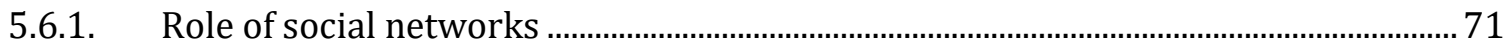

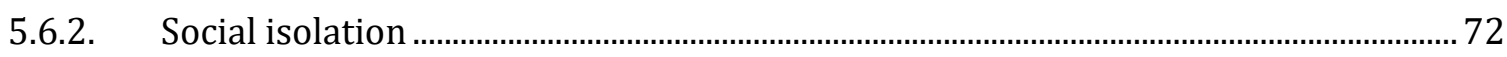

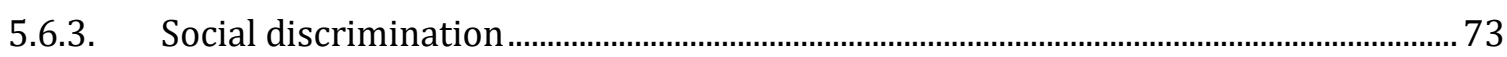

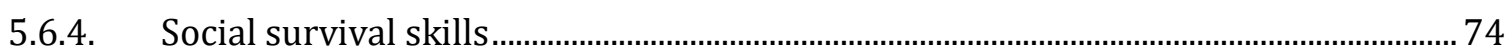

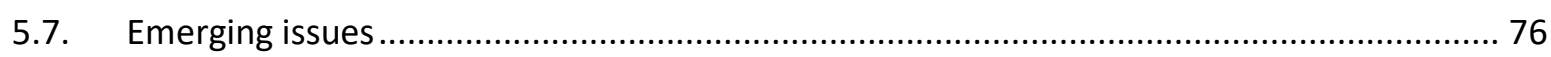

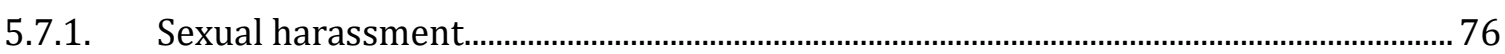

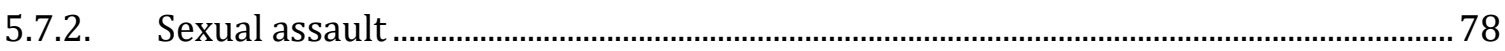

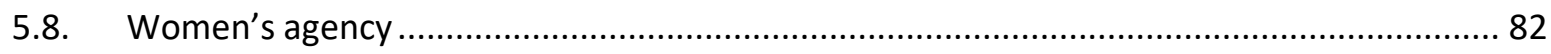

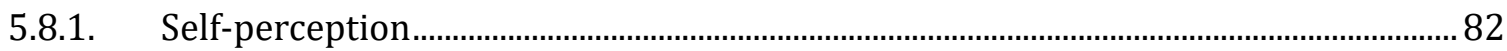




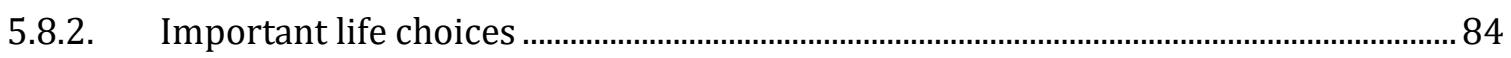

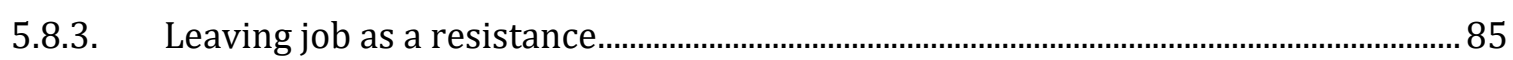

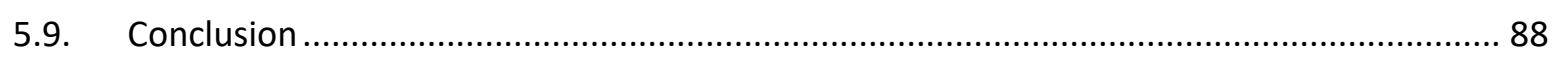

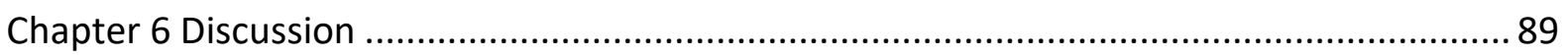

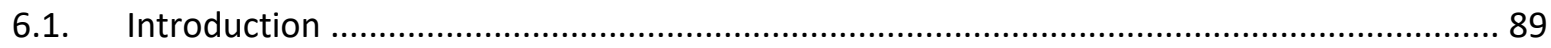

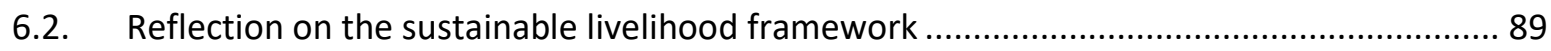

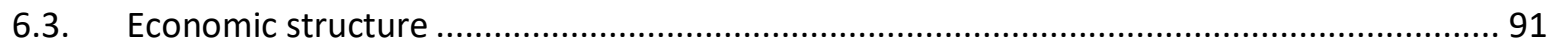

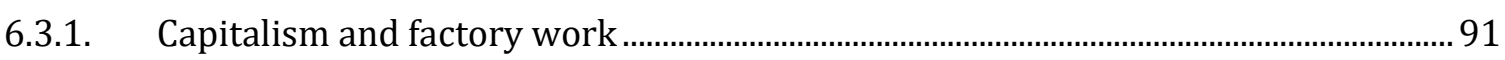

6.3.2. The reserve army of labour ...................................................................................... 94

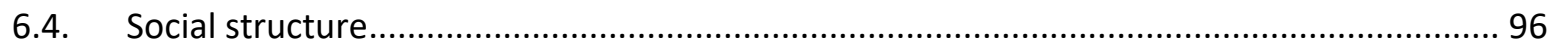

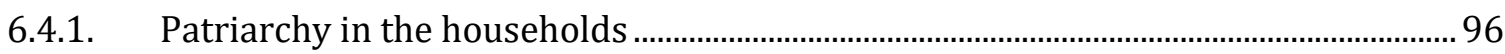

6.4.2. Workplace bullying and sexual harassment.................................................................... 96

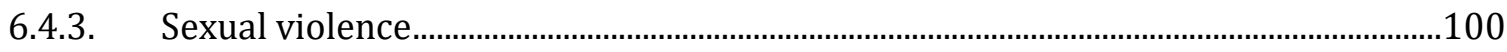

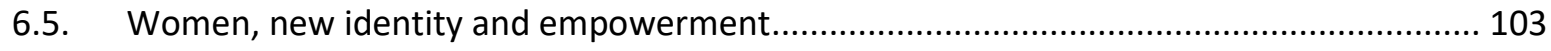

6.5.1. Individual agency ........................................................................................................106

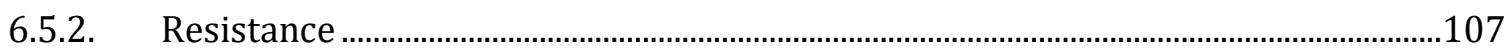

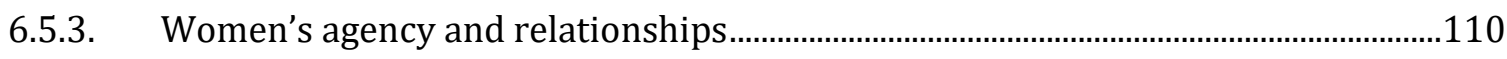

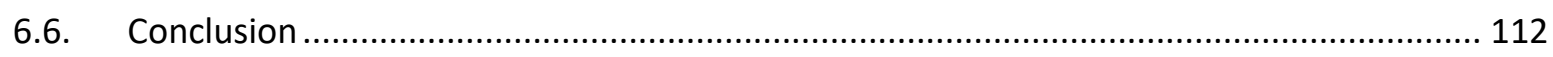

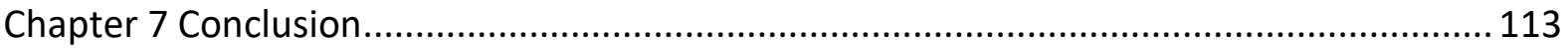

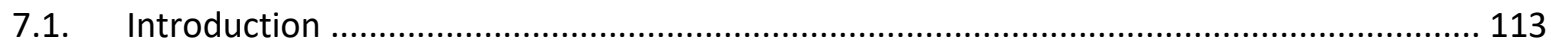

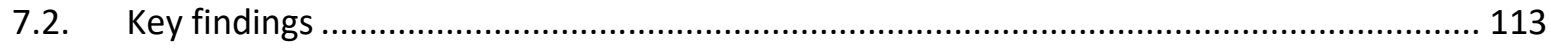

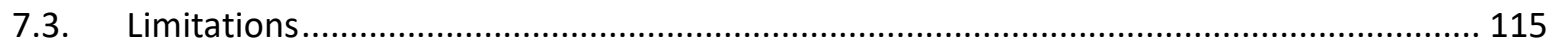

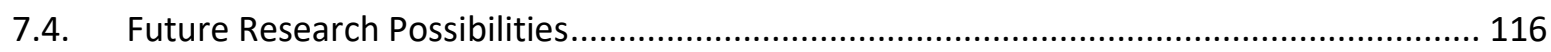

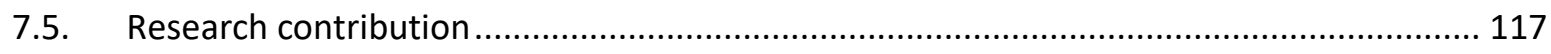

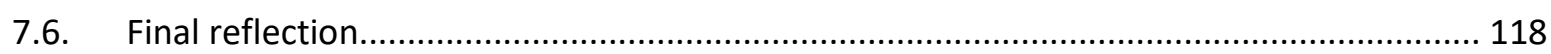

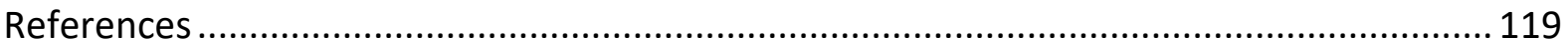

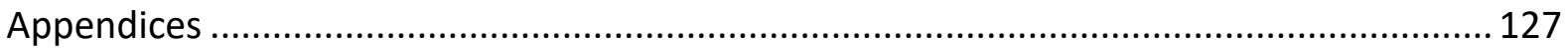




\section{List of Figure}

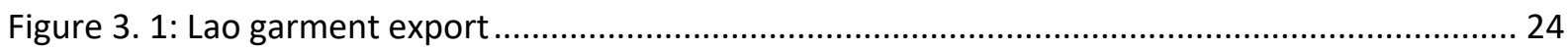

Figure 4. 1: Sustainable livelihood framework combing with feminist theories ............................... 32

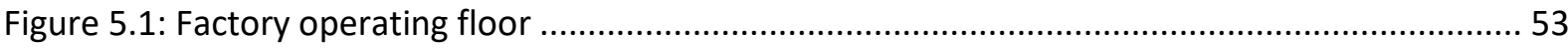

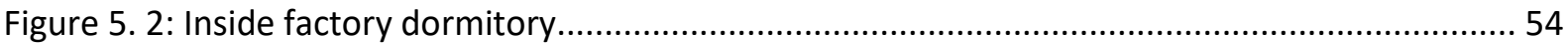

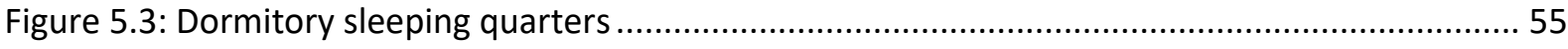

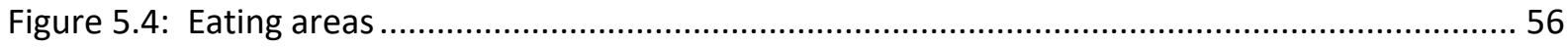




\section{List of Table}

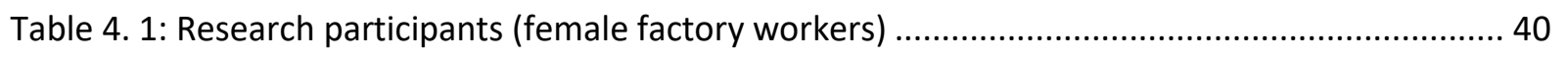

Table 4. 2: Research participants (public and private sector) ........................................................ 42

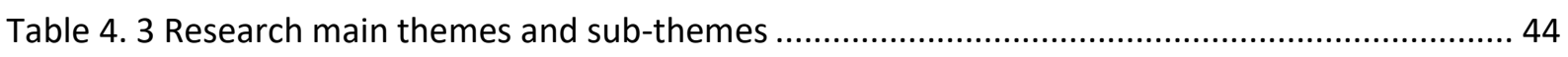




\section{Chapter 1 Introduction}

\subsection{Overview}

Many developing countries follow a modernisation pathway to achieving economic development. These developing countries aim to undertake the transition from traditional societies and economies to industrialised ones. Urbanisation is the result of such industrialisation. People move from rural areas to the city for better job opportunities and higher incomes. The flow of female migrants into the city has been seen widely in developing countries, especially in Southeast Asia, when these countries have undergone changes to pursue industrialisation (Phouxay \& Tollefsen, 2010).

In Laos, the introduction of the 'New Economic Mechanism' by the Lao government in 1986 has gradually transitioned Laos from 'a centrally planned economy' to a 'marketoriented economy' (Rigg, 2005). This was not just an economic reform, but also a political reform which opened the country after being closed for a long period of time under the socialist regime during the post-war period (Phouxay \& Tollefsen, 2010). This change resulted in reducing state enterprises and increasing private companies and foreign direct investment (FDI) (Phouxay, 2010).

The implementation of a new market economy has attracted foreign investment which has been highly concentrated in urban areas such as the capital city, Vientiane (Rigg, 2005). The outcome of these economic and political changes has been job opportunities in urban areas which attract young people, especially women, to migrate from rural to urban areas (Phouxay, 2010; Rigg, 2007). According to Phouxay (2010), the influx of young rural females into the capital city began in the 1990s. This was a period when foreign investment and urbanisation were government priorities. During this time, investment mainly concentrated around infrastructure, hydropower, transportation and construction (Rigg, 2005). In the manufacturing sector, many garment factories were established in the capital city, which created a large number of jobs. The garment industry exports $80 \%$ of its products to European countries (Freeman, 2001). Also, the improvement of infrastructure, such as transportation and communication, facilitated peoples' mobility in this period (Phouxay, 2010). This explains why there is a movement of young female workers from rural areas to the capital city. 
The migration of Lao women to urban areas is seen as a breaking away from traditional culture norms. Previously, Lao women were expected to be active only in the domestic sphere and had limited mobility due to customary rules. Also, the government restricted the movement of people from rural to urban areas (Phouxay \& Tollefsen, 2010). The change in government policy after 1968 helped women to move more freely as well as break free from social norms that had limited women's roles solely to the domestic sphere.

Since the 'New Economic Mechanism' was implemented, Laos has made progress in industrialisation and economic development despite its heavy reliance on overseas capital and investment. One significant factor that has driven the industrialisation in Laos has been its labour. The country would not be able to achieve growth without its workers, especially lowwage migrant workers who work long hours. Therefore, the study of economic and social impacts on the wellbeing of these workers is necessary. Much of the recent literature illustrates the development of this industry, but less attention has been paid to the wellbeing of factory workers. The limited literature means that voices of migrant women workers have not been heard.

This study aims to explore the wellbeing and livelihoods of migrant women workers in garment factories in Vientiane, the capital city of Laos. The main focus will be on the challenge these women face as low paid migrant workers under the capitalist system, as daughters in patriarchal households and as members of a subordinated group in the urban society. This study also presents another side of the story of how migrant women develop strategies to cope with their working and living conditions in their everyday lives.

\subsection{Research objective and research questions}

The main objective of this research is to explore the experiences of women who migrate from rural areas to work in garment factories in Vientiane. It investigates how working and living in urban contexts influences the lives of rural-urban migrant women and how these women adapt to, embrace, respond to and resist the capitalist system and patriarchal society for their betterment.

In order to respond to the main research objective, the following central research question and sub-questions were developed: 
How has migration to the cities and factory work affected the livelihoods, wellbeing and development of women from rural areas in Laos?

1. What are the current livelihood and wellbeing conditions of migrant women working in the garment factories?

2. To what extent has working in the garment factories and living in the city changed women's livelihoods and wellbeing?

\subsection{Research motivation}

My interest in the issues faced by women factory workers stems from my own curiosity. Growing up in Vientiane, I used to pass by the factories and see a large group of women walking out from the factory gates to buy food at the pop-up stalls. It was like seeing a parade and it would always catch my eye. For me, the gates of the factory were like a boundary that separated the women from the outside world. Previously, I had volunteered to teach fundamental computer skills to the factory women workers. This was my first time getting in contact with the real factory workers. During my volunteer work, I was surprised, fascinated and impressed by the willingness of these women to learn. However, I felt that the women that attended these classes were better off. They probably did not represent the majority of factory workers.

Whenever people in my community talked about 'sao hong ngarn' or women factory workers, they often stigmatized them. For example, they always assumed they were poor, earned low wages, and were involved with sex work and had abortions. This perception can be seen widely in society, even in some of my friends who made jokes when I told them that my thesis is about female factory workers. Throughout my life, I have heard rumours and unpleasant stories about female factory workers from people in the Lao society, but I never heard from the women themselves. I always questioned why. This curiosity and questions are the reason why I am conducting this research. I want to bring out the voices of those women who were stigmatised by Lao society. 


\subsection{Thesis outline}

This thesis consists of seven chapters:

Chapter 1 explains the background of the research, research motivation, research objectives and research questions.

Chapter 2 reviews the literature and relevant studies internationally on the migrant women working in the garment factories. It starts with a discussion on women in relation to the labour wage economy and then examines women's lives inside the factories. The chapter then discusses violence against women which is the prevalent issues affecting women workers wellbeing. Finally, the chapter discusses factory work, women's agency and empowerment.

Chapter 3 describes the context of Laos. It briefly explains industrialisation in Laos, then discusses the issues of migration and migrant women's wellbeing in the garment factories. The chapter also identify the research gap.

Chapter 4 explains the methodology used in this research. It outlines how the research was conducted, including the conceptual framework and theories used, the methodology employed, and the participant selection process, as well as data analysis. Human ethics and positionality are also considered in this chapter.

Chapter 5 provides answers to the first sub-questions of the research. It explains the factors of migration as well as the current livelihood situation of migrant women in the factories in four main aspects: physical capital, human capital, financial capital and social capital. This chapter also highlights a theme that emerged from the research, that is the sexual harassment and violence that the migrant workers frequently experienced.

Chapter 6 discusses the capitalist system and patriarchal society and compares this with the agency of the women. The first part of the chapter explores the role of the capitalist system and how patriarchal society hinders the wellbeing of migrant women. The second part presents the counter-argument of how women individually and collectively find ways to survive and resist those structures. The discussion draws on the sustainable livelihood framework and feminist theories. 
Chapter 7 concludes the main findings and discussion of the research. The chapter clarifies how it has answered the research questions. Limitations, potential further research and research contribution are also identified in this chapter. 


\section{Chapter 2 Literature review}

\subsection{Introduction}

This chapter reviews international literature associated with the rural to urban migrant women working in the garment factories. The aim of this chapter is to provide an overall picture of this issue globally in order to apply these studies to the analysis and discussion in chapter six. This chapter begins by explaining how rural to urban migration occurs. It then reviews the concept of how gender norms influence women's participation in a labour wage economy. It follows by examining the worldwide situation of factory workers' working and living conditions. The issue of violence against women is also raised. The chapter ends with a discussion on migrant women's empowerment and agency.

\subsection{Rural to urban migration}

Rural-urban migration is a significant global issue. In the cases of Laos, China and Vietnam, rural to urban migration emerges because of the transition from a socialist economy to a market economy (Barry, 1996; Fang \& Dewen, 2008; Rigg, 2005). This economic transition is founded on industrialisation to drive economic growth. Most economic activities operate in the urban areas or big cities. Cheap labour is in demand to increase productivity in the industrialisation sector, and the emergence of urbanisation creates a large number of urban jobs (Barry, 1996; Fang \& Dewen, 2008). At the same time, the urban populations in various places are inadequate for supplying labour to the industrial sector. Many urban residents are not willing to take cheap labour jobs, while the development of agricultural technology creates a labour surplus in rural areas (Barry, 1996; Fang \& Dewen, 2008). This situation leads to the movement of populations from rural to urban areas.

Rural-urban migration is seen as a livelihood strategy for many rural households. In developing countries, rural people cannot completely rely on government welfare systems (Massey et al., 1993). Sending family members to work in urban areas is one strategy for diversifying households' incomes if unexpected events such as agricultural failure and economic crisis occur (Stark, 1991). For example, Zaman (2001) found that poverty, unemployment in rural areas, and the death of a male breadwinner are the main push factors for Bangladeshi women to migrate to the city. Similarly, Attanapola (2006) explains that poverty, debt, crop failure and the illness of a family member pressures Sri Lankan women to 
migrate to the city and take up factory jobs to support their families. However, economic motivations such as better job opportunities and higher income are not the only drivers of migration. Many researchers claim that there is also the desire of young women to experience an independent way of life and to become modern women (Khamphouvong \& Santasombat, 2014; Mills, 1997; Sisaleumsak, 2012). On the other hand, there are also negative drivers of migration. In patriarchal societies, gender discrimination and norms play roles which drive women's migration. Jolly and Reeves (2005) explain that some single women migrate to avoid being controlled by a patriarchal family and being forced to follow customary rules such as arranged marriage. Also, divorced women in various regions migrate to escape stigma (Jolly \& Reeves, 2005). Such patriarchy systems, along with social and gender norms, can not only drive and restrict women's movement, but they can also have an impact on women's participation in the labour market as well.

\subsection{Patriarchy, gender norms and women's position in the labour force}

Walby $(1990$, p.20) defines "patriarchy as a system of social structures and practices in which men dominate, oppress and exploit women". Lim (1997, p.220) defines patriarchy as "the system of male domination and female subordination in economy, society and culture that has characterised much of human history to the present day". Sultana (2010) claims that the patriarchal ideology of male superiority creates norms and practices that keep women under control and produce women's subordination. The norms and practices of patriarchy exist in all aspects of women's lives, including both private and public spheres. For example, the division of masculine and feminine in the private and public spheres was created by the gender socialisation process which begins in early childhood (Sultana, 2010). Sultana also points out that the socialisation process is made possible by social agents in the society (e.g. families, religious institutions, education systems, economics, and political and media systems). These agents are the main actors in defining roles of women and men and making sure the patriarchal norms and ideology are preserved (Sultana, 2010). Due to the existing patriarchal norms and ideology, women have experienced subordination in various forms including discrimination, control and violence in households, both in their workplace and in society. Parental preference for sons over daughters, burdensome domestic duties assigned to women, violence against women, and control over women's sexuality, reproduction and mobility are some examples of widespread patriarchal norms (Sultana, 2010). These norms also have an impact on women's employment as discussed below. 
Gender norms regarding women's roles and responsibilities explain why women become trapped in labour-intensive and low-paid sectors in the wage economy. The common gender norms regarding women's roles in the household create a double burden for women. Birdsall \& McGreevey (1983) explained that prior to the establishment of a market economy, the time and effort women contributed in their households (including child care and unpaid family farm work) were not regarded as a form of employment. Even though women contributed significantly to their household's economy and well-being, their contribution was often undervalued by their families because it did not generate a cash income. Since the market economy was introduced, the transformation of the economy has changed the lives of women dramatically. Women can now enter the labour market and it has created opportunities for them to earn an income. This creates a double burden for women of not only working for a cash income, but also contributing to their households' duties. Women have to work longer hours inside and outside the home compared to their male counterparts (Birdsall \& McGreevey, 1983). Hancock (2006) illustrates the double burden that Sri Lankan garment factory women workers experience. These women feel exhausted working in the garment factories the whole day with few breaks, before going back home to cook and do house work for their families at night without the help of their husbands. Female factory workers in Hancock's studies felt overwhelmed coping with their many responsibilities (Hancock, 2006).

Gender norms not only influence women's roles in the households and economy. These norms also determine women's characteristics, attributes and behaviours. In Southeast Asia, manufacturing employers prefer to employ women, especially young migrant women, because of their perceived nature as docile, well-behaved and submissive (Foo \& Lim, 1989; Ong, 1988). They are also considered to be obedient to managers' orders, they lack legal knowledge, and they are unlikely to form a union against their employers (Birdsall \& McGreevey, 1983). Elson and Pearson (1981) explains that the preference for a female labour force in world market factories is due to the higher profits they can earn for the capitalist system and their natural attributes of feminism. Capitalists employ female workers because the cost of employing them is cheaper and they are often more productive than their male counterparts (Elson \& Pearson, 1981). This creates higher profits for capitalist firms. The following paragraph captures the powerful idea of how women's natural attributes benefit capitalists: 
Women are considered not only to have naturally nimble fingers, but also to be naturally more docile and willing to accept tough work discipline, and naturally less inclined to join trade unions, than men; and to be naturally more suited to tedious, repetitious, monotonous work (Elson \& Pearson, 1981, p.93).

These natural attributes of women lead to women holding secondary status in the labour market. This includes 'natural wastage', a term which refers to female labour leaving work for marriage or pregnancy (Elson \& Pearson, 1981). Cho, Zammit, Chung, \& Kang (2004) discuss why some factories prefer to employ young unmarried female workers more than male and married female workers. Unmarried female workers "were socialised to accept their situation and gender inequality as an acceptable outcome" (Cho et al., 2004, p. 39). These workers were passive which benefited employers by minimizing conflicts in the factories and maintaining low wages. Also, unmarried women spent less time contributing to their households compared to married women. These reasons make unmarried women more desirable for employers.

Gender norms regarding women's main role in reproduction cause young female labourers to have short working lives and make them prone to accepting low wage jobs. Foo \& Lim (1987) claim that the norms that prescribe reproduction as women's primary role restrict them to a short working life because they have to swap paid work for marriage. In Foo and Lim's (1987) study, Malaysian female factory workers perceived themselves as secondary breadwinners of their family, while men were the primary and long-term breadwinners. After completing their education, women looked for informal employment such as factory work because it was easy to get hired and to leave these jobs. As a consequence, women were not willing to bargain for higher wages or positions. This also caused a lack of females holding senior positions in the factories and an overrepresentation of females in this sector, which contributed to the low salaries of female labourers (Foo \& Lim, 1987). Employers gained the advantage of being able to dismiss female workers easily due to significant life stages such as marriage and childbirth (Birdsall \& McGreevey, 1983). Therefore, we have seen the creation of sex-segregated divisions of labour with women overrepresented in low skilled and low wage occupations, such as garment factory work. 


\subsection{Working and living conditions in the factories}

Due to the demand for labour from export-oriented factories and the preference for female workers in this sector, a large number of young females migrate from their homes to work in urban areas. There are common characteristics of female migrants working in the factories in several Asia countries: young, unmarried, migrants from rural areas, low levels of education, a lack of rights and legal knowledge, and from poor families (Zaman, 2001; Khamphouvong \& Santasombat, 2014; Phouxay \& Tollefsen, 2010). Most of the women's families are associated with agricultural activities. They have little or no prior waged labor experience. However, the literature from Sri Lanka found that female factory workers have different characteristics in terms of education. Many studies in Sri Lanka found that female factory workers were reasonably well-educated with 10-12 years of school attendance (Attanapola, 2006; Hancock, Carastathis, Georgiou, \& Oliveira, 2014). This is in contrast to some Southeast Asian nations such as Cambodia, Laos, Vietnam and Thailand.

Many studies across the Southeast Asian region point out similar working and living conditions experienced by factory workers. These conditions include poor living conditions, low wages and unfair employment practices by employers. Migrant women workers, particularly those from the same ethnic group and regions, often prefer to live collectively in shared dormitories provided by the factories (Attanapola, 2006; Elmhirst, 2002; Phouxay, 2010). Their accommodation is usually overcrowded and is of a poor sanitary standard (Bélanger \& Pendakis, 2010; Tran, 2007; Phouxay \& Tollefsen, 2010). If the factories do not provide accommodation, many women rent cheap rooms near the factories together because they cannot afford to pay for individual rooms.

Generally, in many Asian countries, female migrants work under exploitative conditions. Women receive low wages and face an unpleasant working environment at the factory. For example, female workers work long hours with short breaks for lunch and dinner and are forced to regularly work overtime in order to supply products for the worldwide markets in a timely manner. In some cases, women are forced to work overnight. Late salary payments, no pay for overtime work, and public humiliation, such as yelling and shouting at employees, seem to be common practices in many factories (Hancock, 2006; Tran, 2007; Ong, 1988; Phouxay, 2010; Zaman, 2001). 
Along with the harsh working conditions, unfair labour treatment can be seen in several Asian countries. For example, in Vietnam, many multinational factories avoid signing a permanent contract with employees even when they pass a probationary period (Tran, 2007). Sub contracts, temporary contracts, and in some cases no contracts at all were used by factory owners and management to avoid paying social security, health care and social benefits (Tran, 2007). This kind of labour violation happens widely. Also, many factories require workers to be flexible. Women workers have had to cope with production fluctuation such as overwork during peak seasons and underemployment during periods of low demand from the global market (Tran, 2007).

In addition to unpleasant and unfair working conditions, job insecurity and hazardous workplace environments put workers at risk. In Bangladesh, fire accidents and a lack of safety precautions are serious concerns for factory workers (Zaman, 2001). For example, according to Zaman (2001), from 1990 to 1997, 50 fire accidents happened in Bangladeshi garment factories, causing hundreds of lives to be lost and thousands of injuries. The accidents resulted in many international organisations calling for the improvement of factory safety worldwide (Zaman, 2001).

\subsection{Violence against women}

One of the most critical issues impacting the wellbeing of factory workers is violence against women. Sexual harassment and violence towards women workers in the factories was reported in several studies in South and Southeast Asia (Hancock, 2006; Lawreniuk \& Parsons, 2017; Zaman, 2001)

The United Nations defines violence against women as:

Any act of gender-based violence that results in, or is likely to result in, physical, sexual or psychological harm or suffering to women, including threats of such acts, coercion or arbitrary deprivation of liberty, whether occurring in public or private life (United Nations, 1993, Declaration on the Elimination of Violence against Women Article 1, para.1).

The term violence against women refers to a variety of experiences such as "intimate partner violence, sexual violence, and sexual harassment including physical, emotional and other forms of abuse within these" (Powell, Sandy, \& Findling, 2015, p.7). 
One of the important causes contributing to sexual harassment and violence is unequal social and gender norms between men and women which regard men as being superior to women (Scott, Bell, \& Holden, 2016; Lawreniuk \& Parsons, 2017; World Health Organization \& London School of Hygiene and Tropical [WHO \& LSHT], 2010).

The ideology of patriarchy and male superior norms has an effect on society, individual attitudes and actions (Sultana, 2010; Scott, Bell \& Holden, 2016). According to Scott, Bell and Holden (2016), this patriarchal ideology and unequal gender norms are the main factors supporting gender power hierarchies. Due to socially constructed norms, males were raised with the idea of being the dominant gender and were seen as having a high economic, social and religious value compared with women. Women, on the other hand, were socialised to think that they are subordinate and should be under male control. When society places a higher value on men than women, male power and domination emerge from this privilege (Scott et al., 2016). "Women's subordination and submission is then considered to be normal, expected, accepted and, in some cases, attractive to men" (WHO \& LSHT, 2010, p.26). The privilege and superiority given to men by many societies prevents women from participating in important decision-making and leadership roles (WHO \& LSHT, 2010). If there is any woman who is strong, well-educated and does not allow herself to be under the norms of male domination, she often faces disfavour from society.

The World Health Organisation points out some social and cultural norms support violence against women and girls. These include:

"[when] a man has a right to assert power over a woman and is considered socially superior; [when] a man has a right to physically discipline a woman for "incorrect" behaviour; [when] physical violence is an acceptable way to resolve conflict in a relationship;" and "[when] sexual activity (including rape) is a marker of masculinity" (WHO \& LSHT, 2010, p.53).

Despite the fact that different societies construct masculinity differently and multiple forms of masculinity exist, some studies have found a link between the masculine social constructs and male violence against women (Jewkes, Flood, \& Lang, 2015; USAID, 2015). Universally, the control over and violence against women is a male expression of power and a showing off of some aspect of being 'real men' (USAID, 2015). These control and domination tactics are also considered as masculine attributes and "recognised as a shared social ideal" 
(Jewkes, Flood, Lang, 2014, P.3). This reason might explain why violence against women is prevalent in various spaces and why men and women may regard some forms of sexual harassment and violence as acceptable and normal (Jewkes, Flood, Lang, 2014).

The study by (Hlavka, 2014) on youth accounts of harassment and abuses found these transgressions happen routinely across cultures. Young female students in the United States, including white, black and Latina, normalised sexual harassment by regarding sexually harassing behaviours from boys as normal, common, and even customary. Women were regarded as gatekeepers of male sexuality. For example, women were responsible for establishing the boundaries and refusing male sexual behaviours. If any serious sexual cases occurred, women were blamed for it by their peers. Also, sexual assault perceptions related to the term 'heteronormativity' or 'heteronormative discourses', tended to "consistently link female sexuality with passivity, vulnerability, and submissiveness, male sexuality with dominance, aggression, and desire" Hlavka (2014, p.339). For example, sex was regarded as "'something they [men and boys] do," or "something he wanted", and sexual assault was a "weird" threat, "something they just say", or "something she let happen"” (Hlavka, 2014, p.351).

According to Lawreniuk and Parsons (2017), factories in Cambodia were reported to be tolerant of sexual infringements and to not take jokes, verbal intimidation and annoyances seriously. These cases of sexual harassment and violence were described as an 'abrasive work culture' which happened regularly and were perceived as normal by workers. Additionally, no effective measures were taken by employers to solve the reported cases of sexual harassment. Women coped with these incidents by changing their own perceptions of sexual harassment as 'nothing serious' (Lawreniuk \& Parsons, 2017).

Migrant women workers are exposed to higher risks and higher degrees of sexual harassment than non-migrant women (Lawreniuk \& Parsons, 2017; Zaman, 2001; Hancock, 2006). Migrant women lack social support in urban areas and are unfamiliar with the new environment, which exposes them to risks (Lawreniuk \& Parsons, 2017). Also, migrant women travelling and living alone without male protection are often seen by men as vulnerable (Hancock, 2006; Zaman, 2001).

Sexual harassment and assault are prevalent inside and outside the factory (Lawreniuk \& Parsons, 2017; Zaman, 2001; Hancock, 2006). Women workers suffered impacts from 
violence mentally, physically, emotionally, and economically. Sexual harassment occurs regularly in many forms. Lawreniuk and Parsons (2017) interviewed 1287 workers, both female and male, across 52 factories in Cambodia. They found that nearly one in three female workers had faced sexual harassment inside the garment factories in the previous 12 months. However, few women reported these incidents to the authorities. Importantly, the study also noted the productivity lost due to sexual harassment. This was due to workers going absent or quitting their jobs to escape the harassment. Those women that continued working on the factory floor felt a sense of insecurity and a loss of mental energy. Anticipating, preventing and escaping sexually harassing behaviour made it hard for the women to concentrate on their work. Absenteeism and staff turnover, on average, cost the garment industry around 89 million USD annually (Lawreniuk \& Parsons, 2017).

Perpetuator of sexual harassment are often the male manager of female factory workers. Garment factory workers in Thailand reported that their production manager offered women promotions in exchange for sexual intercourse (Zaitun, 2001). In this case, some women decided to leave the job or move to another workplace. Similarly, in Sri Lanka, Hancock (2006) found factory workers who were victims of sexual violence and harassment by their male managers in the workplace did not want to speak up or take legal action. Reasons for this included the high expense, a lack of support and fear of losing one's job. Hancock (2006) explains that some victims of sexual violence decided to leave their job to escape the shame associated with sexual assault and harassment procedures. This procedure often put women in the spotlight because social norms generally place the blame on the victim (Hancock, 2006).

Harassment and abuses are serious problems for female factory workers in South and Southeast Asia. Young female migrants in the export oriented factories were not only harassed in the workplace, but also faced further harassment and abuse by society, host communities and local men (Attanapola, 2006; Hancock, 2006; Hewamanne, 2003). The forms and degrees of harassment and abuse varied. Serious cases of harassment can be seen in Sri Lanka in the studies of Hewamanne (2003) and Attanapola (2006). In Sri Lanka, Hewamanne (2003) found that the public considered factory women as morally-loose workers and third class citizens. Female workers coming from other regions and travelling without male protection drew public attention. "Popular accounts of widespread pre-marital sex, rape, prostitution, abortion, and infanticide simultaneously portray these women as victims of labour and sexual exploitation and as victims of their own loose morals" (Hewamanne, 2003, p.74). People in 
the community disrespected and regarded these women as damaging Sri Lankan culture. People regarded the export processing zone where these women worked as a 'whore zone' (Hewamanne, 2003). These perceptions lead to sexually violent behaviours by men that women have had to face in their daily life (Hewamanne, 2003). Similarly, in Sri Lanka, all women in the export processing zone participating in the research of Attanapola (2006) experienced harassment by local men. Many women in the study pointed out that local men harassed them in daily life, both verbally and physically (Attanapola, 2006). For example, women reported men touching their bodies and being robbed or hit by the men if the women resisted their advances. Most of the cases happened when women travelled alone outside the export processing zone (Attanapola, 2006).

\subsection{Empowerment and agency}

In order to explore and understand these concerning processes of exploitation, oppression and violence, it is important to see how women themselves respond. Here we see not just passive submission but also active and strategic measures by women. Notions of empowerment and agency provide insight into these responses.

\subsubsection{Concept of empowerment and agency}

Empowerment is about power and the process of gaining power. According to (Batliwala, 1994), power is the "control over material assets, intellectual resources and ideology" (p.130). She defines empowerment as "the process of challenging existing power relations and of gaining greater control over the sources of power" (P.130).

Rowland (1997) unpacks the concept of empowerment by distinguishing between different forms of power. She categorises power into four main forms namely 'power over', 'power to', 'power with' and 'power within'. 'Power over' refers to controlling power (Rowlands, 1997). It means one group has power over or dominates over another group, such as men over women and elite over working class (Rowlands, 1998). This form of power is "in finite supply; if some people have more, others have less" (Rowlands, 1998, p. 13). In this sense, the idea of women gaining more power or being empowered may result in men losing power and control.

Rowlands claims that 'power to', 'power with' and 'power within' focus on the process of empowerment and work in a different way of empowerment to 'power over.' In 'power to,' 
gaining more power does not cause anyone to lose power (Rowlands, 1998). 'Power to' is defined as generative or productive power. This can sometimes come in forms of resistance and manipulation (Rowlands, 1997). "It is a form of power which can persuade and open up new possibilities" (Rowlands, 1998, p.13). It does not necessary conflict with other interests or result in reducing power of other groups even though sometimes it may (Rowlands, 1998). 'Power with' is the power of a collective group and solidarity among the group to be greater than an individual (Rowlands, 1997). It is the ability of the collective group to work together to achieve shared goals in order to change the system in which domination is most prevalent (Allen, 1998). 'Power from within' refers to the internalised individual attributes such as spiritual strength, self-respect, self-acceptance, self-worth and dignity that exist inside each individual (Rowlands, 1997).

These forms of power link to Kabeer's empowerment concept. Kabeer (1999) defines power as "the ability to make choices" (p.436). She argues that empowerment is "the expansion of people's ability to make strategic life choices in a context where this ability was previously denied to them" (1999, p. 437). There are three core elements in Kabeer's empowerment concept: resources, agency and achievement (Malhotra, Schuler, \& Boender, 2002). Resources are "enabling factors" that can foster an empowerment process (Malhotra et al., 2002). Education and employment can be counted as enabling factors or resources. The concept of resource is not limited only to economic resources, but also social and political resources. These resources support people's ability to make their own choices (Kabeer, 1999).

Agency is the main component of empowerment. Kabeer $(1999$, p.438) defines agency as "the ability to define one's goals and act upon them. Agency is about more than observable action; it also encompasses the meaning, motivation and purpose which individuals bring to their activity, their sense of agency or the "power within'".

There are many forms of agency ranging from decision making to "bargaining and negotiation, deception and manipulation, subversion and resistance as well as more intangible, cognitive processes of reflection and analysis" (Kabeer, 1999, P.438). Kabeer (1999) also categorizes agency into both negative and positive aspects. She refers to 'power over' as a negative sense of agency. She defines 'power over' as "the capacity of an actor or category of actors to override the agency of others" by using some forms of violence and coercion (Kabeer, 1999, p.438). For positive agency, Kabeer refers to 'power to'. 'Power to' is "people's 
capacity to define their own life-choices and to pursue their own goals, even in the face of opposition from others" (Kabeer, 1999, p.438).

Despite the different forms of agency, it does not mean that women should be left alone to empower themselves. Instead, policies and interventions from various organisations should support women to have better access to resources (Malhotra et al., 2002). Social, economic and political resources are important as enabling factors for women's empowerment (Malhotra et al., 2002). However, having access to resources does not always mean that women will have control over these resources or be empowered. Resources alone cannot help empower women. Women individually and collectively should exercise their agency to recognise and utilise resources for their own interests. This fits with the feminist idea that "empowerment is not something that can be done to or for women" (Cornwall, 2016, p.356).

\subsubsection{Factory work and empowerment}

There is evidence to suggest that factory work can empower women. Some studies point out that women feel empowered in households or their private sphere, while being victims of capitalism under exploitative working conditions (Mill, 1997; Zaman, 2001; Bélanger \& Pendakis, 2010). Also, other studies mention that despite their unpleasant working conditions, women are seen as 'agents of change' and not as victims of globalisation because of their planned strategies and their negotiating roles in both public and private spheres (Hancock et al., 2014; Kabeer, Mahmud \& Tasneem, 2011). It is worth noting here that cultural backgrounds of each region might have an effect on the varied results of the research. Hence, it is important to take into account the specific context of each region.

Foo and Lim (1989) and Bélanger and Pendakis (2010) explained the relationship between factory employment and women and marriage in Malaysia and Vietnam, respectively. Both studies found that wage work delayed the marriage age of women. Bélanger and Pendakis (2010) claimed that the belief that women enter adulthood by getting married in Vietnam is somewhat replaced by the attainment of employment and economic independence. Similarly, Foo and Lim (1989) claimed that Malaysian female factory workers get married later in life than their mothers. They were able to negotiate and choose their own partner in marriage and did not fall into the arranged marriage custom in the past (Foo \& Lim, 1989). Delayed marriage and the freedom of women to choose their future life partner 
emphasises that some aspects of labour work contribute to women's empowerment (Foo \& Lim, 1989).

Many studies found that after migrating to work in the factory, women felt a sense of empowerment and were able to take control of their own lives. Mill (1997) found that by participating in paid work, Thai women have an ability to express their opinions, and have a voice in family decision-making due to their financial contributions to their family and through donations to religious organisations. Thai women in Mill's study were treated as independent adults by their family (Mill, 1997). Similarly, Zaman (2001) concluded that Bangladeshi women felt positive about their future and being consulted for advice by others. Being employed in the factory enabled women to become one of the bread-winners in the family and to be able to negotiate in patriarchal households with their husbands, fathers and brothers (Zaman, 2001). Moreover, Bélanger and Pendakis (2010) found that young Vietnamese migrant women working in factories felt a great sense of pride. This was because they were able to live independently in urban areas, earn an income and no longer depend on their family financially. Despite their low salary, Vietnamese women managed to give a contribution back to their family. In Vietnam, the society valued sons over daughters. However, remittances are seen as repayment to parents and as women proving their self-worth. Remittances also change the social norm that daughters generally rely on their parents for support. Hence, by contributing to their family, these migrant women felt a sense of pride and empowerment (Bélanger \& Pendakis, 2010). These studies reflect how a labour wage in the market economy brings more than economic change or material value to women. They have a positive impact on the social value of women's lives as well.

While much of the literature points out the relationship between household financial contribution and the sense of empowerment, Kabeer et al. (2011) and Hancock et al. (2014) claim that women feel empowered if they focus on one's self more than contributing to their households. Kabeer et al's (2011) study of migrant workers in Bangladesh found that women in formal work are empowered when they have control over income through investing in assets under their own name (i.e. not in family accounts) and have knowledge about labour laws. Similarly, Hancock et al. (2014) found that female factory workers in Sri Lankan factories felt empowered if they had control over their personal income through accumulating their own savings over a period of time. If contributing to family income resulted in reducing their own savings, factory women were more likely to feel disempowered. Hence, the feeling of 
women's empowerment depended on the benefit to the individual rather than the collective group (Hancock et al., 2014). These findings are opposite to various studies which state that family income contribution is the way to empowerment.

Women who focused on individual selves more than on their households were also seen in Elmhirst's (2002) study. According to Elmhirst (2002), the autonomy of Indonesian migrant daughters was displayed in the way they controlled the spending of their income. Even though migrant daughters sent money home to their mothers, they stated clearly how they would like it to be spent. For example, the daughters advised their mothers to purchase goods that they would be able to transfer to their own households when they got married. Factory work and remittance spending contributed to an increase in bride price, in turn contributing to the future household of women and their husbands. It also reduced the burden placed on parents of providing materials once the women married. In this case, the daughters' autonomy mirrors the individual investment of women rather than that of households. Income from daughters was not seen as contributing to household support, but instead to increasing bride price for marriage (Elmhirst, 2002).

\subsubsection{Women's agency, coping and resistance strategies}

Factory women in developing countries face various challenges in daily life, so they adopt survival skills to cope with these issues. According to Zaman (2001), to fight exploitative conditions in the workplace, Bangladeshi workers used personal resistance strategies. For example, women asked their supervisor to stop the verbal abuse for their work quality and requested the supervisor teach them how to perform more efficiently. They used assertive language to urge their supervisors to pay their overdue monthly salary. Many workers were aware and participated in protests, meetings and demonstrations to claim their rights. Many women built relations with activist groups and labour unions in order to maintain their rights and maximise their social benefits (Zaman, 2001). In Sri Lanka, Hancock (2006) noted that women developed many strategies to avoid harassment by local men. Some women travelled in groups. Others hid their identity as factory women. Some women restricted their travel at night and avoided being in risky situations. Some workers participated in NGO activities to learn about garment women's rights and used this knowledge to confront employers in cases of unfair treatment (Hancock, 2006). 
According to Tran (2007), in Vietnam, the factory women would show resistance by taking action in the form of strikes. The aim was to raise awareness, to guard against unfair treatment and to disclose labour violations brought upon them by the factories. After the Vietnamese government legalised strikes in 1995, most strikes have happened in foreignowned factories. Also, a soft form of protest in state-owned factories included petitions and complaint letters sent to the local newspapers and local government departments. Many women workers in Vietnam took a lead role in organising and directing strikes. These women were regarded as elderly sisters or experienced workers with knowledge about labour rights. These 'sisters' recruited young and low skilled workers who respected and obeyed them to participate in the strikes. The existing culture bonds in terms of religion, native place identity and their sense of dignity were used by elder sisters to encourage young workers. The women strike leaders in Tran's (2007) study used the local newspaper and TV channel for spreading protests and strikes news. This put pressure on relevant parties to discuss and negotiate in order to solve the problems. Strikes and protests were organised during critical times such as close to product delivery dates. Machines were stopped at critical stages. These women were well aware that their employers were afraid to lose their credibility in supplying orders and failed to act in accordance with international labour standards. Women workers used the aforementioned tactics to grab attention of advocates at all levels ranging from local to city, and newspaper to government departments (Tran, 2007).

While Vietnamese women made a huge impact with their resistance aiming for public exposure, there is evidence that factory women in Malaysia used their characteristics as women and cultural practices to protest against unfair treatment. According to Ong (1988), Malay girls are perceived as shy, fearful, obedient and subordinate to their managers. Instead of protesting publicly or using assertive resistance, Malay women used their female characteristics to resist the hard work by slowing down their work pace, increasing time spent in prayer rooms and the toilet and being careless in their work. If the foreman complained about the long time spent in prayer rooms, Malay women argued that they should not interrupt their traditional and cultural practice. That is, the Malay women used their traditional beliefs in protest. Women reported being fearful, worried and obsessed by seeing ghosts and spirits in the prayer room. One by one the women started screaming and crying becoming unable to work because they were possessed and afraid. In some case, factories closed down to heal and remove the spirits from the factory by way of traditional spirit 
healers. Also, claims of spirit possession in factories was a form of thinly disguised protest, a way of Malay women drew public attention to unfair treatment and control and poor factory working conditions (Ong, 1988).

\subsection{Conclusion}

Overall, this chapter has discussed the factors that impact women's migration, women's participation in wage labour and women's wellbeing. It drew on particular cases of migrant women factory workers internationally, particularly in Southeast Asia. The existing literature suggests women become the victims of the existing economic and social structures. In terms of economic factors, changes in economic policies drive people to migrate from rural areas to work in the city. Women are exploited inside the capitalist factories through unpleasant working and living conditions. In addition to economic factors, social and gender norms regarding women's roles in households and reproduction put more burden on women. These norms also determine women's characteristics and create sexual division of labour. Women encounter sexual harassment and violence on a daily basis. Some types of the sexual harassment are normalised and accepted by the workplace as well as by some women.

On the other hand, this chapter has presented women as active agents capable of improving their own conditions. Women workers find ways to empower themselves by controlling their own income, contributing to their households or by participating in household decision-making. Also, women use their agency to combat exploitative conditions in the workplace. Women individually and collectively develop coping and resisting strategies. Their strategies range from soft forms involving traditional approaches to aggressive ones such as strikes and protests. 


\section{Chapter 3 Lao context}

\subsection{Introduction}

The previous chapter outlined relevant studies internationally. This chapter looks specifically at rural-urban migrant women in the context of Laos. It discusses industrialisation in Laos, the current situation of the garment industry and how it impacts the labour force development of Laos. The chapter also provides an insight into rural-urban migration and the current studies on migrant women workers in the garment factory. Furthermore, the relevant studies associated with Lao women workers perspectives are also presented in this chapter. The chapter ends with identifying the research gap.

\subsection{Industrialisation in Laos}

The introduction of the 'New Economic Mechanism' by the Lao government in 1986 has gradually transitioned Laos from a centrally planned economy to a market-oriented economy. This economic mechanism has opened up the economy and allowed market forces to operate. This reform has resulted in reducing state enterprise, increasing the number of private companies and attracting foreign direct investment (FDI) (Phouxay, 2010). In 2002, the first industrialisation and modernisation strategy of Lao outlined five major industries: agriculture production, mining, electricity production, tourism, and construction material manufacturing (Oraboune, 2012).

Promoting private investment is an example of supporting policies to achieve this strategy (Lengsavad \& Vanthana, 2017). To support the industrialisation strategy, the government has facilitated economic integration. Large infrastructure projects have been invested in, such as the 'land link' strategy: road construction to facilitate economic movement and link the country with its neighbouring as well as integrate regional areas. Special economic zones have also been developed to distribute several industries throughout different parts of Laos (Oraboune, 2012).

The Lao government has set an impressive goal of graduating from the least developed country status by 2020 . To achieve such an ambitious goal, the country aims for achieving rapid economic growth in each of its National Socio-Economic Development Plans (NSEDPs). After opening the country to the outside world, FDI has contributed significantly to the socialeconomic development of Laos through the flow of capital and large investment projects. For 
example, in the Seventh (2011-2015) and Eighth (2016-2020) NSEDPs, the country aimed for an annual average of at least 8 percent economic growth. Laos has been able to achieve such impressive growth with a GDP growth rate of 7.9 percent on average from 2010 to 2015 (MPI \& UNDP, 2017). Even though Laos can achieve such high growth, the growth rate does not translate into sustainable development. In the past decade, most FDI was capital intensive and concentrated in the natural resource exploitation sector mainly hydroelectricity and mining.

These sectors generate high economic growth and large profits, but do not promote inclusive growth. That is, they are capital intensive and not labour intensive. Many people are concerned about an uncertain future as the economic growth of Laos is highly dependent on its natural resource sectors. This can potentially restrict the growth of other sectors, particularly non-resource ones. Also, production in natural mining and other resources are expected to decline, which brings up the question of the sustainability of these sectors (Oraboune, 2012). Rapid growth in Laos is concentrated in particular regions while poverty remains widespread and this has caused income disparities between rural and urban areas to increase (OECD, 2014). Also, many FDI projects have threatened the livelihood of rural people since they are located in the rural agriculture areas, causing displacement (OECD, 2014).

\subsection{Garment industry in Laos}

The current Lao garment industry grew rapidly but now declining each year. According to the Lao Association of Garment Factories LAGF (2018), from 2003 to 2011, Laos experienced an increase in foreign investment and the garment industry continued to grow. However, there were 124 factories with 27,000 workers in 2005 , but this has reduced to 78 factories with 26,000 employees at the beginning of 2018. Since 2012, an average of six to seven factories have closed down each year. The main reasons for closing down are labour shortages, low productivity (World Bank, 2012), increasing costs of labour, unstable production orders during peak and low seasons, low returns on investment, and high competition between production bases of many ASEAN countries (LAGF, 2018).

According to the data from LAGF (2018), Vientiane is the main hub for factories in Laos, with 74 factories located there in 2018. This is due to its geographical location, in close proximity to the Thailand border where the garment logistic bases to other ports are located. There are four other factories: one in Vientiane province, two in Savannakhet and one in 
Champasack province. Fifty out of the 78 factories are export-oriented factories, while 28 are subcontracting factories producing for main exporters and the domestic market (LAGF, 2018).

Figure 3.1 shows that the European Union (EU) has long been the main market for the Lao garment industry, which received nearly 90 percent of Lao garment exports in 2016, while Japan is second with 6 percent of Lao garment exports going there (LAGF, 2018). The primary reason for this is the benefits under the trade agreement between Lao and the European Union that exempt tariffs for Lao garment products entering the EU market (World Bank, 2012).

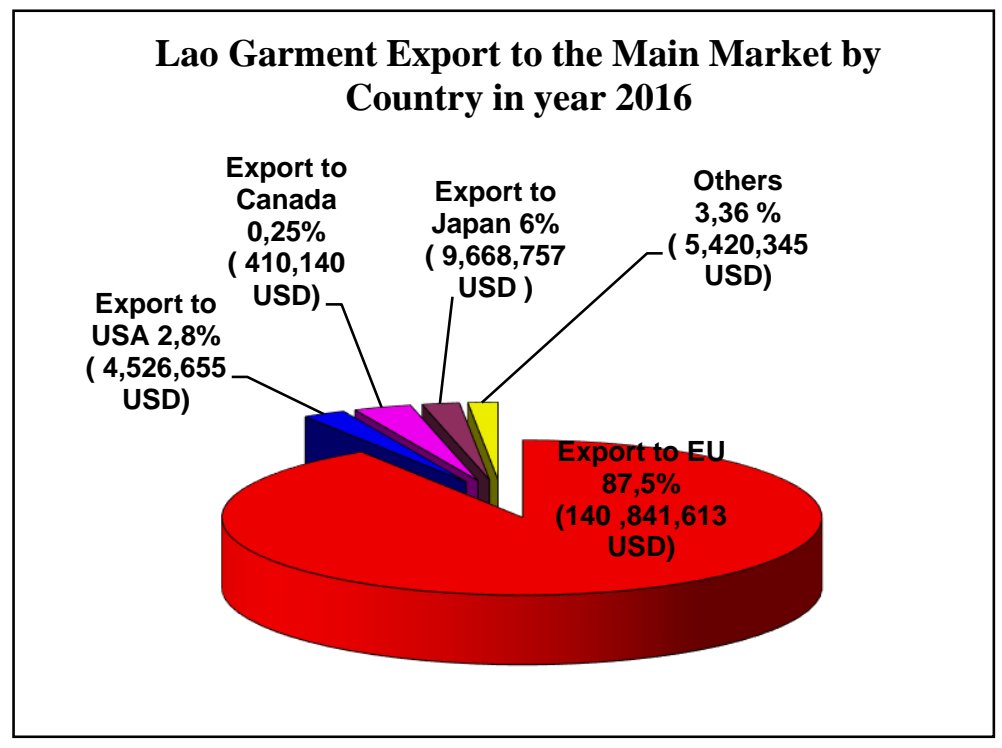

Figure 3. 1: Lao garment export

Source: Lao Association of Garment Factories

In 2016, Lao has 33 supporting factories for the garment industry, including 13 embroidery factories, 11 printing factories, 5 washing factories and 4 carton factories (LAGF, 2018). It can be seen that Laos lacks the factories to provide the raw materials needed for the garment factories such as cotton, textiles and machinery. These necessary materials are imported from neighbouring countries. This is a disadvantage for Laos as it means it cannot easily compete with other Southeast Asia countries.

\subsection{Human development and Garment labour force in Laos}

Holding the status of a least developed country, Laos gains benefits from the Generalised Scheme of Preferences (GSP) agreement that allows Laos to pay no duties on garment exports to Europe (MPI \& UNDP, 2017). The share of the garment industry which 
used to be high in the past has become a smaller proportion of the export sector because of the growth in the natural resource sector (MPI \& UNDP, 2017).

Many countries in Southeast Asia such as Cambodia, Vietnam, Thailand and Malaysia are competitive due to their surplus labour. Laos is in a different situation. With a population of just 6.8 million people, Laos does not have a large population like its neighbouring countries (MPI \& UNDP, 2017). The working population of Laos is the least literate and numerate in the region and its lack of skilled workers is one of the main concerns for garment investors (World Bank, 2012). With its relatively small size and non-skilled labour force, Laos is at a disadvantage and struggle to compete with its neighbouring countries in employment intensive sectors like the garment industry. One of its only advantages is the low rank of prevailing wages.

Along with the labour force, Laos is a landlocked country. The labour issue drives most foreign investors to invest in the natural resource sector. However, by focusing on the natural resource sector, diversification of the Lao economy cannot be achieved. Therefore, Laos needs to upgrade its human capital and diversify its economy to reduce vulnerability in order to elevate to more complex manufacturing production (MPI \& UNDP, 2017).

The garment industry is considered to be a significant non-resource sector of the Lao economic diversification and trade integration. Compared to the natural resource intensive sector, the garment industry can produce a large number of jobs and offer more employment opportunities for rural migrant workers than the natural resource sector (World Bank, 2012). The garment industry also employs workers for longer periods of time unlike the natural resource sector which employs people only during construction and implementation periods.

\subsection{Rural-urban migration in Laos}

According to the Lao Statistics Bureau (2016), women in Laos migrate within the country more than men, constituting 59.2 percent of all internal migrants. Vientiane is the most popular destination, especially for migrants from the Northern provinces of Huaphanh, Xiengkhuang, Luang Prabang and Phongsaly which consist of a large number of ethnic minorities (Phouxay, 2010). Vientiane has the highest number of lifetime migrants (38.1 percent in 2015). From 2005 to 2015, around four percent of the population, or 206,000 people, were internal migrants moving from one province to another (Lao Statistics Bureau, 
2015). The majority of people in Southern Laos are likely to migrate to Thailand due to geographical proximity (Phouxay, 2010).

The legal migration process consumes time and money and migrants are faced with a highly restrictive immigration process. Due to this arduous process, a large number of migrants choose to cross the border, illegally or through informal agencies, into Thailand. The illegal migration of female migrants to Thailand exposes them to a high risk of human trafficking and labour exploitation (Phouxay, 2010). Even though females dominate this migration process, they are often perceived to be working in informal sectors such as domestic work, restaurants and entertainment venues (Gender Resource Information and Development Center [GRID], 2005). A large number of female migrants enter work in garment factories where they have already established social networks (Phouxay, 2010).

\subsection{Working condition of garment factory workers in Vientiane}

The majority of rural-urban female garment workers in Laos are young, unmarried migrants with a low level of education, from low-income farming families, and whose families are associated with agricultural activities. They have little or no prior waged experience (Khamphouvong \& Santasombat, 2014; Phouxay \& Tollefsen, 2010).

The working conditions of rural-urban female workers in Laos are quite similar to those of other Asian countries where female migrants work under exploitative conditions. In Laos, "women work hard, long hours, with overtime work at night and on holidays. They have low wages and work under strict rules with only short breaks for lunch and dinner" (Phouxay, 2010, p.55). From previous studies in Laos, it seems that factory work is regarded as temporary work for many young rural-urban migrants and they do not intend to work in the factory for a long period. Women regard factory work as temporary and are willing to change jobs for a better opportunity elsewhere (Phouxay \& Tollefsen, 2010). This temporary job status and lack of knowledge makes them prone to becoming victims of exploitation.

While young female migrants in the garment factories work hard in unpleasant conditions to send money back home, society views them negatively. Phouxay and Tollefsen (2010) focused their study on Lao rural-urban female migrants' status inside and outside garment factories. They found that workers were labelled as being involved in bad conduct such as sex work, or as mistresses of married men, by their home communities, their 
employers and urban society. They realised that people in their place of origin disliked and disrespected them and that they perceived the women's actions as being detrimental to Lao women's culture (Phouxay \& Tollefsen, 2010).

Money plays a significant role for the factory workers. Some factory women work in a bar or as sex workers to earn extra money at night (Sene-Asa, 2006). However, there is evidence that some of these women pursue a better lifestyle by trying to increase their knowledge and capabilities through studying subjects such as English, finance and accounting at the local college in the evening. Also, some of the women try to learn vocational skills such as sewing, and beauty salon skills in their free time (Khamphouvong \& Santasombat, 2014). These studies require investment and a lot of women struggle to save up in order to learn. In the existing literature on Laos, there is no evidence showing how institutions have helped factory women to enhance their knowledge and achieve their desired aims through training, studying or any other kind of support.

\subsection{Women as subjects}

There are few studies that regard factory women workers as active agents in Laos. The research of Khamphouvong and Santasombat (2014) and Sisaleumsak (2012) argues that women migrate to experience the modernity of the city. Sisaleumsak (2012) conducted studies on young rural migrant women working in the three garment factories in Vientiane. She discussed how young migrant women viewed modernity as it relates to urban consumption and is associated with 'kwarm saduak sabai', 'a set of values relating to ease, comfort and freedom'. These modern perceptions are displayed through women's daily life consumption practices as well as their efforts to achieve their dreams of living a comfortable life, or kwarm saduak sabai, through working and socialising in the city. She argued that urban consumption enables women to construct a new self-identity both in urban society and within their family. That is, women in her study constructed new self-identities as modern women and did not consider themselves rural women after moving to the city. They retained a strong relationship with their family back home and carried on daughter values by sending home remittances. However, the women struggled in a capitalist working system, with social isolation and some with the realisation that they could never achieve 'kwarm saduak sabai' as they had dreamed of (Sisaleumsak, 2012). 
The other study that saw women as subjects was conducted by Khamphouvong and Santasombat (2014). Their study focused on the feminisation of modernity by migrant factory workers and found that women pursued modern lifestyles in urban areas. Female workers have a strong desire to be 'modern women' as displayed through their actions, their behaviours, and their consumption of urban goods. While some women fulfilled their desire to be modernised by investing in learning new skills such as sewing outside the factory, others spent their spare time at night earning extra money at entertainment venues. A small percentage of women decided to enter the sex industry and/or to have sexual relationships with married men to earn money to fulfil their desire to become 'modern' women (Khamphouvong \& Santasombat, 2014).

\subsection{Research gap}

There is limited literature in Laos that studies the experiences of migrant women working in factories. Several studies investigate the macro level, such as government policies and economic structure which aim to increase the productivity and the growth of the garment industry (Vixathep, 2011; LAGF, 2018). However, less attention has been given to how these macro level structures impact the livelihoods and wellbeing of migrant women.

Empirical studies internationally have raised the critical issues regarding the wellbeing of women workers, such as gender norms (Birdsall \& McGreevey, 1983; Foo \& Lim, 1987; Hancock, 2006) and sexual harassment (Hancock, 2006, Hlavka, 2014; Hewamanne, 2003; Lawreniuk \& Parsons, 2017; Zaman, 2001). Also, the issues of women's agency and empowerment of how women workers develop their own strategies to cope with their everyday lives have been addressed widely in international literature (Hancock, 2006; Ong, 1988; Tran, 2007; Zaman, 2001). However, the studies in Laos have paid less attention to these aspects.

This research aims to fill this gap by exploring various aspects of the livelihoods and wellbeing of migrant women working in the garment factories in Laos in detail. It also explores how the current economic and social structures influence women's lives and how women respond to them. 


\subsection{Conclusion}

In summary, after the transition of the economy, Laos has set an ambitious goal of graduating from the status of least developed countries. Laos has achieved a high economic growth rate. However, the growth rate mostly comes from the natural resources exploitation sector, which only employs labour during implementation periods. The sustainability of this high growth remains questionable. The garment industry is the only non-resource manufacturing sector in Laos that employs a large number of labourers for long periods of time. However, Laos is less competitive in garment development compared to its neighbours, due to its small scale and its lack of skilled labourers. The availability of jobs in garment factories has drawn a large number of young Lao women to migrate from their rural homes to the capital city. The working and living conditions of these migrants is similar to those of other developing countries who also work and live under exploitative conditions. Lao society also looks down on and stigmatises these women workers. However, by working and living in the city, some women have agency to construct their identity as modern women. Some invest their money in learning new skills, while others find work in bars or enter into sex work. All of these activities of women aim to improve their living conditions and wellbeing, but the results vary significantly. 


\section{Chapter 4 Methodology}

\subsection{Introduction}

This chapter begins by describing feminist epistemology. It then describes the sustainable livelihood framework which has been employed as the fundamental framework of this study. The chapter continues by explaining feminist theories. These theories have been incorporated into the sustainable livelihood framework in order to provide a critical analysis of gender issues. Next, the chapter presents the research methodology, research participants, recruitment method and research location. The chapter ends with a description of the data analysis and consideration of ethical issues.

\subsection{Epistemology}

"Feminist epistemology is about the ways gender influences what we take to be knowledge" (Anderson, 1995, p.1). This means that feminist epistemology is concerned with how gender, power relations and social interactions play vital roles in our understanding of knowledge and justification.

Feminist epistemology understands knowledge as subjective. There is no universal knowledge that can explain all life settings because knowledge depends on the way it is constructed and who constructs it (Sultana, 2007). This means knowledge is constructed differently in different contexts, geographical areas, times, cultures and genders. Therefore, the construction of knowledge of each woman is different (Sultana, 2007).

This research has focused on the engagement between researcher and migrant women as research participants. It views the world through the standpoint of women workers by observing and talking in-depth to them about their life experiences. In doing this, this research aims to understand the social constructive meaning, gender and power relations behind these women's experiences in the specific context of Lao.

\subsection{Sustainable livelihood frameworks}

In this research, the sustainable livelihood framework (SLF) has been used as an analytical framework to explore various aspects of the migrant women's livelihoods and wellbeing. SLF is a people-centred framework. It works with local people and builds upon their own strengths to realize their potential (Carney, 1999). Chambers and Conway (1992) 
provided a definition of sustainable livelihood that is widely used and accepted by many organizations:

A livelihood comprises the capabilities, assets (stores, resources, claims and access) and activities required for a means of living; a livelihood is sustainable when it can cope with and recover from stress and shocks, maintain or enhance its capabilities and assets, and provide sustainable livelihood opportunities for the next generation; and which contributes net benefits to other livelihoods at the local and global levels and in the short and long-term (Chambers \& Conway, 1992, p.6)

Several international organizations have adapted SLF in implementing development projects. For example, the Household Livelihoods Security Framework was developed by Care International in 1994 to handle food security issues in rural areas. The SLFs developed by various scholars and organisations have been rurally-centred (Krantz, 2001). However, the Assets Vulnerability Framework designed by Moser (1998) was developed to examine the vulnerability context and livelihoods in urban areas (Farrington, Ramasut, \& Walker, 2002). Even though rural and urban areas are different in many aspects, Farrington, Ramasut and Walker (2002) claim that SLF can be applied to both rural and urban settings because the models are conceptually broad enough, and because of the SLF focus on contextual specificity.

This research adapted the sustainable livelihood framework from Carney et al. (1999) as shown in Figure 4.1.

In Figure 4.1, there are five main elements in SLF including (1) Vulnerability Context, (2) livelihood assets, (3) transforming, structure and processes, (4) livelihood strategies and (5) livelihood outcome. These elements are linked together.

The Vulnerability context is the external factors which influence people's livelihood assets including trends, shocks and seasonality shifts. These include trend (economic, political, population and technological), shock (economic, natural) and seasonal shifts (price, production, employment opportunities) (DFID, 1999). The vulnerability context is out of people's control. However, this does not have to be negative. For example, the introduction of new technology might help improve rural agricultural production. 


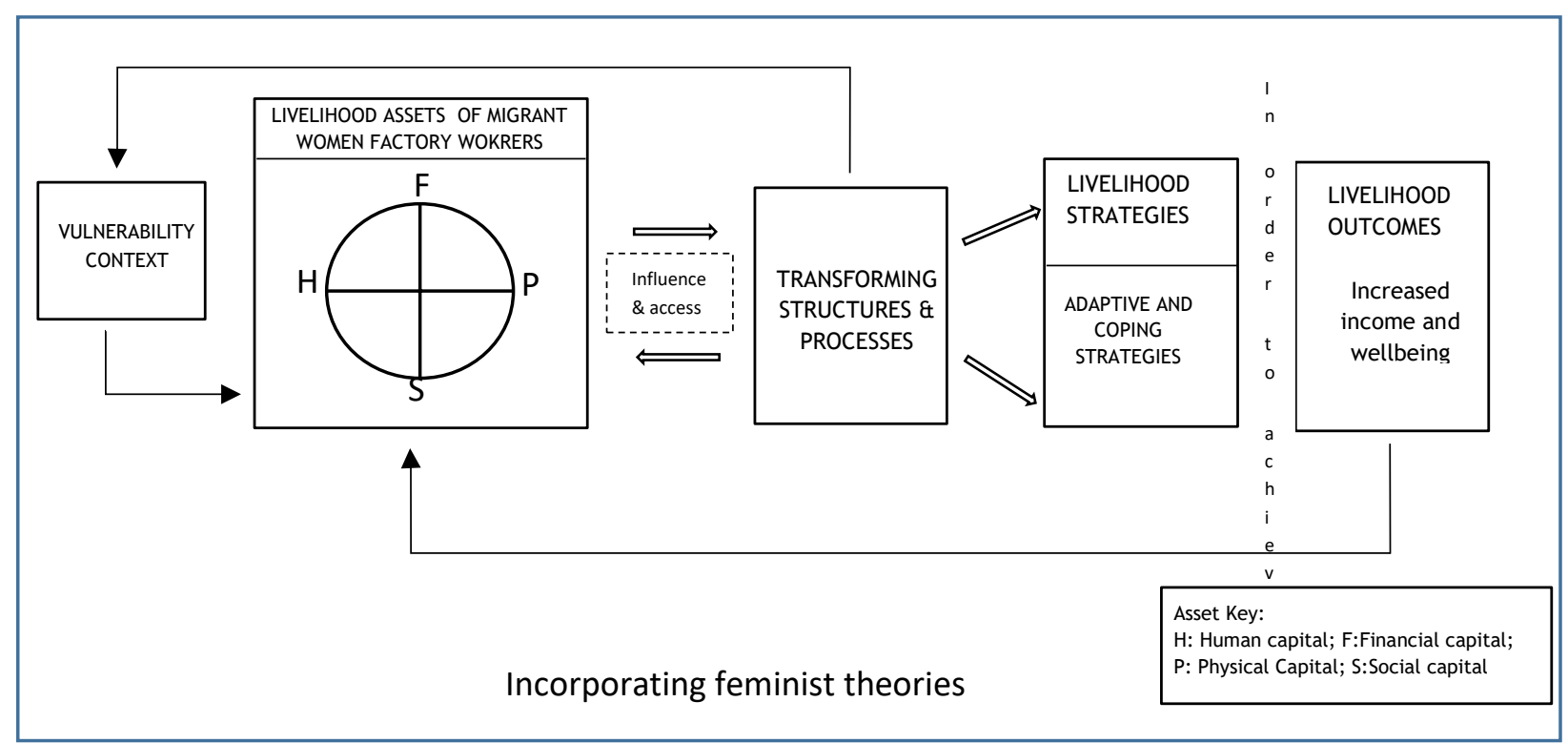

Figure 4. 1: Sustainable livelihood framework combing with feminist theories

Source: adapted from sustainable livelihood framework, Carney et al. $(1999$, p.9)

This research used the livelihood assets definitions from (Carney et al., 1999)

Human capital: the skills, knowledge, ability to labour and good health important to the ability to pursue livelihood strategies;

Physical capital: the basic infrastructure (transport, shelter, water, energy and communications) and the production equipment and means that enable people to pursue livelihoods;

Social capital: the social resources (networks, membership of groups, relationships of trust, access to wider institutions of society) upon which people draw in pursuit livelihoods;

Financial capital: the financial resources which are available to people (whether savings, supplies of credit or regular remittances or pensions) and which provide them with different livelihood options (Carney et al., 1999, p.9).

Generally, there are five elements of livelihood assets: human capital, physical capital, social capital, financial capital and natural capital (Carney et al., 1999; DFID, 1999). In this research, natural capital was excluded because it is not relevant to analyse in an urban context. Women in this research rarely draw on natural resources (such as forests, rivers or the land) for their urban livelihoods. 
Transforming structures and processes refer to institutions and their policies. Structures are organizations such as those in the public and private sectors, and in civil society. Processes refers to policies, legislations and culture implemented by structures which influence livelihoods. These structures and processes play important roles which shape the vulnerability context because policies determine economic and market trends. They determine people's access to livelihood assets. They also have an impact on promoting or restricting people's choices of livelihood strategies (DFID, 1999; Scoones, 1998).

Livelihood strategies refer to the wide range of activities and choices that people undertake to pursue their livelihood outcome (DFID, 1999). For example, diversification of livelihood to seek alternative non-farm earning, and migration to seek a better livelihood (either short or long term) are seen as livelihood strategies for rural people (Scoones, 1998). People who have more choices for their livelihood strategies tend to be better at adapting to and coping with the vulnerability context (DFID, 1999).

Livelihood outcomes are the goals or outputs of livelihood strategies (DFID, 1999). Livelihood outcomes can be increased income, reduced poverty, increased well-being and capabilities, reduced vulnerability and increased adaptive abilities and resilience. DFID (1999) claims that researchers should not jump to conclusions or be judgmental about the outcomes of particular groups. Instead, the process of understanding outcomes is through paying attention to what people say, observation and investigation to understand the diverse potential livelihood goals and their constraints (DFID, 1999).

This research focuses mainly on exploring livelihood assets (human capital, physical capital, financial capital and social capital) of migrant women. It also explores how these women develop livelihood strategies (adaptive and coping) based on their existing assets. This research touches briefly on how the structures and processes have an effect on livelihood assets, livelihood strategies and livelihood outcomes.

This framework was very helpful in looking at the livelihoods of migrant women from multiple perspectives, such as women, employer and government. It also helped in obtaining a large amount of data and framing findings. However, this framework lacks a critical theory to analyse gender power relations that influence women's wellbeing. To fill this gap, I included a theoretical feminist perspective into this framework to provide an inclusive analysis on how gender and power play a role in the livelihood and wellbeing of women. 


\subsection{Feminist theory}

Initially, this research planned to use only a sustainable livelihood approach as a framework. However, some issues such as labour exploitation, sexual harassment and violence in the factory emerged from the field work. These issues are outside the scope of the sustainable livelihood framework. Therefore, I included feminist theories such as Marxist feminist, radical feminist and post-structural feminist theory. These theories allowed me to explore some ideas critical to my study of migrant women. They also brought me to explore the underlying causes of women's oppression, as well as the development of women's agency.

\subsubsection{Marxist feminism}

Marxism emphasises hierarchical classes in society, particularly with regards to the conflict between the proletariat (wage employees) and the bourgeoisie (the capitalist employer who employs wage labourers) (Mann, 2012). These class relations are created based on the inequalities of wealth and resources and are the root of inequalities in society (Beasley, 1999).

According to Beasley (1999), Marxist feminism gives little attention to male privilege and unequal sexual power relations between men and women. However, much attention is focused on economic aspects such as class, profit and personal wealth. Even though women experience oppression by men, at the same time, men and women are both subjected to a similar treatment by capitalism. Women face particular exploitation under capitalism: their reproductive work is not given value or paid; and their involvement in formal wage labour is often at the lowest level with poor wages conditions. Hence, Marxist feminism argue that in order to achieve women's emancipation, the economic system needs to be reformed and capitalism must be overthrown (Beasley, 1999)

Marxist feminism sees capitalism as the cause of gender inequality. In this theory, women are categorized into classes under the class structure. Marxist feminism provides an insightful analysis of economic exploitation including class power relations, class conflict, class consciousness and 'capitalist alienation' (Eisenstein, 1979). Marx assumes that there is no difference between men and women in this economic exploitation as Eisenstein $(1979$, p.11) explains: 
Marx perceived the exploitation of men and women as deriving from the same source and assumed that their oppression could be understood in the same structural terms. Revolutionary consciousness is limited to understanding the class relation of exploitation.

According to Eisenstein (1979), socialist feminism critiques Marxist feminism for generalising proletariat women and men as having the same experiences. However, he ignores the sexual division of labour and pre-existing sex roles that assign unpleasant work specifically for women. Also, the theory limits the oppression of women to instances occurring within the bourgeois marriage and the family as a result of capitalist society. Therefore, it is argued that the demolition of class structure and capitalism cannot ensure that women will experience better conditions (Eisenstein, 1979; Beasley, 1999; Mann, 2012).

\subsubsection{Radical feminism}

Unlike Marxist feminism, which is focused on the economics of male domination, radical feminism focuses mainly on "ideas, attitudes, psychological patterns and cultural values" (Beasley, 1999, p.57). Radical feminism argues that women are oppressed not because of their social class and capitalism, but because of their sex and as women in societies that value men (Beasley, 1999; Rowland \& Klein, 1990). Radical feminism emphasises patriarchal ideology and cultural practices that control women's lives, such as their sexuality and reproduction (Andersen \& Hystock, 2009).

In radical feminism, patriarchy is defined as a "sexual system of power in which the male possesses superior power and economic privilege. Patriarchy is the male hierarchical ordering of society... Patriarchy is rooted in biology rather than in economics or history" (Eisenstein, 1979, p.17). Radical feminists claim that these patriarchal systems exist in every aspect of women's lives, including both the private and public spheres and from marriage and households to sexual division of labour in society (Eisenstein, 1979; Walby, 1990). Also, the issue of rape and sexual violence is seen as the cultural and existing system of oppressing women, unlike empirical perspectives which see these issues as 'psychological problems' (Walby, 1990). Radical feminists believe that patriarchal society needs to be removed in order to liberate and emancipate women (Andersen \& Hysock, 2009). 
In the second wave of feminism, during the late 1960s and 1970s, radical feminism brought various aspects of personal and private life into public discussion using the slogan 'personal is political' (Walby, 1990). According to Mann (2012), this slogan has two meanings for emancipation and discipline. In terms of emancipation, it helps empower women by highlighting the number of gender associated issues that should not be considered as personal problems but as wider issues which are ingrained by social and political norms, particularly, the case of violence against women, such as rape and domestic violence. Regarding the personal as political issue, second wave feminists argue that these individual problems "were political issues and demanded that they be addressed collectively by the women's movement as important political concerns" (Mann, 2012, pp.78-79). The solution for these problems were found in the macrostructural (institutional level) and not the micro interpersonal (household level).

In terms of discipline, Mann (2012) claimed that the slogan called upon feminists to have consciousness, to recognize their problems and act to protect themselves in everyday life. In other words, women "should make every effort to change their lives so that their personal practices are consistent with their political view" (Mann, 2012, p.79).

Marxist and radical feminist theories both have their own strengths and weaknesses. Some scholars have attempted to synthesize both Marxist and radical feminist views. Socialist feminism sees the core elements of capitalism and patriarchy joining together and analyses oppression as both class and as sex. Some socialist feminists look at the two theories as a unified system. For example, Eisenstein (1979) considers the two theories as a unified system and uses the words 'capitalist patriarchy' to represent the interrelated that both systems have become one. Walby $(1990$, p.5) emphasizes the unified system:

Patriarchy provides a system of control and law and order, while capitalism provides a system of economy, in the pursuit of profit. Changes in one part of this capitalistpatriarchal system will cause changes in another part, as when the increase in women's paid work, due to capitalist expansion, sets up a pressure for political change, as a result of the increasing contradictions in the position of women who are both housewives and wage labourers.

Combining Marxist and radical feminist theories in this research enabled me to explore both the economic and patriarchal aspects in the Lao context. In the economic aspect, the 
theory provides analysis on how economic transition in Laos draws women to work in the city and how this impacts the livelihood and wellbeing of the women. On the patriarchy side, this theory has provided me with an analytical perspective to see how the Lao culture, social norms, and cultural practices have an effect on women.

\subsubsection{Post-structural feminist theory}

Marxist feminism and radical feminism tend to generalise women's experiences as having the same oppression from the capitalist and patriarchal systems. Post-structural feminism, on the other hand, sees each woman's experiences as unique and different. These differences can be seen in their subjectivities.

According to Weedon (1997, p.32), post-structuralist feminism defines subjectivity as "the conscious and unconscious thoughts and emotions of the individual, her sense of herself and her ways of understanding her relation to the world". Post-structuralist feminism challenges the notion of humanist discourse which regards individuals as "unique, fixed, coherent and which makes her what she is" (Weedon, 1997, p.32). In contrast, it suggests that subjectivity is fragmentary rather than unique, unstable rather than fixed and constantly changing over time. Post-structural feminism embraces the notion of subjectivity by claiming that "individuals are always the site of conflicting forms of subjectivity" (Weedon, 1997, p.32). Even though women were brought up with particular discourses, one can resist or embrace change in their subjectivity when exploring contradictory values and beliefs.

In this research, the post-structural feminism concept of subjectivity has helped me to expose the complexity of subjectivities of migrant women that are constructed by specific historical contexts, culture and social norms, how these dominant discourses conflict or create tension for women and how women actively shift their subject positions back and forth in particular spaces, times and social situations. It has also helped me to analyse women as subjects in shaping their own lives and how they exercise their agency to benefit themselves.

\subsection{Qualitative research methodology}

Qualitative research methodology has been used to answer the research questions. Qualitative methodology fits well with a feminist epistemology. This is because qualitative research focuses on the narrative that helps researchers explore marginalised groups of people to bring out their voices (Creswell, 2009). This method uncovers insightful perceptions 
of the research participants because it helps researchers focus on learning the real meanings behind the participants stories (Creswell, 2009).

Qualitative methodology was used to explore female factory worker experiences, perceptions, and feelings of being a migrant factory worker. Focus group discussions and semistructured interviews were used as methods.

Focus group discussions were conducted in order to gain an understanding of the factory workers livelihoods and wellbeing both inside and outside the factories. In this research, the discussion explores how women workers as a collective group experienced and reacted to specific issues related to their livelihoods and wellbeing (Kumar, 2014). For example, their current conditions, challenges and opportunities of living and working in the factory. The focus group discussions were conducted in a flexible and open style where participants could interact, express and discuss the issues freely (Kumar, 2014).

Semi-structured interviews allow researchers to set guiding questions to ensure that some important questions were explored during face to face interviews (Silverman, 2006). Also, semi-structured interviews have a degree of flexibility allowing for researchers to ask further questions and to elaborate on any important issues during the interview (Silverman, 2006). In this research, semi-structured interviews were used to understand individual stories, perceptions and experiences of interviewees in detail (Creswell, 2009). Guiding questions were used to interview the women workers, public officials and private sector staff.

\subsection{Research participant recruitment}

\subsubsection{Recruitment of factory workers}

There were two main participant groups in this research: female factory workers and officials from private and public sector. The first participant group were young migrant women from the rural areas of other Lao provinces who have moved to work in the factories in Vientiane. The young group was chosen for the study because they represented the main workforce in the garment industry. In addition, their lack of maturity and paid work experience made them more vulnerable, especially in the urban environment.

The selection of participants was both random and non-random in order to include a diversity of migrant women, particularly with regard to their region, ethnicity, responsibilities, age and work experience. The snowball sampling method was used to recruit women. The 
reason why I applied snowball sampling was that despite being granted permission from the factories to approach the women workers freely, doing so was not as easy.

In the beginning, I was a complete outsider to the women. When I tried to break the ice by talking to them I could feel that they were uncooperative, reluctant to talk and did not trust me. One technique I employed was to ask for support from the 'big sister' in each dormitory. The 'big sisters' were ladies who other women trusted and respected. These big sisters helped me tremendously by introducing me to the voluntary participants. With the help of the big sisters, I became less of a stranger to the women. In order to get familiar with the women and to make them feel comfortable around me, I chose to start with focus group discussions. I also wanted to get them accustomed to and comfortable with being asked questions. After the focus group discussions, the women understood why I was there and. they felt more comfortable with me visiting them regularly and I then built a rapport with selected individuals. After that, I carefully examined and intentionally selected women from the focus group for individual interviews.

As shown in Table 4.1, in total, four focus group discussions were conducted. Two focus groups were conducted in factory B because the population in this factory was three times larger than that of the other two factories. Twenty-three migrant women participated in this research, in which 10 out of 23 were selected for individual interviews. 
Table 4. 1: Research participants (female factory workers)

\begin{tabular}{|c|c|c|c|c|c|c|}
\hline $\begin{array}{l}\text { Factory } \\
\left(\text { FGD }^{1}\right)\end{array}$ & $\begin{array}{l}\text { Participant } \\
\text { Makeup Name }\end{array}$ & $\begin{array}{l}\text { Hometown } \\
\text { (province) }\end{array}$ & Ethnicity & Age & $\begin{array}{l}\text { Years of } \\
\text { work }^{2}\end{array}$ & Duties \\
\hline \multirow{5}{*}{$\begin{array}{l}\text { Factory A } \\
\text { FGD } 1\end{array}$} & Nammok * & Oudomxay & Lao-loum & 19 & 1.5 & Sewing \\
\hline & Buaphan * & Phonsaly & Phounoy & 20 & 5 & Ironing \\
\hline & Naly & Luang prabang & Lao-loum & 19 & 1 & Ironing \\
\hline & Kiew & Oudomxay & Lao-loum & 29 & 3 & Quality Control \\
\hline & Son (tom) & Huaphan & Lao-loum & 20 & 3 & Quality Control \\
\hline \multirow{6}{*}{$\begin{array}{l}\text { Factory B } \\
\text { FGD } 2\end{array}$} & Thip & Huaphan & Lao-loum & 33 & 12 & Sewing \\
\hline & Ploy & Bolikhamxay & Lao-loum & 30 & 10 & Sewing \\
\hline & Vone $*$ & Huaphan & Phaun & 31 & 6 & Sewing \\
\hline & Khaek & Saravan & Khmu & 34 & 15 & Sewing \\
\hline & Lisa* & Xaysomboun & Phuthai & 20 & 4 & Snap button \\
\hline & Lam & Huaphan & Lao-loum & 25 & 3 & $\begin{array}{l}\text { Recruitment } \\
\text { and Finance }\end{array}$ \\
\hline \multirow{6}{*}{$\begin{array}{l}\text { Factory B } \\
\text { FGD } 3\end{array}$} & Joy (tom) & Savannakhet & Lao-Loum & 29 & 11 & Sewing \\
\hline & Ser (tom) & Oudomxay & Lao kang & 21 & 8 & Sewing \\
\hline & Lae $(\text { tom })^{*}$ & Champasak & Lao-loum & 23 & 4 & Ironing \\
\hline & Bee & Bolikhamxay & Lue & 19 & 2 & Packaging \\
\hline & Bobo * & Vientiane & Lao-loum & 25 & 8 & Sewing \\
\hline & Mone ${ }^{*}$ & Oudomxay & Khmu & 18 & 3 & Cutting \\
\hline \multirow{5}{*}{$\begin{array}{l}\text { Factory C } \\
\text { FGD } 4\end{array}$} & Mei & Bolikhamxay & Lao-loum & 23 & 5 & Cutting \\
\hline & Yayang * & Huaphan & Hmong & 26 & 2 & Sewing \\
\hline & Noy & Laungprabang & Lao-loum & 30 & 6 & IE \\
\hline & Fone $(\text { tom })^{*}$ & Vientiane & Lao-loum & 31 & 10 & Line supervision \\
\hline & Khouphar & Phongsaly & Hmong & 19 & 0.5 & Trainee \\
\hline $\begin{array}{l}\text { Home- } \\
\text { based } \\
\text { Factory }\end{array}$ & $\operatorname{Kim} *$ & Savannakhet & Khmu & 18 & 0.5 & $\begin{array}{l}\text { Cut \& sew, } \\
\text { housework }\end{array}$ \\
\hline
\end{tabular}

$\left({ }^{*}\right)$ these people were selected for individual interviews.

\subsubsection{Transgender participants}

Five out of 23 participants (Son, Joy, Ser, Lae and Fone) were transgender, or 'tom'. The Lao term tom refers to a person whose biological sex at birth is female, but acts, behaves, dresses and appears as a male. My five participants identified themselves and were identified by others as tom. They had very short hair which is very uncommon for Lao women. They spoke, dressed and behaved in masculine ways. All of them were in intimate relationships with female partners. Some of them reported abusing their partners using violence. They lived in the same dormitory room as other female workers provided by the factory. This made some of the other female workers feel uncomfortable.

\footnotetext{
${ }^{1}$ FDG : Focus Group Discussion

${ }^{2}$ Years of work: the years of work experience is calculated as the sum total of years of factory work. Please note that migrant women in this research moved a lot from one factory to another and sometimes quit for some time before returning to factory work.
} 
In Laos, there is a lack of research on the term tom. The best definition for 'tom' that I could find was a transgender man. As described by Gender Minorities Aotearoa (2017, Glossary of Gender Related Terms, para.14), "trans man refers to a man who was assigned female at birth. He may or may not be identified by others as trans, and may or may not identify himself as trans." Similarly, the LGBTA Resource Centre $(2019, \mathrm{p} .1)$ explains that "a person may choose to identify themselves this way to capture their gender identity as well as their life experience as a transgender person. Some trans men may also use the term FTM or F2M to describe their identity." FTM or F2M is female to male. In this research, I will use the Lao term tom to refer to my trans man research participants.

\subsubsection{Public and private sector recruitment}

The second group interviewed was from the public and private sectors, including government officials from several organisations such as the Ministry of Industry and Commerce and the Ministry of Labour and Social Welfare. These officials' duties revolved around policy making, laws and regulations. I approached this group following government protocol processes such as submitting a letter of request for conducting the research. For the private sector, I approached them by following the Lao formal procedures such as submitting a request letter for conducting the field research. In most cases, I contacted them by email and telephone to ask for their availability and interests in participating in the research.

The snowball technique was also very helpful in identifying participants from the government and private sector. The government officials would have been difficult to get access to if it were not for my network connections. The long procedure of submitting documents and waiting for approval could take up to a month. To save time and get the right person, I decided to use my existing connections to find key officials whose work related to the garment industry. They then referred me to their existing networks in the relevant ministries and relevant private organizations. Eventually, I managed to interview ten officials from various ministries and organizations whose work was directly relevant to my research. As shown in Table 4.2, there were ten officials from public and private organisations that were interviewed. 
Table 4. 2: Research participants (public and private sector)

\begin{tabular}{|l|l|l|l|l|}
\hline Sector & Abbreviation & Institution & Position & Gender \\
\hline \multirow{4}{*}{ Government } & MOIC & Ministry of Industry and Commerce & Director & Male \\
\cline { 2 - 5 } & MOLSW & Ministry of Labour and Social Welfare & Director & Male \\
\cline { 2 - 5 } & LFTU & Lao Federation of Trade Union & High ranking official & Male \\
\cline { 2 - 5 } & LAGF & Lao Association of Garment Factory & Officer & Male \\
\cline { 2 - 5 } & CDR & $\begin{array}{l}\text { Center for Development Policy } \\
\text { Research }\end{array}$ & High ranking official & Male \\
\hline \multirow{3}{*}{ Private } & GSDC & Garment Skill Development Center & Senior position & Female \\
\cline { 2 - 5 } & iCare & iCare benefits (Lao) Co., LTD & Senior position & Female \\
\hline NGO & CARE & CARE international Laos & Senior position & Female \\
\hline Company & & Factory A & Factory owner & Male \\
\hline NPO & & Non-profit organization & Gender expert & Female \\
\hline
\end{tabular}

\subsection{Research location}

This research was conducted in three garment factories located in Vientiane. Vientiane is fast-growing capital city and is the largest city in Laos in terms of population, infrastructure and services. The city had an estimated population of 760,000 people in 2015 with a density of 6000 people $/ \mathrm{km}^{2}$ (Lao Statistic Bureau, 2015). Vientiane is the main hub for factory workers because the majority of garment factories, including Lao, joint venture and foreign-owned factories, are located in the city. In this research, I wanted to capture the diversity of the different factories. However, I was prohibited from conducting my research in several factories and I also had limited time. In the end, I managed to conduct the research in three factories as below:

Factory $\mathbf{A}$ is a joint venture company, producing women garments and exporting them into the East Asian market. It has approximately 300 workers and is located in the suburban areas in the East of Vientiane.

Factory $\mathbf{B}$ is a multinational company, producing work garments and exporting to the European market. It has nearly one thousand workers and is located in the populated areas in the North of the capital. This is one of the longest established factories in Laos since the country introduced foreign investment. 
Factory $\mathbf{C}$ is a subcontract factory and is a foreign owned company, producing clothing and exporting to neighbouring Asian markets. It has approximately 300 workers and is located in the northern part of the city. It is a relative newcomer to Lao market.

All three factories offered dormitories for workers, so it was a good opportunity to observe how women workers lived and interacted as a group. The three factories had similar urban environments, surrounded by beer shops, nightclubs, restaurants, markets, beauty salons, pop-up stores and pharmacies. These surroundings made a good study case for how these rural migrant women socialized, reacted and adapted to the urban lifestyle.

\subsection{Data analysis, coding and interpretation}

In this research, data analysis took the form of a qualitative approach. The data analysis began with transcribing interviews and discussions in the interviewees original language (Lao). I read through the text several times to make sense of all the data. I then made notes to recall the tone, emotion, impression and expression of what and how the participant was trying to express. Next, I coded the data and gave meanings and terms to the data. I followed the coding guidance from Creswell (2009) which suggested to code on four main aspects: firstly, on what the researcher expects to find based on previous studies; secondly, on what the researcher found surprising and unexpected; thirdly, what the research found abnormal; and lastly, on the data that fit with a broader theoretical perspective (Creswell, 2009). After coding, the codes were then categorized into themes and relationships among the themes. These themes are represented in the findings chapter of this thesis and are summarised in Table 4.3 below:

Regarding the final steps of data analysis or data interpretation, I selected interesting segments from themes to analyse based on the theoretical perspective, epistemology and relevant literature used in this research as well as my personal interpretation. However, I also paid attention to specific themes that emerged differently from theoretical perspectives. 
Table 4. 3 Research main themes and sub-themes

\begin{tabular}{|c|c|c|c|}
\hline & Main themes & & emes \\
\hline \multirow{11}{*}{$\begin{array}{c}\text { Sustainable } \\
\text { livelihood } \\
\text { themes }\end{array}$} & \multirow[t]{2}{*}{ Human capital } & $\checkmark$ & Education \\
\hline & & $\checkmark$ & Skill and knowledge \\
\hline & \multirow[t]{3}{*}{ Financial capital } & $\checkmark$ & Wage and spending \\
\hline & & $\checkmark$ & Access to finance \\
\hline & & $\checkmark$ & Savings \\
\hline & \multirow[t]{4}{*}{ Social capital } & $\checkmark$ & Role of social network \\
\hline & & $\checkmark$ & Social isolation \\
\hline & & $\checkmark$ & Social discrimination \\
\hline & & $\checkmark$ & Social survival skills \\
\hline & \multirow[t]{2}{*}{ Physical capital } & $\checkmark$ & Health and safety \\
\hline & & $\checkmark$ & Facilities \\
\hline \multirow[t]{5}{*}{ Emerging themes } & \multirow[t]{2}{*}{ Harassment and violence } & $\checkmark$ & Sexual harassment \\
\hline & & $\checkmark$ & Sexual violence \\
\hline & \multirow[t]{3}{*}{ Women agency } & $\checkmark$ & Women and new identity \\
\hline & & $\checkmark$ & Resistance \\
\hline & & $\checkmark$ & Women and relationship \\
\hline
\end{tabular}

\subsection{Ethical considerations}

Prior to conducting the fieldwork, an ethics application was approved by the Human Ethics Committee of Victoria University of Wellington. Throughout the fieldwork, I always had in mind the ethical rules that I had to follow. I followed formal procedures by introducing and submitting relevant research documents to my target garment factories in the city. After granting permission, I then proceeded to recruit my participants. 
In the fieldwork, consent was obtained from each participant prior to conducting the interview. A certain number of migrant women in my research were not able to read or write, so verbal consent was made. Permission was asked prior to performing any activities and I stored all voice recordings and participant information safely and confidentially.

The research ethics issue was very important in this research. There were potential risks and harms that could occur to my research participants if they were identified. For example, there were times when women criticised their employers and expressed their discontent with poor working and living conditions. Their employers might not want to expose this information to outsiders. Women could potentially be at risk of losing their jobs and/or receiving punishment if their employers found out. Therefore, I took research ethics seriously to keep the confidentiality of women's identity. False names were used in this research. No photos of my research participants were taken to avoid their being identified. Photos used in this research were taken on the general factory floor randomly with permission granted by the relevant authorities.

Before any discussion or interview, I made sure that participants knew their rights to stop participating and to refuse to answer any question without needing to state a reason. The members of the focus group discussion were told to keep confidentiality and not disclose information to anyone outside of the group. The discussions and interviews were conducted outside and away from the factory for the majority of the time. However, some participants requested focus groups and interviews to be taken inside their dormitories. If an interview or discussion took place in these areas, I made sure to keep our distance from others so no one could see and hear what had been discussed.

For the first factory, I contacted my friend who had connections with the factory owner. The owner granted me access to enter and conduct the interview in the dormitory after working hours. Surprisingly, in this focus group conversation and in some of the following interviews, the women mostly kept quiet, and were reluctant or too shy to talk. At first, I thought they did not feel comfortable or did not know me well enough to discuss personal matters. Later I came to find out from my participants that the owner told the managers to gather his employees, distribute information about my research and ask for the worker's cooperation. I understood that the factory owner wanted to help me ease into my interviews. However, his notification symbolised the hierarchical order that factory workers needed to 
follow. I was aware that women could potentially put themselves at risk if they exposed any unpleasant information. Upon realizing this, I stopped making interviews.

For the second and third factories, I was lucky enough to be granted permission to recruit participants from the dormitories after working hours. In this case, no formal notification was made by factory managers and I was free to approach my participants.

Another ethical concern in this research was the psychological wellbeing of the participants. There was a time when some participants shared their past experiences of sexual harassment and abuse. Some women shared their stories without being asked to. Although their experiences happened long ago and some women shared their story voluntarily, recalling those memories could possibly lead the women to feel distressed. In Lao culture, these issues can lead to victim blaming. In this case, I showed respect and listened to my participants with care, and with supportive and non-judgmental behaviour. I watched out for my language. Before or during discussions on sensitive issues, I made sure that they were comfortable talking about the subject. I also reminded them about their rights to terminate the interview or change the discussion subject. During the discussion, I paid attention to details and watched out for any clues or signs that my participants were or could become distressed. Sometimes I paused the interview and changed the topic to ease tension.

My relationship with the research participants was not just an open-close situation. It was an ongoing process where I built a rapport with my participants through several visits, informal conversations and interactions. Sometimes I shared meals with them. This might not have fitted well with conventional guidelines, but it did fit with Lao cultural practices. As a researcher, I felt it was ethically wrong if I treated my research participants simply as a data source without acknowledging their efforts and contributions. As a Lao woman, I felt it would be morally unacceptable and inappropriate if I were to ignore the sister friendship. Being aware culturally, morally and ethically provided me with a sense of being an ethical researcher.

\subsection{Positionality}

Having been born and raised in Vientiane, the capital city of Laos and the place where the majority of garment factories are located, my home is situated near the factories. I am familiar with the area and am comfortable with the environment. Being a young unmarried 
Lao woman helped me gained access to my participants as they could relate to me. Knowing the culture and language also helped me to build a rapport with my participants.

Although I hold the same nationality, and know the language and culture, I acknowledge the differences between me and my research participants. I grew up in the city and come from the majority ethnic group. The dialect I speak is the most spoken in Laos. I am a student and the majority of my life has been spent studying, both in Laos and abroad. Most of the participants I interviewed left school and migrated to the city at a young age. Some were from the ethnic minority groups in the rural areas. These differences in education and social status created a gap between me and my research participants. The participants were also aware of these differences. As one of the participants told me, "you have a blessing from your past life". This is a Buddhist belief that refers to one's privilege of having been brought into a comfortable life. Due to these differences, I felt like an outsider. I slowly tried to build a rapport with them. I made my participants feel comfortable around me by visiting them regularly to get to know them better. I positioned myself as one of their sisters. Sharing experiences of being a woman and the issues we encountered created a friendly environment and helped reduce the feeling of me being an outsider to them.

Growing up in the community nearby the factories I would hear a lot of rumours about the women that worked in there. Also, the amount of literature I read helped shape my research ideas. Because of this, I had assumed I knew a lot about the lives that these women lived. When I went to conduct my field research, I knew how Lao society and some literature had stereotyped these women. However, I tried my best to keep those stereotypes behind. This is to remain unbiased and to keep an open mind. Throughout my research process, I was aware that at times my values and beliefs conflicted with the values and beliefs of my participants. I admit that I felt uneasy, angry and confused with some of the stories that I had been told by the women. When this happened, I reminded myself not to be judgemental so it would help me understand the women better.

During the fieldwork for this research, $\mathrm{I}$ had to position and reposition myself in different places in particular situations. For example, during discussions with government officials, I positioned myself as young Lao women studying in New Zealand. I shared some similarities with these officials in terms of education and research interests. Most of them obtained degrees from abroad, especially New Zealand and Australia. They understood my 
position as a researcher and what the research process involved. Since their experiences related to my research topic, government officials showed their interests and supported me so that the outcome of this research could contribute to their work. In this case, I felt like an insider. I could express myself and my questions fully and the discussions went smoothly.

\subsection{Conclusion}

This chapter explored the methodology used in this research. The research was guided by feminist epistemology which considers women's worldviews and construction of knowledge. The sustainable livelihood framework was applied as a framework to explore the extent to which working and living in the city has changed migrant women livelihoods and wellbeing. Also, Marxism and radical feminism as a unified system provided an inclusive theory to explore migrant women's experiences in the existing economic, social and cultural system. On the other hand, post-structural feminist theory of subjectivities helped examine the unique experiences of each woman and how they acted as subjects.

The conceptual and theoretical frameworks provided in this chapter are highly important because subsequent chapters, such as findings and discussion, draw on what has been discussed here. This chapter also discussed how research was carried out in practice, including research methods, research participant recruitment, research location and ethical considerations. 


\section{Chapter 5 Findings}

\subsection{Introduction}

This chapter presents the findings and addresses issues related to migration, livelihoods and wellbeing of factory workers, drawing on data from the focus group discussions, interviews and my personal observations.

This chapter begins with a discussion on the motives for migration of rural women. It then discusses four livelihood assets: physical capital, human capital, financial capital and social capital. These livelihood assets are adapted from the sustainable livelihood framework which helped me to organise women's urban livelihoods into these four main categories. Finally, this chapter discusses emerging issues which is women's agency, sexual harassment and sexual violence.

\subsection{Migration}

In this research, the majority of rural-urban migrant female factory workers pointed out that employment and income opportunities pulled them to the city. However, we cannot ignore the push factors that influence migration. In this research, I found that push factors can involve internal and external aspects. Internal factors are individual motives and desires that drive an individual woman to make the decision to migrate to the city. External factors are the pressures or forces from households, community or government.

Poverty and lack of employment in the women's rural hometowns are common reasons for migration. However, this is not the case for some young women. Their individual motives to see the outside world and chase the city lights draws them to migrate to the city. This is highlighted in the case of Nammok who came from a family that was well-off. She explained her reason to move to the city:

At home, I weaved for a living. I also worked for my family's retail shop. The income was good. I wanted to come to Vientiane to see new things and see the city lights. There is nothing in rural areas. When I first came to Vientiane, I worked at a weaving house in a sub-urban area. Then I moved to this garment factory (Nammok, Factory A) 
Nummok's comments are similar to the information I received from each focus group discussion. The phrase 'yark hen fai seng see' or 'to see city lights' was repeated by the women when I asked about their motives to come to the city. However, that was not the only reason.

One of the reasons why the women moved to the city was because they could not find the work they wanted in their hometown. For example, Noy had a degree in accounting and Bee had graduated from high school. Both of them migrated to find work in the city because they could not get a job in the public sector. In the following excerpt, Noy recounted her experiences of disappointment in not getting a job with the local government because of corruption:

I got two diplomas in agriculture and accounting. I applied to work as a volunteer in the government district office in my hometown without pay. I worked there with the hope that an opportunity would come up for vacant positions so I could complete an exam and apply to be a permanent officer. I worked for three years, but someone who came after me got a job because they paid money and had internal connections. One of my friends paid a bribe for 50 million kips, but she didn't get the job because someone paid 75 million kips more than her. Even first-class honour students would not get a job if they have no money or connections. I felt like I wasted my time and was disheartened. I decided to come to Vientiane to find a job (Noy, Factory C)

Similar to Noy from Factory C, Bee from Factory B mentioned that after finishing high school, her parents paid some sort of bribe to government authorities for a chance for her to pursue a career in the army. She reported that they wasted their time and received nothing in the end. It seems to be a common practice to pay a bribe to obtain public jobs in rural areas. The public job sector is very popular among rural educated youths because these jobs are seen as prestigious and stable. Rural parents are willing to invest in their children to get into the government jobs because they do not want their children to experience arduous work like they had to do.

The other reason why women migrate to the city is to escape domestic violence. Domestic violence between an abusive husband and wife pushes the wife to escape the violence and migrate to where they feel safe. Vone and Ploy see migration as their strategy to

\footnotetext{
${ }^{3}$ (1 New Zealand Dollar is equivalent to 5700 Lao Kips)
} 
escape from their abusive husbands. By migrating to the city, Vone and Ploy felt they could leave behind all the painful memories and start a new life. Ploy explained how she escaped from her husband:

My husband was addicted to drugs. He always created problems in the house. He often hit me and threatened me. I didn't want to stay in my house and be reminded of the painful memories. I wanted to be in a new environment, see new things and meet good people. I decided to leave my two kids with my parents to take care of. Then I came to Vientiane to work and send money back home. (Ploy, Factory B)

Ploy's story explains how she could not stand domestic violence and shows her courage to leave that abusive environment. Vone, from the same factory, faced similar problems to Ploy where her husband was violent against her. Vone also decided to leave her husband to work in the garment factory in Vientiane and let her parents take care of her kids.

Migration was not the only strategy to escape violence. For tom or transgendered men (as discussed in chapter 4), migrating to the city is a journey to reveal their identity and be themselves. All five tom participants expressed the difficulties of living in their rural village. They were judged by local villagers and had difficulties fitting in the community. For tom, the city is seen as the place to express one's own true self-identity. Son explained,

When I was in my village, I could not be myself, because I am a tom. I could not dress and behave like a man at all. Villagers stared and said to me that I went against traditions and customs and that I was making a spiritual mistake. I feel better here. No one cares about who I am or what I wear. (Son, Factory A)

As discussed above, migration was pushed by internal motives and decisions. Naly's story is an example of external push factors forcing migration. For Naly, displacement caused by government policy pushed her family to leave their hometown even though they did not want to. Naly described her family experience of moving to the city after her land had been taken by the government:

I moved to Vientiane 5 years ago. My land in Luang Prabang province was assigned to be a government project site. They gave little compensation for my house and land. We did not receive any compensation for my rice fields and gardens. My family had nothing 
left. We decided to move to Vientiane as my uncle lived here and invited us to stay. We have settled here since. (Naly, Factory A)

Naly's migration experience highlights the displacement of people caused by the loss of land. The loss of land means a loss of food and an income source which is necessary for continuing the livelihood of rural people.

In summary, while there are many reasons people migrate, the main aim of migration is to pursue a better livelihood and improve the wellbeing of individuals and households. Many push factors are involved, including negative factors such as poverty, displacement, lack of opportunity, identity discrimination and domestic violence. However, positive migration push factors can be seen in each woman's motive to seek and develop oneself for life betterment. I will now examine the migrant women's working and living conditions in the factory.

\subsection{Physical capital}

In their rural home, women can enjoy the fresh air of nature, work at their own pace on their family farm and in their own house. Coming to work in the city is a huge change for women. They are scheduled to work at fixed times determined by their employers. They also work with machinery on the factory floor which is full of people and machines.

\subsubsection{Health and safety}

According to my participants, the environment inside Factories B and C was acceptable due to comforts such as the installation of fans and air conditioners, but unbearable in Factory A due to the lack of a proper ventilation system. When I visited Factory A, I walked through the main operations floor and could feel the humidity which made it uneasy to breathe. I could only imagine how horrible it would be to work in there for an entire day. All women in factory A reported that they had fainted due to the environment inside the factory. All of the factories in this study had no natural light and workers were exposed to the heat emitting from fluorescent lights (See Figure 5.1). 


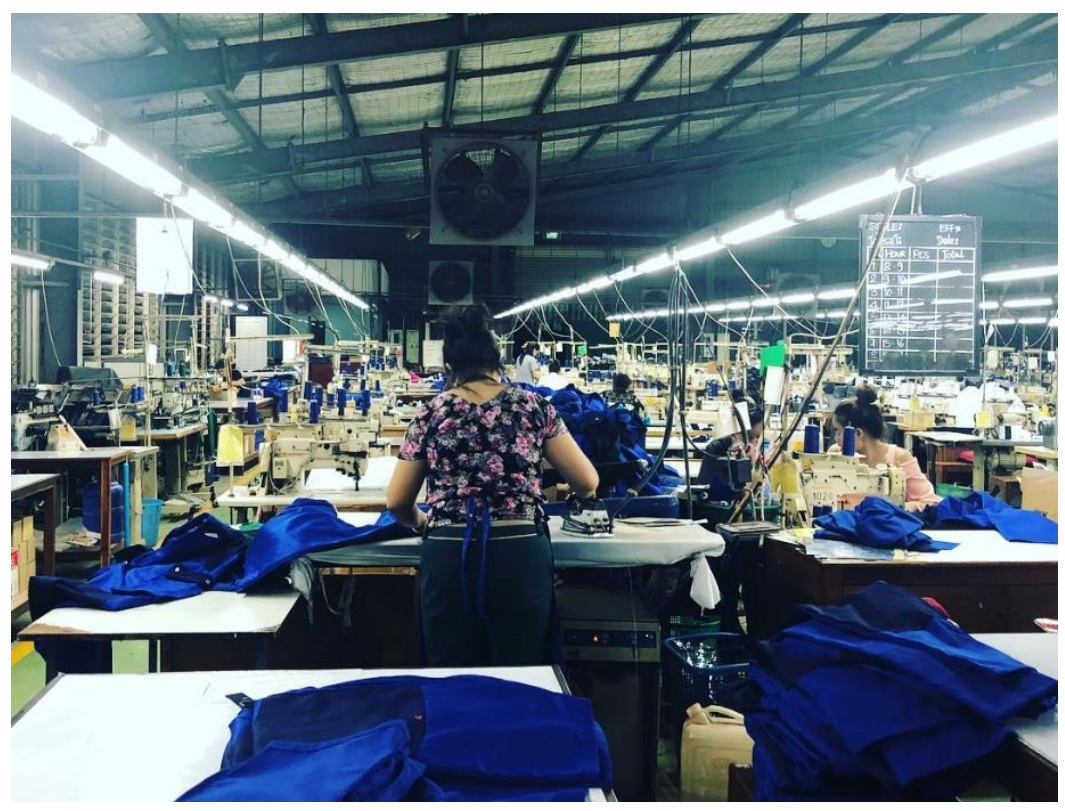

Figure 5.1: Factory operating floor

Source: author

Regarding health and safety, all three factories did not provide any uniform or protective gear for the employees. Workers wore what they wanted which was not always appropriate.

Factories B and C practiced emergency drills, but not all employees were allowed to take part due to heavy workloads. In Factories A and C, workers complained that there was no on site medical staff. Administration staff often takes the role of providing medical care. In serious cases, women will be taken to the hospital without having first aid administered. This situation is common practice in the factory and can be a serious issue if an employee is not treated correctly in the first instance. As Naly explained,

Many women have fainted while working. It was so hot in the room without fans and windows. I worked as an ironer. I felt the heat both from the room and from my iron. This made me faint last month. There is no doctor or nurse at all. People there don't know what to do. My friends carried me around here and there to find a place for me to rest. Finally, the factory decided to send me to hospital... Since I began working here, I've always felt headaches. At the moment while I am talking, I can feel it now too. It never happens to me back home. (Naly, Factory A)

Naly's explanation emphasises clearly the lack of proper health service management of Factory A. The lack of medical service available in the factory is extremely dangerous and puts workers health and wellbeing at risk. 


\subsubsection{Accommodation}

The benefits of working in the factories are that the migrant workers are provided with free accommodation. They share dormitories which also include free electricity and water. The majority of migrant workers rely on the dormitories, while a small number of migrant workers choose to rent accommodation nearby.

According to my research participants, the most common complaints regarding living in the dormitories are that they are too overcrowded, unhygienic, and lack privacy (see Figure 5.2 and Figure 5.3). I had the opportunity to visit all three dormitories of the factories. From my observations and interviews with workers, Factories A and B were very crowded, while Factory $\mathrm{C}$ had a relatively decent quality of accommodation

The different factories varied in their accommodation standards and surrounding environment. Factory A's dormitory was one big storage unit built of concrete located about one kilometre away from the factory. Transport was provided in the form of shuttle buses which picked up the workers at seven o'clock in the morning. Most women reported that they preferred to walk as they did not like waking up very early to catch the bus. The dormitory was surrounded by beer shops which played loud music late into the night every day. It was not possible to use my voice recorder at all due to the loud music from the beer shops. Each room had three bunk beds which left no space for workers to walk or to store any of their items. No fire alarms were installed in the dormitory.

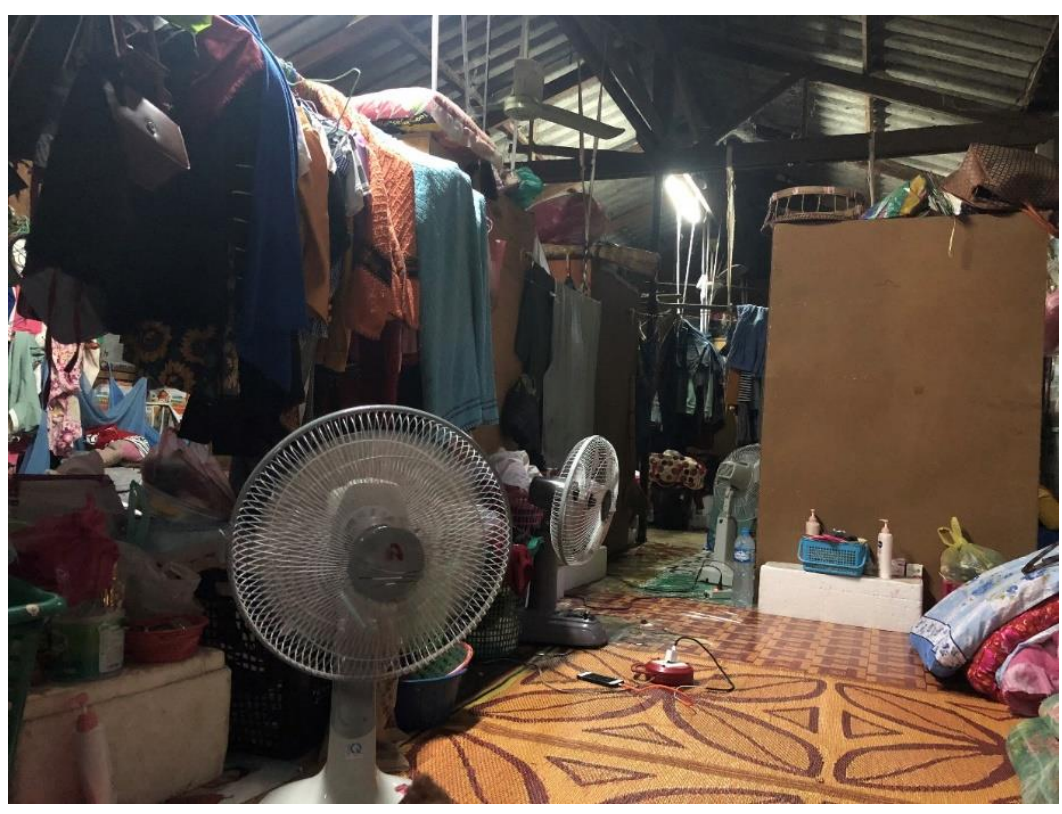

Figure 5. 2: Inside factory dormitory Source: author 


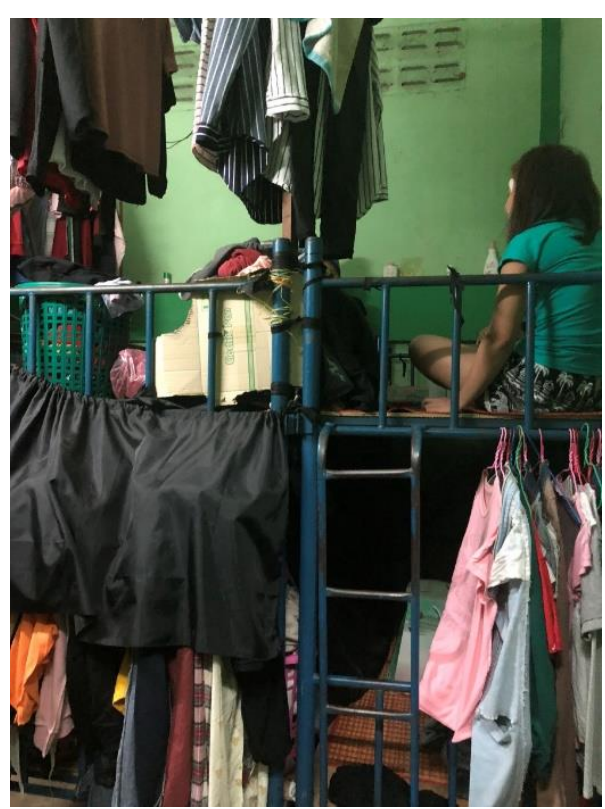

Figure 5.3: Dormitory sleeping quarters Source: author

The dormitories at Factory B were located right behind the factory. These were one storage dormitories and were built with dry, thin layers of wood and zinc roofing. These types of buildings can easily catch fire which can then spread quickly from one dormitory to another. These dormitories had fire alarms installed but would only activate manually. I was surprised to see more than 20 women living in one big room. They had no beds. Instead, every woman had their own small mattress. A certain number of women bought their own personal wardrobe to store their personal belongings.

Factory $\mathrm{C}$ had good quality dormitories. The dormitories were located inside the factory fence. One room would be occupied by around five to six people, but everyone had their own bed and large space inside the room. However, women were concerned about their safety as these dormitories housed both males and females in separate rooms, but in the same areas. Women in Factory $\mathrm{C}$ had to walk pass the male building at night before arriving at their own room.

All dormitories had a curfew time of $10 \mathrm{pm}$. Workers who came in after $10 \mathrm{pm}$ were not permitted to enter.

\subsubsection{Facilities}

One important issue raised by the workers in all the factories was the quality of drinking water and the inadequate supply of water. Most of my participants told me that they 
had to buy their own drinking water because they did not trust the water that was provided. As Noy reported,

They never cleaned the drinking water tank. One day we found a dead lizard in it. We all felt disgusted with what we had been drinking for the past week. The factory will do big cleaning only before the headquarter company or government officials come inspect. During this time, everything is perfect. The toilet smells really good because of the fragrance. After the inspection, everything returns to normal. (Noy, Factory C)

All three of the factories provided cooking and eating spaces for the workers (see Figure 5.4), but there were no kitchen facilities provided. Workers needed to buy their own electric pans, plates and many things for their own use. This was a financial burden, especially for newcomers who needed to establish themselves with the little money that they had.

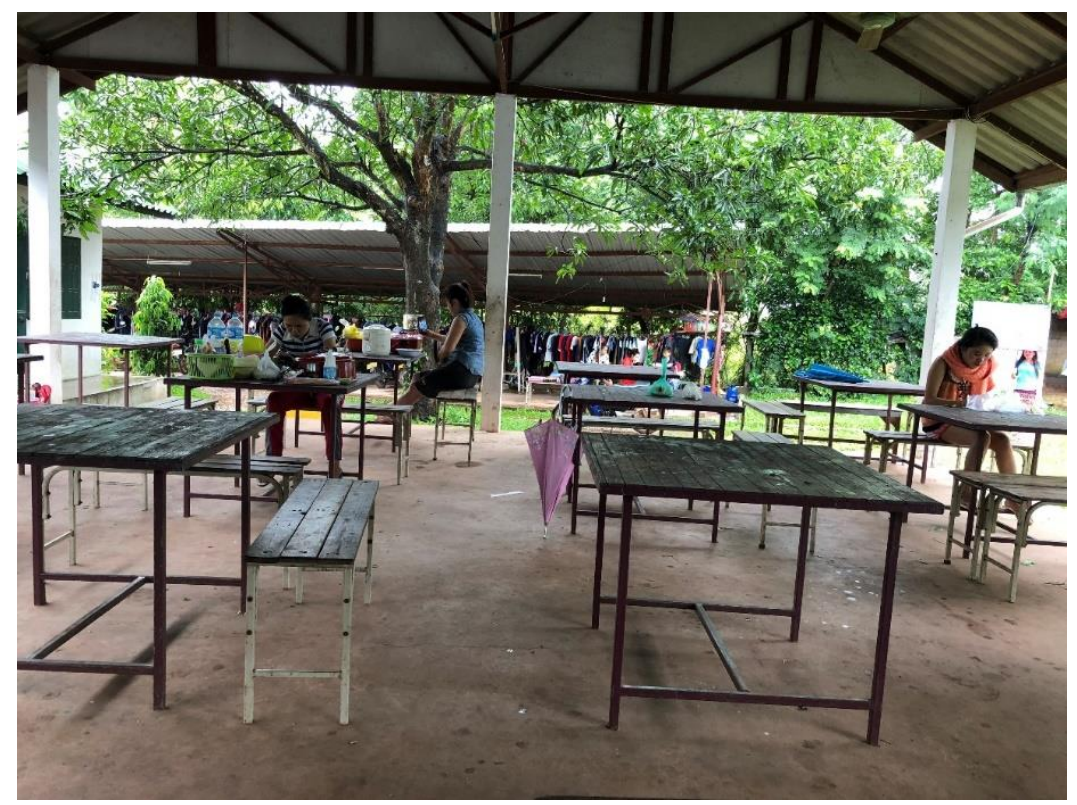

Figure 5.4: Eating areas

Source: author

Many toilets were installed, but most of them were out of order and only a few could be used. This was insufficient for the number of workers on site. This problem applied to all three factories. Also, the women were responsible for cleaning and taking care of housing facilities. Many women reported that they simply lacked energy to do cleaning or cooking after long hours and hard work. Most of them bought cheap food from pop-up food vendors nearby. Quick meals, particularly instant noodles, are commonly consumed by the workers due to their cheap price and convenience to obtain and cook. 


\subsection{Human capital}

\subsubsection{Education}

As noted in Chapter three, most rural urban migrant women in Laos have a very low education level. In my research, most women did not complete primary school. Few completed high school and only two women (Lam, Factory B and Noy, Factory C) completed vocational school. These two women were not operation workers, but one worked as a recruitment and finance officer and the other as a secretary. Rural migrants in my research started school at a later age, so they were absent from school regularly to help with family farm work, and later they dropped out of school. When asked about the reason for dropping out of school, most of them pointed out the struggle of continuing school and the unwillingness to be a burden for parents. Son explained,

I felt pity for my parents to support me study. They are old and have no energy to support me. No one helps them with farm work. I have three sisters, but they are already married. If I insisted to continue study, I know I will not complete it anyway so I quit school so that I can help them working. (Son, Factory A)

Dropping out of school seems to be a survival strategy for many individuals and households. Women need to help parents do farm work. By dropping out of school early, many ethnic women in my research were unable to read or write fully in the Lao language. As mentioned by Yayang,

Back in my hometown, my people are known as Hmong and we have our own language, and this is the main language we speak and use. My last year of education was year 5 of primary school. Up until that point, I was just learning how to read and write Lao language. Therefore, there are some Lao words and phrases which I cannot read, write and pronounce well. (Yayang, Factory C)

With limited education, no skills and no waged work experience, plus some language barriers for ethnic women, migrants really do not have many career choices to choose from in the city. What they have to offer is their labour and physical energy due to their young age. The most popular entry level jobs for many women migrants I interviewed were domestic and factory work. For many northern migrants, traditional skirt weaving was the popular urban entry job for them. Working in these types of jobs can earn them only the minimum wage or 
below. Garment factory work seems to be the most popular job for young rural migrants due to its female dominance, the availability of factories to choose from in the capital city, and the regular salary it provides.

Due to their young age and experience, many of these women have limited knowledge of the labour wages, laws, rights and benefits. Many participants in my research have no idea about the benefits they are entitled to receive. When I asked the women whether they signed a contract before working, many women did not even know if there was a contract or not and what the benefits of a contract were. This was confirmed by one factory owner who said,

Previously we did sign contracts with the employees, but now we have no contracts. This is due to the employees not understanding what a contract is used for. Even when they sign the contract, they don't abide by it. They quit when they want to quit and don't care whether there is a contract or not. (Factory Owner, Factory A)

This means that the knowledge and awareness of women towards their contract and legal rights is very limited. When there is no contract, workers are not protected by the law and because of this they can be exploited.

Also, from my interview and focus group discussions, I found that the majority of my participants lacked knowledge on how to calculate their own salary, overtime work and other benefits. Some women complained to me about how their salary was cut too much for tax, social security and leave.

\subsubsection{Child labour}

Although I interviewed women over 18 years old, I found evidence of child labour in the factories. Ser, at 13 years old, has the youngest starting age I found in my research. A few women in my interview confessed that they started their factory job when they were under 18 years old and had to lie and hide their age with fake documents. In some cases, when the factories were in urgent need of employees, they helped women hide their age by telling them not to expose the fact to the officials or inspectors when they came to inspect. Mone commented,

I'm 18 years old, but I have been here since I was 15. I'm quite tall and look like an adult so the factory staff didn't question me about my age. The factory needed people 
urgently at that time so they told me to lie about my year of birth if the SA8000 examiners from foreign countries inspect the factory (Mone, Factory B).

SA8000 is 'an auditable certification standard' and one of the criteria it states is that businesses must not support child labour. This standard was used by the factory headquarters in foreign countries.

Similarly, Ser shared her experiences of when she first came to work in the city at 13 years old. She said,

I came to work in this factory when I was 13. I could not speak Lao at all. When I first arrived, I cried every day. Luckily I got help from a senior colleague who taught me the work. At that time there were no authorities checking anything. I was paid a very low wage. (Ser, Factory B)

The story from Ser and Mone illustrates how factories have employed child labour and how they can get away with it. However, according to Lao labour laws, the legal age for starting work is 14 years old, so employing people as young as 14 is not illegal. However, employing children breaks the rules of the many foreign buyers. The company might get into trouble if the buyer finds out. Children working as labourers in the garment factory lose their opportunity to gain an education. Most importantly because they entered the workforce at such young age they also lose their childhood and are more vulnerable to being exploited.

\subsubsection{Factory work and skill development}

The garment factory sector requires intensive labour. Many factories have a permanent advertising board for job vacancies posted at the front gate due to their demand for labour. Public officials from line ministries and the owner of Factory A mentioned that factory jobs actually require skilled labourers, but there is a shortage of skilled labourers in Laos. Many factories have to accept non-skilled labourers and offer training to them.

Similarly, my participants reported that when new labourers first come to the factory, they will be assigned to the department that has many vacant positions. They will be trained to do the jobs. If they are unable to do it quickly and within the specified time limit, they will be transferred to other departments. In the worst cases, if they are really bad at working or unable to be trained, they will not get the job. The main department for first entry is sewing. 
Many women will be trained between three and seven days per week before they know if they have to move to other departments or if they will stay. For example, Bee said,

After I finished three days of training on how to sew, I was put through a pressure test which required me to sew a piece of material within a set time limit. If I managed to complete it successfully, I would be given the job. Unfortunately, this was not the case. I was not successful and was transferred to the packing department (Bee, Factory B).

In Laos, the primary place women seem to seek work are in the garment factories, which require intensive labour. Many women pointed out that it is not hard to return to a factory job after leaving. If women have work experience they are likely to get a job. Some also mentioned that they have choices. After leaving for a period of time, if the same factory does not accept them when they return to work, they will apply to other factories. These reasons might explain why the staff turnover rate in the garment factory sector in Laos is very high.

The high staff turnover rate in the garment industry is one of the main issues for many factories and is one of the reasons why this industry has been stagnant in recent years. The factory work is product-specific. After women leave the job, many factories lose the cost of training and need to invest in training new staff. When women come back to the same factory, there are some skills lost as well because the women might not be returned to the same department and it also takes some time for them to re-familiarize themselves with the same work. If women return to another factory, they have to learn again starting from zero because different factories produce different products.

Factory work does not build skills for migrant women to further their careers. The skills women obtain from the factory are hardly passed on to other occupations or even to other factories. Workers repeat the same job every day without gaining any new skills or knowledge. As pointed out by many factory workers, women work based on their line of production such as ironing, cutting, sewing, stamping, quality check and packing. In each line of production, the work is divided to meet specific duties. For example, workers in the ironing line of production will divide the work into ironing shirt collars, sleeves, body and buttons. Women in the sewing department will sew only specific parts such as shirt sleeves, collars and the body line. 
By doing the same job, workers become familiar with their task and faster in their productivity, but they also get bored and want to learn about other duties. Many participants point out the willingness to learn more, especially sewing. Many said that sewing is an important skill in the factory and gains the highest wage compared to other operations such as ironing, quality check and other departments. They are aware that sewing is a very important skill that can be applied when they want to open their own clothes shop. Some of the women were aware that the skills they learned in the factory cannot be applied to other occupations, such as those skills used in the quality check and ironing departments.

From my interviews, I found that some women seeked opportunities to learn more, to develop their skills and to take their own initiative to work hard beyond their duties. As Nammok narrated,

They taught me only how to sew waistbands. I saw others sewing various different parts of clothing than what I was doing. I was curious and wanted to learn. Sometimes when my line had no clothes, I observed others and how they sewed their parts. After observing many times, I asked my colleague to teach me until I knew how to do it. When they go to the toilet or I come back from lunch break early, I take some of their clothes and help them sew (Nammok, Factory A).

Nammok's story shows us how she took the initiative to further develop her skills and how she seeked opportunities to do so. Still, many women do not have a chance like Nammok to learn due to their overloaded work and the different departmental areas they work in.

Despite Nammok's effort to learn more about her jobs, it is uncertain to me how much working in the factory develops skills for women workers. In the three factories I visited, the middle and high manager positions were held by Lao or foreign males from neighbouring countries such as Thailand and Vietnam and some other countries including Japan, India and Sri Lanka. It is very rare to see Lao women workers having a higher position than line operation supervisors. The garment factory reflects the division of labour where women workers are concentrated in the factory floors, while men hold higher positions.

Also, I found that some women who have worked for the same factory for more than five or ten years were capable of doing several things and did not want to pursue higher positions. Thip, Khaek and Vone from Factory B told me that the higher positions come with 
hard work and are low paid. Unlike many other women workers, Fone, who had 10 years of experience decided to take up a line supervisor role two years ago. She said,

I was just a worker before, but I knew how to sew everything. The foreign manager asked me to be the line supervisor. I was unsure at first because I was afraid of the workload. Importantly, many workers would hate me and I don't want to have conflicts with other colleagues and friends. For economic reasons, I decided to take the position. Now I'm so tired of having to control a lot of people. Sometimes I have to work instead of my workers. My foreign managers blame me when productivity does not meet the target. I passed on the anger to my workers. My workers are unsatisfied. It's a losing situation no matter which way I look at it. However, this position helped me to improve my livelihood and be able to save up to buy some land (Fone, Factory C).

The story of Fone shows us that her factory offered opportunities for her to get promoted, but did not offer her any training opportunities. Without proper training, Fone lacked confidence in management and leadership skills as can be seen in the way she described how she managed her work colleagues and her boss. However, after hearing more about Fone's background, I admired her for having courage to take up that position in the workplace. By taking a line manager position, Fone broke the norms and ideology of rural Lao women which women should display their humbleness. In regards to her married life, she told me how she chose to end her marital relationship to get out of an abusive relationship. In this case, she broke the Lao social norms which posit that women should be good supporters to their husbands and remain in the marital relationship no matter the circumstances.

In summary, factory work provides women with jobs but these jobs do not develop women workers into skilled labourers. Factory labour allows women to work in only monotonous and repetitive jobs without opportunities to learn beyond their tasks. Also, the skills women obtain in the factory can rarely be applied to another occupation. However, occasionally there are some women such as Nummok who have agency to seek every opportunity to learn as many skills as possible. 


\subsection{Financial capital}

\subsubsection{Urban wages}

Coming to the city is a significant livelihood change for many women, moving from a non-cash to a cash economy. The majority of women mentioned the importance of money to survive in their daily life in the city. The women received their salary every month and relied on it as the only source of income. However, they also received a weekly food allowance of around 6000 to 7000 kips per day. The food allowance varied depending on each factory's policy. In addition to their salary, women received social security to cover medical expenses. As mentioned earlier in the physical capital section, factories also provide dormitories for rural women free of charge.

Factory A and Factory B tended to delay salary payment. Both of these factories paid workers on the $5^{\text {th }}$ and $10^{\text {th }}$ of the following month, respectively. The salary each woman received varied depending on their productivity, hours of overtime and number of years working at the factory. The majority of women received salary equal to the minimum wage of 1,100,000 kip (approximately 195 NZ dollars).

In 2018 , the government declared an increase to the minimum wage from 900,000 kips to $1,100,000$ kips. However, increasing the minimum wage does not make any difference. As an official from the Ministry of Industry and Commerce discussed:

The increase of minimum wage is just a number, but not value and does not improve the wellbeing of factory workers. This is due to the high inflation. The food prices in the market have also fluctuated. Our government fails to control the market price. As a result, the new minimum wage causes everything to be more expensive. This is called currency depreciation - where the money you received cannot buy anything (official, MOIC)

Newcomers in Factory $\mathrm{C}$ received a salary lower than the minimum wage and did not get some of the benefits such as the food allowance and social security due to the factory's policy. Newcomers received benefits only after they passed a probation period or even later. This is legally and morally wrong. However, most newcomers might have known that their employer was treating them unfairly. In these cases, they may just have kept quiet and 
accepted whatever benefits they received. This is most likely due to them lacking power, having a small social network and being afraid of losing their job.

Experienced workers who have been working at the factory for a few years are more likely to spot the unfair treatment and question the manager for the lack of consistency in their benefits and unfair rules. The women said that their questions had been heard, but the managers did not take any actions to solve them. As Mei pointed out:

The salary we received tends to be less than what we work for. If I don't ask them about it, they will act like nothing has happened. If someone resigns from the job, they will not receive any money. They cut our salary a lot more than 100,000 kips for social security. They cut 200,000 kip if you don't work overtime or are absent one day without informing them. They will cut 100,000 kip if you are absent with permission. When we gathered as a group to go ask the office about our salary, they were angry and said they will get the officials to explain to us, but they never did. (Mei, Factory C)

Similarly, Noy pointed out how her factory gets away with forcing workers to work overtime more than the standard as defined by the labour law:

In the past, they forced us to sign a piece of paper which we didn't understand. Afterwards we found out that the paper we signed was an agreement to work overtime late at night. When the department of labour inspected the late overtime work, nothing happened to the employers because they showed that paper to them. Also, when I asked to leave overtime work early at 7pm, my manager asked me to talk to them about the reasons and showed me my signature on the signed piece of paper. They only allowed two people to leave overtime per production line. The first time you ask to leave for overtime work you will get a warning letter. The second time you leave overtime work you will be fired. I was patient and chose to continue to work overtime because I am poor. Some people couldn't bear it anymore and decide to leave (Noy, Factory C).

The stories of Mei and Noy illustrate the unfair treatment that some women have experienced while working in the factory. During the group discussion, I could feel the frustration amongst the group towards the managers. Mei also showed me the video that she 
recorded every time she and her friend reached out to their manager. She said she would like to report it to the Ministry of Labour and Social Welfare, but she did not know how.

\subsubsection{Spending habits}

Initially, when women first come to the city, their salaries were not enough for their living costs. They have to establish their living situation and pay for many expenses. Most of the women mainly spent their money on daily necessities not provided by the dormitory, such as cooking and cleaning equipment, bathing items and food. For newcomers, I found that they spent quite an amount of money buying new clothes and cosmetics. This can be interpreted as their willingness to assimilate to urban life and look more like urban women. A lot of women reported how they changed their appearance after living in the urban area. Below are some of their comments:

After pay day, I go out on the weekends, I like to go buy new shirts. Not too many, probably around 3 to 4 pieces depending on the price, and cosmetics, lipstick, skincare, and bath stuffs at the Mekong night market (Naly, factory A)

My skin is whiter and I'm prettier here because I am rarely exposed to sunlight. Previously I worked in agriculture and spent most of the day exposed to the sun. My skin was dark and I developed a lot of pimples. Dark skin is not pretty (Son, factory A)

I never put on makeup back in my hometown. I didn't even know how to do it. When I saw the other girls that work here and how urban girls dress up, I wanted to wear makeup and dress up like them every day. Sometimes I want to dress in the latest styles like my friends. When I see them wear or use something new, I want to follow them. (Buaphan, factory A)

This shows that the women were trying to adapt to the urban life by adjusting their outside appearance and changing the way they dress and wear make-up. It also shows that many women do not want to look different from others. This may explain why newcomers spent a lot of money on clothes and cosmetics.

The experienced workers tended to know more about how to manage their money, only spending it on necessary items and saving the rest for the future. Yayang and Mei shared their experiences of saving their money: 
When I first came here, I bought a lot of clothes and cosmetics because I wanted to fit in with the other girls and be like them, but now I focus on saving money and don't spend much on unnecessary things anymore. (Yayang, Factory C)

Before, I was addicted to night life and always went out. Then, as I got older, I realized I had nothing and no savings at all. My money was only enough for my mom to buy some rice. That is the reason I stopped going out and now I like to save as much money as I can. (Mei, Factory C)

During the first week after the women receive their salary, their spending is greatest. This can be observed by the many pop-up shops that all of a sudden appear along the road in front of the factory or dormitory at this time. These pop-up shops disappear as soon as they appear and are gone by the end of the week after the women receive their salary. Women celebrated their salary in many ways. The women often travel a lot right away after they receive their salary. For example, TukTuks (motorised rickshaws) were hired by the women to travel to the Mekong river night markets during that week. The beer shop and stores that surround the factory seem to be more occupied by factory workers during this period.

\subsubsection{Access to finances}

The women in my research faced problems accessing formal financial services from financial institutions such as banks which did not allow them to borrow money. This is because the factory workers have low credit ratings due to their low wages and unstable employment. Informal financial services, such as borrowing from administrative staff or line-supervisors working in the factory, are the most common option because they are easy to access. This kind of money lending has a 20 percent monthly interest rate which can trap women in debt.

During this fieldwork, I observed that when the women did not have money, they were able to obtain basic necessary items by getting them from the retail or pop-up shops nearby and paying them back later when their salaries came out. Clothes and cosmetic stores nearby also offered their products up front each month and allowed the women to pay them back for these items later. Similarly, inside the dormitory, some women sold instant food, bottled water and phone credit top-up cards to their peers. Also, cosmetic and skincare products were being sold at low prices by some women inside the dormitory. Usually after work around $5 \mathrm{pm}$, sellers displayed their products on the table in the canteen where women cooked, talked and 
gathered. These sellers offered their products at cheaper prices than the retail and pop-up shops so the women could afford to buy them outright or make payments later when they receive their salary. This shows that there are small businesses going on inside the factory and dormitory. Some women understand the needs of female factory workers and see an opportunity to make extra money.

In addition to taking informal loans or hiring products, some women pointed out that they rely on their relatives when they have financial problems. Even though some women have a good social network in the urban area, many still decide not to ask for financial help from their relatives or friends and prefer taking an informal loan. As Bee stated,

I don't want to feel like I am a burden on someone. They are probably having money issues themselves. (Bee, Factory B).

Bee's reflection gives the sense that women want to be independent and to be regarded as adults who can take care of themselves financially.

\subsubsection{Remittances}

The majority of women I interviewed send money back to their rural home. Some women send at least half of their salary every month. Others send money every three or six months. A small number of women did not send money regularly, but did when their family requested it or in case of emergencies. Some women pointed out that they had become the main breadwinner of their family.

The remittances of factory work contribute to the increase of assets at home. Remittances can improve the livelihood of the women's families as Khaek and Ser explained:

I support my brother to renovate the house since my mother lives with him and he is the one who takes care of her. I also send money if my mother is sick (Khaek, Factory $B)$.

I'm the oldest daughter in the family. They need me and rely on me for everything. I should send money every month. My money was spent on sending my younger siblings to school and to build a new house (Ser, Factory B).

Khaek and Ser's stories well explain how remittances can improve living conditions and support education. Since there is no social security available in rural areas, remittances are 
used as insurance or an alternative source of finance in case of emergencies. Ser's comments highlight how remittances are also used to support education. Likewise, Ploy explained how remittances improve her family's agricultural production:

I helped my parents to buy a tractor, but they don't know how to drive it so our neighbours offer to help. My money was used for petrol for the tractor (Ploy, Factory $B)$.

Ploy's explanation emphasizes the importance of remittances in transforming agricultural production. Using a tractor to plough the rice fields improves production. Most of rural Lao still relies on the water buffalo for ploughing the rice fields. Having a tractor saves time and gives faster results for production.

However, remittances are not always seen as improving rural livelihoods. As Naly stated,

Most of my money sent back home was used on hiring someone instead of me to plough the rice fields, which costs around 40 thousand kip per day. The remaining money was used on daily life expenses such as water and electricity bills. (Naly, Factory A)

Naly's description illustrates that remittances are sometimes used simply to replace agricultural labourers due to the absence of young family members. Remittances do not produce or increase agricultural productivity in this case.

Also, women pointed out that their remittances were used for daily consumption and buying new items for the house, such as wardrobes and televisions. This also means that remittances were used to buy items that show the status of migrant families rather than to invest in income generating activities.

During this research, I also observed the exchange of items between rural homes and urban areas. Sometimes, many of the women received food packages sent to them by their family. This demonstrates how remittances are sometimes paid back to the women in the form of food.

\subsubsection{Savings and assets}

Various techniques were used by my participants to save money. Some of the women saved a little of their money each month to buy gold jewellery, but a few pointed out that they 
did not really want to buy gold because of the price drop that occurs when they sell it. Others just leave their money in their bank account to gain at a small interest rate. Still others send money to their older relatives to hold onto for them and so the women do not have money left to spend on unnecessary stuffs. The main reason for doing these things is because many of the women don't want to spend money.

The most popular savings technique for factory women is to establish an informal financial collective with a group of friends working in the same factory. Every month each woman in the group puts a set amount of money into the collective and the women then take turns each getting the total amount collected. This forces women to save money to put into the collective each month. As a result, they can each get a large sum of money.

Also, the factory income is unstable and depends on the volume of production. During the low season, there is low production in the factory. This means workers will not receive productivity money (rate per pieces they produce) or overtime pay and some of their benefits will be cut. As a result, their income decreases significantly. In one of the focus group discussions the women revealed that,

The money we get is not enough. We need to spend wisely and make every Kip stretch as far as it can. We got a very low salary this month, almost not enough for me to put any in the group money collective. We got lower than our minimum wage this month because the factory forced us to take unpaid leave for eight days due to a low number of clothing orders from overseas clients. (Ploy, Factory B)

At the other end of the scale, when the factory received large orders from overseas, women workers complained that they had to work very long hours, day and night and in some cases, overnight.

Saving money from factory work in urban areas creates stress for workers. Many women mentioned that they wanted to return home when they had saved enough money. However, the money they earned seems very little for their dreams to come true. Yayang shared how hard it was to manage her savings:

The expenses in the city are very high. We work very hard, but the salary is so little. I am curious why I have no savings. I really want to find a part time job, but I have no time. I feel disheartened. Some months I don't spend money on anything and focus on 
savings the money. However, I only can save around 500,000 to 600,000 kip per month or around 8 million kip a year. During the year there will always be times of need when I must spend my savings on family emergencies or any other issues that come up. I have worked for a couple of years, but I have no savings. I feel tired and disheartened. (Yayang, Factory C)

Most of my interview participants did not have any assets of their own, even though they had been working in the factory for many years. This might be due to the high amount of remittances they are sending back to their families.

There were a few people who had significant assets, and in one case owned a piece of land in Vientiane. These people shared some similarities. For instance, they rarely sent remittances back home, had a good social network and had worked in the factory for at least seven years. Thip, a factory worker with more than ten years of work experience, described how she was able to purchase some land from the money she earned from factory work:

I don't normally send my parents money. Only when they ask for help, I will send it to them. My friends from the same village recommended me to buy a piece of land. I and two of my friends gathered the money and bought a piece of land together and we divided it into three parts. I borrowed some money from my sister. Also, a while back I had bought my mother a gold necklace as a gift, but she gave it back to me when I bought the land to pay the debt I owe. Now I have finished building a small house there. (Thip, Factory B)

Thip's story shows us that having a good social network acts as a key source of information about assets and access to finances. Also, she has control over her income by not sending her remittance back home. Furthermore, it can be observed that gifts are repaid to her by her mother giving her back her gold necklace to pay for her debt.

In summary, financial capital gained from working in the factory brings some improvements to women's lives. Women's remittances were important sources contributing to improving conditions of their rural households. Also, some of the women's income was spent on items which helped create a new identity and build their confidence. However, their financial capital is not enough to make a real difference in the women's lives. The income women earn is just a minimum wage which is barely enough for them to make a living and 
enjoy a bit of urban consumption. Many women struggle to save for the future. The amount they do save is often not enough to significantly transform their lives. Sometimes, they have to rely on informal loans which can trap them in debt. Despite these negative aspects, women's agency was seen in the way they formed strategies to save up collectively, as well as how they combined their savings to purchase urban assets.

\subsection{Social capital of migrant women}

\subsubsection{Role of social networks}

Social networks play a very important role for women before and after arriving in the city. The majority of migrant woman I interviewed indicated that they have some contacts in the city such as their siblings, relatives and/or friends. After arriving in the city, women depend on these social networks for support and resources. Upon arriving, these people pick the women up from the bus station and provide temporary accommodation. Also, these networks support the migrant women in various ways such as by seeking jobs, taking them to apply for the factory work, and providing information on how to establish their life in the city. Migrant women also rely on their existing networks to support them during times of trouble such as when there is a shortage of money, an illness or an emergency at home.

The participants mentioned that their social network had increased after moving into the city compared to that in their hometown. They had limited mobility and rarely associated with new people at home, while they gained many friends in the city. The role of the social network was described very clearly by Yayang, a 26-year-old from a small Hmong village in Huaphan province:

When I was in my hometown, I didn't know anyone or anything. I only stayed at home, or went to rice fields and then back home again. I feel like I am capable of many more things in the city. I have friends from various provinces. I have visited and seen many places. I have gained new knowledge and am able to speak Lao clearly. I do things that I never thought were possible. For example, I wanted to send money back home. My friends advised me that I can do it in the bank and told me the instructions. I had never been to the bank before so I was worried if it was possible. After thinking and worrying again and again, I decided to walk to the bank and send the money. If I don't know something, I can ask my friends. Now I feel more confident to go many places and to speak out than ever before. (Yayang, Factory C) 
Yayang's comments highlight the positive role of increasing social capital. This can be seen from the improvement of her language, mobility and daily life skills through social interactions.

After migrating to the city, women formed a new social group in the factory and dormitory. They socialise through the time they spent eating and living together. In some cases, this new social group of women created a strong bond and network. They helped each other to survive in the city. Bee recalled an example of how a group of colleagues helped her when someone stole her money:

That day I got my first month's salary and I left it in my bag. I went to the toilet. When I came back, my co-workers sitting around me told me that my money was stolen. They knew who stole it and offered to be witnesses. They helped me by taking me to the office and reported the case to the manager. It was my sewing teacher who stole it, but she refused to admit it. Because of this, my co-workers showed the manager a video someone sneakily took of the incident. Finally, I got my salary back, but my sewing teacher got only a warning. (Bee, Factory B, Focus group 3)

Bee's story demonstrates the support women have for each other in the factory when treated unfairly. This support is very important and helpful in preventing an individual woman from being victimised.

\subsubsection{Social isolation}

Some women may find it hard to socialise in the city. This causes social isolation, which is likely to happen to an individual who cannot integrate into a group. Social isolation, such as the feeling of being an outsider, happens to those who are excluded from the group, particularly the newcomers. For the newcomers, the feelings of belonging and acceptance into the group is very important. Newcomers tend to do many things to make some friends. As Lisa mentioned:

When I first arrived, I had no friends. I always gave massages to other women, helped them with many things and talked to many people. That way I could make friends. (Lisa, Factory B)

Mone told me her story about how she kept relationships with friends when she first arrived: 
When they were talking in the group, I only listened, agreed and was patient even though sometimes they would make fun of me because at that time I was new and I didn't want to create any conflicts with others. (Mone, Factory B)

Lae, who had just moved into the factory a month earlier, sold some daily necessities on a small table in the living area inside the dormitory, but those items were owned by her co-workers. By helping out, Lae built a good relationship and increased her opportunity to talk to other women.

It can be seen that Lisa and Lae were offering something in exchange for friendship or to build friendships, while Mone was compromising to avoid conflict and maintaining the relationship.

\subsubsection{Social discrimination}

Women not only want to be accepted as part of a group, but also want society to accept them and view them positively. Women workers shared their experiences of how society views them negatively. The words 'vaohaihao neo bordee' (rude comments), 'du thouk' (look down), and ' $h$ thar thang lung kied' (condescending) were repeated by the women when they described the way society viewed them. Strong expressions such as 'saohongngarnngye' (women workers are easy to get) and 'Kalee' (prostitutes) were described when women were asked how men viewed them. When asked how they responded to these criticisms, most of the women said they kept quiet or did not care. The narratives of Naly and Yayang are selected examples which capture how their society views them:

When I tell others that I am a garment factory worker, some people, even some of my friends look down and disrespect me by saying that factory women have done negative things. However, I don't care. I didn't do any bad things like they said. (Naly, Factory A)

When we go somewhere as a group, some girls see us and make rude comments towards us like 'Sao hongngarn' (female factory workers) with a condescending expression. (Yayang, Factory C)

The women feel unsatisfied with the way society views them. The story of Lisa summarises the feelings of many participant women as well as the hard time women face in integrating with other social groups outside their social circles. 
Every man and woman in Vientiane look down at us. Social stigma is true for some, but not all. I always face patronising behaviour from friends of friends. For example, in beer shops, they don't want to sit near me. If some of their male friends talked to me, they told him that this girl is a factory worker, no need to flirt with her, you can find a better girl. Some guy even said to me that he treated a women worker to noodle salads and he got to have sex with her.

I felt really angry, but never responded back. Female factory workers also work hard to earn money. Our salary is probably more than those that work in the office and look down on us. When I went to a party with friends at the beer shop, I paid and shared equally. I never let them pay more. Now there are certain beer shops and restaurants around here that I don't dare to go to because I hate the attitude and patronising behaviours of the people there.

A friend of my partner also said "no matter how beautiful factory workers are I will not be interested in them." Some guys are not willing to talk to me. I am well aware that they just want to deceive me; especially soldiers, they are like two headed snakes. (Lisa, Factory B)

Lisa objected to the negative views of other people which caused her difficulty fitting into the society. Through her words, I could sense that she saw the value of her work, and that she wanted others to accept her. It could be seen in her eyes and heard in her tone of voice that society's perceptions of her hurt her feelings.

\subsubsection{Social survival skills}

As mentioned in Lisa's story, men often deceive women workers and approach them with a hidden agenda. On the other hand, social isolation makes women vulnerable, homesick, and lonely. Being far away from home, they miss the warm relationship of family and need emotional support in the city. Simply phoning their family back home might not be enough. They need to have a person in the urban area who they can talk and share everything with. Hence, almost all the women I interviewed had a partner and many of them had more than one partner.

In this case, women's agency was demonstrated through the way women purposely chose to enter relationships and draw resources from men to survive. Also, having multiple 
partners is one of the strategies some women used to find emotional and financial support. As Mone pointed out, the reason she has two partners is because she needs someone to support her in times of crisis:

Currently, I have two partners. One I have been with almost three years and the other one around 8 months. The reason I am in multiple relationships is because if some guy dumps me it would be fine, at least I could draw on some support from the other one. Sometimes when I urgently need money and my long term partner does not have it or is not available, I can talk to my second partner and ask it from him. All of my friends know about it, but they keep quiet because they understand my situation (Mone, Factory B).

Similar to Mone, Ploy pointed out that the reason she chose to have multiple partners was because she wanted to have choices. She stated:

I don't want to be an option for them, I want to be the one who chooses who I have relationships with. If someone dumped me, I let them go. I don't really feel hurt because I still have other choices. Sometimes when one of us is struggling, we help each other. Yesterday I sent a big box of instant noodles and 100,000kip to one of my partners in the southern province (Ploy, Factory B).

Ploy and Mone's narratives show that having multiple partners increases their options of support, financially and emotionally. Also, they can feel that at least they have choices. At the same time, both Ploy and Mone used the phrase "if men dumped me." This can mean that women feel their relationship is unstable and not secure.

However, having multiple partners leads to health issues and creates social problems. Sexually transmitted diseases, unwanted pregnancy and abortion are widespread among female workers. I asked a pharmacist near one of the factories which medicine she has sold the most of, and she told me:

The top selling medicine is related to Gonorrhoea and other sexual transmitted diseases, as well as the drug to force your period to come regularly. Previously, abortion pills were the top seller; every day I sold at least two packages and always sold out (Chemist). 
From the chemist's narrative, despite women having multiple partners, women do not take measures to protect themselves from sexually transmitted diseases. Mone explained the inadequate contraceptive methods used by women workers and her personal experiences:

After having sex, I will drink M150 [an energy drink] mixed with Pepsi as a contraceptive method used widely in the factory. I also count seven days before and after my period comes and I will stop going out for a while. However, I was accidentally pregnant with my partner because during that time I went out at night almost every day and forgot to notice my period cycle. Both of us were not ready for a baby. I was just 17 years old, I had nothing and I could not afford to raise another life. My partner was afraid that his family and cousin would not accept pregnancy before marriage. We have different religions which go against us living together. I decided to ask my partner for 80,000 kips to buy abortion pills at the nearby pharmacy. They advised me how to take them and I decided to take that pill at the dormitory on Sunday. After taking the second pill, a two-month baby came out. I lost a lot of blood, had stomach pain and could not stand for a long period of time. I told nobody about it. I then went to have papaya salad at my friend's house. I took a day off work. After a week, my stomach pain disappeared. (Mone, Factory B)

In summary, women reported an increase of social capital in urban areas. These increases played important roles in supporting women, especially newcomers, to establish their life in the city. Women individually and collectively learned a lot from each other and formed strong bonds with one another. However, the issues of social isolation and discrimination have negative impacts on factory workers wellbeing. Social discrimination towards factory workers created difficulty for women to socialise in their daily lives. Despite these challenges, some women found agency within themselves to build their own strategies for increasing their social networks in order to draw on some resources in time of crisis and prevent themselves from feelings of isolation.

\subsection{Emerging issues}

\subsubsection{Sexual harassment}

In general, sexual harassment in the factory is widely under reported, hence the lack of reported data which undervalues the true scale of the problem. Sexual harassment might occur in a variety of situations in both the workplace and in public areas. In Laos, sexual 
harassment in the factory is not well documented by the authorities. An official from the Ministry of Labour and Social Welfare mentioned during my interview that his factory inspection team rarely found sexual harassment occurrences in the factories. This contradicts my research findings which show that women experienced sexual harassment in a variety of forms on a daily basis.

In the beginning of my research, I only intended to focus on the livelihood and wellbeing of the migrant women workers. With the government inspectors confirming the nonexistence of sexual harassment in the factory, this issue was not on my radar. Unexpectedly, I came across the sexual harassment and violence issues accidentally while I was asking women in one focus group in Factory B about NGOs and other organisations implementing their activities in the factory. Since then, I came to realise that these issues occur widely, inside and outside the workplace.

In Factory B, many women experienced multiple forms of sexual harassment including verbal, non-verbal and physical. These actions were performed by their male co-workers. In focus group one in Factory B, all women reported that sexual jokes and staring from men are common practices in the factory. Surprisingly, women also experienced incidents of men harassing them frequently as some of their discussions revealed:

Our co-workers, the male mechanics, like to touch my arm, pull me close and pull my shirt up and grope my ribs (Lam, Recruitment and finance officer, Factory B).

After Lam finished her sentences, Thip continued the conversation by pointing out that Sometimes when I wear shorts, they like to come to my desk while I'm sewing and grope my legs (Thip, Factory B).

The conversation about this issue went on for around 20 minutes, with each of the participants recalling the incidents which happened to them and others. However, this sexual assault behaviour was not considered as sexual harassment by the women themselves. I was surprised to hear from women in the same focus group that they thought it was just a joke from their colleagues and that they did not take it seriously. When I asked about how they raised this issue to higher authorities, the responses surprised me:

We did nothing. It was just a joke; if they don't like us, they will not do so. They don't do it to the girls they dislike (Vone, factory $B$ ). 
Vone's explanation reflects the normalised sexual harassment behaviours in her workplace. Joy added more to the point made by Vone that:

Our line supervisors got the same treatment from the male mechanics and they also said nothing. No one took it seriously. We've gotten used to it. No one sulks or complains about it (Joy, Factory B).

Joy's statement emphasises the prevalence of sexual harassment in her factory. Even women in higher positions got the same harassment as workers. At the same time, Ploy downplayed her workplace sexual harassment as a normal occurrence in the society.

This kind of harassment happens everywhere, not only here. It's not a big deal. Just turn a blind eye (Ploy, Factory B).

I was surprised by the way they answered the question and how women workers perceived sexual harassment behaviours (touching, verbal, groping) as a joke and how workers had little awareness of the sexual harassment. I could feel the dissatisfaction among them, but I was also confused about how they handled it by turning a blind eye. I was in shock, confused and unsure of what I heard from the women. The next day I went back to ask them again individually to confirm their perceptions regarding this matter. The answers I got were the same, that they treated these incidence as a joke.

\subsubsection{Sexual assault}

Surprisingly, sexual assault is not limited to what happens between men and women workers in the factory, but serious cases of sexual harassment and bullying also happened between tom (transgendered man) and women in both the factory and dormitory. As Khaek explained:

In my previous factory, I used to run away from tom until my knees had scratched because the tom always followed me to many places, and one day one of the tom insisted that she would sleep with me. (Khaek, Factory B)

Similar to Khaek, Bobo told a story how she could not tolerate the bully tom in her previous factory.

A tom pointed her burning cigarette into my arm while I took a bath in the dormitory. She also made joke about my name. All I could do was just run away. I wanted to jump 
off the building to escape the bully. I also saw another tom who groped women workers while they were sewing in the factory. I reported it to the managers, but they didn't even listen or care. That's the reason why I moved to this factory. (Bobo, Factory B)

Bobo's story highlights the violence in the factory and dormitory. Also, when it comes to sexual harassment with the same gender, her managers care little about it.

Domestic violence of same sex couples and between tom and girls in the factory appeared to not be of any concern to managers. Some women reported to me that there was fighting and arguing among women couples in the dormitory. Fone, a tom in Factory $\mathrm{C}$, told me that she used to beat her partner because her partner wanted to break up with her:

I devoted everything to her, but she loved another man. I felt resentful so I hit her and we fought. Then we were brought to the factory office, but I didn't get punished for anything, just warned because the rules were not strict at that time. (Fone, Factory C)

Outside the workplace and dormitory boundaries is where the most serious cases of sexual harassment happened to women workers, particularly new comers, by outside men. Women were introduced to these men through their factory colleagues.

The majority of the sexual harassment and incidents are likely to occur to newcomers as well as underage girls. The young rural migrants are more likely to be victims of men in the urban areas because they are naive, gullible, and too positive about the urban environment. They also are curious about going out at night, lack preventive knowledge, such as knowledge of how to negotiate with men and can be easily beguiled by sweet words and gentle behaviour from males. Importantly, newcomers do not know how to refuse men and get themselves out of risky situations. These things make newcomers vulnerable and prone to being victims of men's violence.

The majority of serious sexual assault cases began at beer shops and continued at 'ban phak' or cheap guest houses for hourly or overnight stays. A small number of the women in my research reported that they were forced to have sex with their colleague's male friends. This situation unfolded in a similar way in each case. It often happened when naive young rural migrant girls were invited to go to beer shops, restaurants or bars with female factory friends. The women went together as a group and were joined at the table by many men, including partners and male friends of their colleagues. They drank until late at night and then 
some of the female friends separated from the group by going away with their partners privately, leaving the other women alone to go home with the colleague's male friends. However, in some cases, the male friends would take the women to a guest house far away and the women would have no idea about how to return to the dormitory. Even if they returned they had no place to sleep because the dormitory would be closed. Due to their naivety, limited social networks and lack of knowledge on how to negotiate with the men, these women did not have many options. This scenario often resulted in a man forcing a woman to have sex. Mone from Factory B recalled:

After a party, my friend went out with her boyfriend and left me alone in the beer shop with the man whom l'd just met. He lied to me that he would see me back to the dormitory, but he took me to a guest house somewhere on a very dark off-road far away. I was a bit drunk. I had no idea where I was. He threatened to drop me off in the middle of the dark road when I kept asking and begging him to take me back to the dormitory... He dragged me into the guest house room. I had no energy to resist (Mone, Factory B).

At this point, I needed to stop the interview for a while and change the topic because I could feel the depression which came through in Mone's facial expression. The incident has led her to have recurring nightmares. After this incident, Mone admitted that her life was spoiled, and she had many one night stands. At the moment, she has stopped all of those behaviours and has held long-term relationships. However, the incidences in the past remained her nightmare and have an impact to her mental health. She said,

I felt disgusted with myself. I felt disgusting every time I closed my eyes trying to sleep at night. The picture of me having sex with some random guys appeared. I felt disgusting because of what I have done before (Mone, Factory B).

Another way that sexual assault can happen is through social media. Social media can be a dangerous source for perpetrators to keep in contact with women. Kim, a former homebased factory worker, was the victim of rape by a man she met on Facebook. That man is a popular country singer in her rural region. Her current boss told me how Kim was thinking of committing suicide after her rape incident by bringing rat poison into her room, but fortunately her friend spotted her unusual behaviour and comforted her. 
Women like Mone and Kim who are victims of rape tend to partly blame themselves for the incident and do not take any action to report it to the authorities. One of the reasons for this might be because women are afraid of humiliation and are ashamed of having been raped. The women said that most of the time they chose to cry alone with a blanket covering their face.

Despite the prevalence of violence towards female workers, some women have agency to resist being forced to have sex. Many women I interviewed pointed out several ways to survive a potential assault, such as by jumping off the vehicles such as motorbikes and cars. However, this was not a really good idea and leaves women injured.

After he parked the motorbike in front of the room and was about to pay, I ran out quickly as fast as I could to escape. Luckily he took me to a guesthouse not too far from the factory so I remembered the way back to dormitory. (Vone, Factory B)

Social networks play an important role in helping prevent women from becoming victims of sexual assault, as mentioned by Noy and Mei. Noy, Factory C reported that she used to help her friends' younger sister from being a victim of rape.

After finishing drinking at beer shop, a man took my friend's sister somewhere. She called my friend to help, but she had no idea where she was. She was new to town and the man took her to a far away place. My friend was crying, therefore I needed to help her. We had no vehicles, so we borrowed our friend's motorbike and started riding. We rode past the beer shop and followed the road to where there had potential guesthouse. Luckily we rode pass her by chance and saw her on the back of the man's motorbike. She decided to jump off the motorbike after she saw us. She was injured. (Noy, Factory C)

Similarly, Mei witnessed her friend jumping off the back of the pickup to escape male perpetuator. Mei described the incidence:

After I realised that the guys in the pickup would take us to guest house, I went down the back of the pickup. The guys saw me leaving the pick up so he started to drive because he wanted to take my friend. My friend was drunk. She jumped off the pickup while it was running. I and my friend took her to the back of tuktuk nearby and went to 
hospital. My friend's cousin was a policeman so we called him to help by following the pickup. She was hospitalised for seven days. (Mei, Factory C)

Some women were not as lucky as the women I interviewed. I heard through community networks that a woman died jumping off a running motorbike to get away from a man that took her to a guesthouse.

To sum up, sexual harassment and violence are prevalent in the garment factory sector and more widely in Lao society. In this research, there were many cases of harassment and violence towards young migrant women. Surprisingly, some of the sexual harassment instances were normalised by workers and were perceived to be common practices. The most important findings were that violence in my research is not only limited to violence carried out by men on women, but also by tom (transgender) men on women as well. Interestingly, some women were involved as a cause of these violent incidents by leaving their female colleagues with a male perpetrator after introducing them to each other.

\subsection{Women's agency}

In the previous section, women's agency was displayed through various dimensions such as migration, seeking opportunities for their skill development and helping each other through difficult times. This section presents women's agency through their self-perception and their decision making. It also explains women's resistance and livelihood strategies.

\subsubsection{Self-perception}

The majority of participants revealed that they formed a new sense of self or a new identity. Many of the women referred to their and others former selves as 'bannok' or rural girls. The word bannok has connotations of lacking knowledge and being rural, stupid, humble and afraid to do things.

To develop a new identity, the women tried very hard to learn and adapt to everything new, ranging from language and gestures to changing their outside appearance. These women learned by imitating and copying others. In their current self, they dressed and ate more like the urban women and also talk more politely. Regarding their perception, they thought more about their future. They also felt stronger and were more confident compared to the version of themselves. 
Women in my research felt positive toward themselves for being able to live independently in the city, and also to be able to help their families in terms of finance. The key words 'Phoumjai' (proud), 'munjai' (confidence), 'pen phou yai' (becoming mature), 'kar harn' (brave) and 'keng keun'(smarter) were repeated by women when asked how they felt about themselves. Yayang described how she felt a sense of pride by contributing financially to her family:

I feel proud to help my family out when they are in need. Even though it is just a little money I sent to my family, I earned it by my own capability and energy. I'm proud that I can pay back my parents. (Yayang, Factory C)

In regards to family relations, many women stated that their relationship with their family has strengthened. Even though they lived far away from their parents, women found that they have better decision making power in family matters. In particular, they were able to have their voice heard in the family. They also had control over their remittance. Bee explained how her remittance contributed to her household and gave her a voice in making decisions in the family:

My parents listen to me more than ever before. Every day they will call me and share their daily life with me. They always ask me for advice on important matters. For example, I proposed the idea of renovating the house. I also supported them with money, around 7 million kip, last year for this. They often asked for my opinion about the house design. They reported to me what has been built and how my money was used. It was so funny because we always fought back home, but now we talk nicely and miss each other. (Bee, Factory B)

Bee's comments show her influence in the family's decision making and how she has control over her remittance.

Women gained respect not only from family, but also their hometown community. This can be seen in the way that other villagers reacted to the women when they returned home for a visit. As Phone mentioned:

People in my village feel afraid when they talk to me because I talk to them maturely and politely. Previously they called me by name, but now they call me by my title, such as sister. Even my brother's wife calls me sister-in-law. (Phone, Factory B) 


\subsubsection{Important life choices}

One of the most significant changes of the women's new self-identities is having the ability to control important life decisions such as whom and when to marry without being forced by their parents. An example can be seen from a quote of Buaphan, of the Phunoy ethnic group:

My thoughts changed. I don't think about anything at home. I think about my life and my future here... When I was in Huaphan, I had to listen to and obey my father. He always tried to force me to get married by introducing many men to me. I didn't like them. I didn't want to get married and I was still in my teenage years. But things changed after I moved to the city. My dad does not try to force me to get married anymore. He told me it's up to me whether to get married or not. He will not force me. He will let me choose what I want now. Previously I didn't understand him, but I think I understand him now. He wanted me to have a family, so someone can take care of me. Now, he feels that I am adult and can take care of myself. My dad sometimes calls me to ask for my advice. He didn't dare to teach anything much because he knew I already know. I'm proud of myself because I can earn money to take care of myself (Buaphan, Factory A).

Buaphan's experiences indicate that her father looked at her differently after she went to the city. She was treated as an adult by her father. She gained power to control important life decisions such as marriage which is not easy for people of the Phunoy ethnic group. At the same time, she understood her father more. Similar to Buaphan, other participants pointed out how their parents reduced the pressure for them to get married and let them make their own decisions.

Besides gaining control over their own decisions, women also developed an understanding or their sense of purpose in life. Some women stated that they didn't want to get married yet. They were more concerned about their future. Even though their friends in their hometown already married and their family encouraged them to get married, the women did not feel pressured by those social environment and norms. Some women stated assertively that they will marry only when they feel ready. This idea occasionally conflicted with their partners. Lisa told a story of her past relationship and how she was assertive regarding what she wanted from a relationship: 
I just broke up with my boyfriend three months ago. I was the one who broke up. I know he loves me and wants to marry me, but I'm not ready. He always asked me to move in with him, but I don't want to. I am worried about our future. I am afraid that if we stay together, if we had kids, how could we raise kids and pay rent? I always told him to save money so that we can build a house together. If we have a house, everything will be easier. But he didn't understand my points. Also, he always got jealous of me easily and tried to control my mobility. He asked me not to go out with my friends and just wanted me to stay at my dormitory all the time... I know he loved me, but the jealousy was way too much. I want to marry someone who understands me so we can keep a long-term relationship. I don't want a husband who forces me. I want an equal and understanding partner. (Lisa, Factory B)

Lisa's story highlights the power within herself. She knows that what she wants in life is an equal partner and a sense of security. She is concerned about her future. This is similar to Kim, who manages her partner's salary and saves for their future. Khouphar is an example of a woman who dreams of starting her own business before marriage.

My parents want me to get married, but I don't want to. I want to have a house and a business on my own, to reduce the difficulties when I am married. If I don't have anything of my own, I'm afraid the man will look down on me. I'm not ready now. I'm afraid that the men want only my body. I want someone who truly loves me. (Khouphar, Factory C)

Phone's statement highlights the importance of not relying on a man for a living. It also refers to her sense of dignity as well as her purpose in life that she only wants a man who truly loves her.

\subsubsection{Leaving job as a resistance}

From the women worker's perspective, the garment factory job seems easy to enter, easy to quit and easy to return to. The majority of women I interviewed revealed that they used to leave the factory job for a period of time and then return again. Their reasons for leaving varied. The owner of Factory A confirmed that some staff would leave work after they receive their salary each month. Similarly, officials from MOIC and MOLSW mentioned that women tended to leave their job especially during the cultivating season to help their families 
cultivate rice and crops in their hometowns. Once the cultivating season finished, they tended to come back to work at the garment factory.

However, there are more complex reasons for leaving jobs than helping their family during the cultivating season. From what I was told in the interviews, women left work not only to help their family, but as a survival strategy, as Kiew indicated:

One time I was assigned to the stationery department. The salary was so low and I was charged for many miscellaneous things. The work was physically demanding. I had to not only work for my department, but also had to help with work in the quality check line operation. It was so tiring and caused me to have health problems too. I didn't want to be in that department. I wanted others to replace me. If I asked my manager to move me, but I needed good reasons. Simply saying the work is tiring was not a reasonable explanation. So I left the job after getting my salary without telling the manager. I went back home to relax and worked on handcrafting rice boxes which I sold. The money l earned from this was not enough to make a living. After two months, I went back to the same factory. (Kiew, Factory A)

The story of Kiew explains how she escaped the work overload from working in two different departments at the same time, as well as low pay and health problems, by going back home. Returning home can be seen as a strategy to break the chain of being exploited at work.

Likewise, some people decide to leave work because they could not tolerate the working and living environment. Mei and Joy recounted their experiences:

The dormitory in my previous factory is so crowded. I felt like I cannot breathe and can't move. If someone moved a bit, everybody in the room could hear it. The beershop in front of the dormitory always turned the music loudly late into the night. I could not sleep. (Mei, Factory C)

I left the job in my previous factory because the working environment was unbearable. The factory has no ceiling just a low lying tin roof. It felt like I was staying in a hot house after sewing just one piece of clothing I would be drenched in sweat. (Bobo, Factory B) 
Mei and Joy's story explained how the women refused to work in the unfavourable working conditions. Leaving to other factories which have a better working environment is seen as one of the most obvious options for the women workers.

While strong resistance movements such as protests rarely happen in Laos, leaving work might be considered a form of protest against the unfair treatment the women workers receive from the factory. In addition, some leave work to try out a new opportunity in other sectors, such as hospitality, because the social image of those jobs is better than factory work, even though they pay the same amount of money. Factory work is like a first step en route to the service sector jobs. Many women first come to factory as it offers a dormitory, salary and facilities and then tend to move on to try other occupations if they find an opportunity.

For example, some women planned to leave work to go to Thailand for a higher wage and experience the lifestyle there. A number of women I interviewed were planning to migrate to Thailand in the near future, as Mone explained:

In the future, I want to go to Thailand. I want to work and travel. I want to see if it is like Vientiane. I want to see the beautiful image of civilisation that I always saw in the television. Probably next year I will go. My boyfriend has a cousin there. (Mone, Factory B)

While many women chose to leave work to escape unfair employment, Joy used to be assertive and follow rules if she was not satisfied with the condition, policy or system in the factory. She recalled her experiences:

At that time it was New Years Eve which meant that we should get at least a day off, but the manager wanted us to work overtime. I gathered up some of the other women and we decided to resist and not to work overtime. We achieved what we wanted but this action also backfired on me. I was seen as the culprit of this which caused me to get fired. (Joy, Factory B)

Joy's story shows us that women can come together to achieve a common goal although there may be undesirable consequences. This also means that group power has a strong influence to negotiate. 


\subsection{Conclusion}

In conclusion, this chapter discussed migration, four types of livelihood assets and emerging issues from the research. The main findings illustrate that migrating and working in the city has benefited, but also cause hardship for women. In the city, women enjoyed a new lifestyle and integrated with new social groups. They also experienced being formally employed and gained incomes regularly. On the other hand, there were unfavourable consequences as well. Women were trapped in low wage positions and were exploited by employers. In addition, they were victims of sexual harassment in their workplace and violence in urban areas. Women individually and collectively developed their agency to come up with strategies to deal with these issues. Also, some women developed new identities which helped build their self-esteem and self-confidence. 


\section{Chapter 6 Discussion}

\subsection{Introduction}

This chapter discusses the research findings and provides discussion on issues that affect the wellbeing and development of rural-urban migrant women. The chapter begins with the reflection on the sustainable livelihood framework. It then explores how capitalism and patriarchy affect the urban livelihood and wellbeing of women. Lastly, women's agency, identity and empowerment has been discussed.

\subsection{Reflection on the sustainable livelihood framework}

Looking through a sustainable livelihood lens, rural-urban migrant women have increased their livelihood assets after migrating to the city. This research found that factory work and living in the city increases the human, financial and social capital of women workers.

In this research, women's human capital is increased through learning new knowledge from working in the factory and living in urban areas. At the same time, the financial capital of women increased through income women received from working compared to their nonincome in their rural home. Remittance, savings and access to finance as explained in the findings section are some examples of how women's financial capital increased. Additionally, women's social capital increased from interacting and socialising with female colleagues. Because of the interaction and socialisation among women, they are able to build strong bonds and support networks inside the factories and dormitories.

According to the School of Oriental and African Studies (n.d., Access to Assets, para 1), the increasement of livelihood assets is important because:

the more assets someone has the less vulnerable they are to various shocks and trends

... Better access to assets is a desirable outcome of any livelihood strategy. Livelihood strategies may focus on increasing the range of assets to which a person or household has access, or on increasing access to particular types of capital.

However, this research found that the more assets women have, the more risks they are exposed to and the more vulnerable they become. This increase in livelihood assets does not always translate into the improvement of livelihood outcomes such as increased wellbeing of women. Instead, factory work and living in the city increases the vulnerability of women. In 
urban areas, migrant women have better access to livelihood assets. They therefore experience an increase of livelihood assets than they would have had in their rural home. However, women experienced new forms of exploitation and oppression. Migrant women experienced exploitation from their capitalist employers through low wages, unfair and unpleasant working and living conditions. Likewise, the culture and social norms of male superiority oppress and create difficulty for women living in the city.

Despite vulnerabilities women face, there is a lack of support and interventions from related institutions to address these issues. The existing laws and regulations are likely to favour capital investors rather than labour workers. The government is focusing on transiting the country to industrialisation. However, it raises the question to what extent the government policies address the wellbeing and livelihoods of workers who are prone to accept low wages and work hard to make the transition to industrialisation possible. The interplay between vulnerability contexts and the role of institutions raise questions of whether increased livelihood assets will really result in achieving livelihood outcomes such as better quality of life and long-term livelihood security for women.

In this research, the sustainable livelihood framework allows me to see the complexity of livelihoods such as the construction migrant women's livelihoods, the context they live in and how these main elements link together. According to (Serrat, 2010), the sustainable livelihood framework emphasises the importance of people at the centre and the relationship between micro and macro as well as the formal to the informal perspective. In this case, this framework helps me map out the issues of women on the ground and high level institution policies.

This framework also encourages me to compare the livelihood conditions of women before and after migrating. However, this framework lacks some critical points which makes it insufficient on its own as an analytical framework for rural-urban migrant women issues. One reason is that this research focuses mainly on women's experience, and this framework underplays the gender issue. Due to its lack of gender aspects, the critical issues emerging from this research such as sexual harassment and violence that particularly happen to women could not be analysed within the framework.

Furthermore, the framework has been criticised for its lack of attention on power (Serrat, 2010). In this research, the power inequality exists everywhere both inside and 
outside the factories, between women and men, between women and women, between women and their capitalist employers, as well as between women and their households. Also, the research shows the internalised power or 'power within' of each individual woman and collective who form coping and resistance strategies to change their own lives. These critical dimensions of power interplay between each level are not well addressed in the sustainable livelihood framework. That is the reason why feminist theories were added to analyse women's issues and make this framework more inclusive.

\subsection{Economic structure}

\subsubsection{Capitalism and factory work}

Capitalists gain profits from the exploitation and surplus values of workers (Mann, 2012). Surplus value is the value difference workers produce for capitalists over their labour values. The concept of capitalist profits was seen in this research in how migrant women were exploited by their employer for profits. This research revealed that the working conditions and policies in the factories exploited women in many ways. For example, there are poor working and living conditions in the factories. Women workers were forced to work overtime and received minimal wages. These minimal wages were sometimes paid unfairly. Occasionally, such as when no orders were received, women were forced to take unpaid leave so that their employers could save costs by not having to pay wages. No written contracts had been made between employers and employees. From the above findings, surely, the profits of garment factories in my research were made possible by migrant women workers who accepted the low wages and unpleasant working conditions. As Mann (2012) argued, capitalist profits are rooted in exploitation. They also explained that workers rarely realised the additional values they contribute to the actual production process because their contributions are paid per hour. Interestingly, this exploitation can be seen not only in this research, but in research on factory workers from other developing countries such as Bangladesh (Zaman, 2001), Cambodia (Lawreniuk \& Parsons, 2017), Sri Lanka (Hewamanne, 2018; Hancock et al., 2014; Attanapola, 2003) and Vietnam (Tran, 2007). This means that the capitalist system of exploitation is generalised across different contexts in different countries.

Capitalism prefers female employees in garment factories because their feminine attributes drive productivity and profitability. My research shows that despite being exploited, the majority of women in this research are likely to accept those exploitations, especially the 
newcomers who are very submissive. Also, most of the women lack legal knowledge to claim their rights. This is similar to what Elson and Pearson's (1981) claim that the capitalist society employs women for productivity and profitability because women are either cheap to hire, have high productivity, or both. Another reason why the garment sector prefers women is because of their perceived nature of being feminine with 'nimble fingers', docile, dexterous (Elson \& Pearson, 1981) and passive (Cho et al., 2004). Women are also perceived as being obedient to managers' orders, lacking legal knowledge, and unlikely to form a union against their employers (Birdsall \& McGreevey, 1983). The rural migrant women in this research, particularly women from the Northern provinces in Laos, have dexterity and some sort of skills due to years of traditional weaving and handcrafting at home. These works taught women to pay high attention to details, and to be patient and be creative. As Elson and Pearson (1981) claimed, the patience and manual dexterity of women from doing women's work back home is needed in assembly line jobs to handle the high volume of apparel and achieve a high level of productivity. As a result, women workers benefit their employer both in terms of productivity and profitability. Their feminine attributes make it easy for the employer to control the women workers. It also helps the employer in minimizing costs and conflicts in the factories, as well as in maintaining low wage salaries. This might explain why women were seen to work repetitively and monotonously in the factory.

Even though the garment sector is occupied heavily by women, they are concentrated in the low paid ranks of this sector. In my research, it was rare to see Lao women in the higher positions above operation line supervisors. Also, high managerial and garment expert positions were occupied by foreign men. Most of the middle managerial positions were mostly occupied by local men. This represents the division of labour within factory where women are in the low positions, while men are in higher positions. The gender division of labour can be explained by several reasons. First of all, there is a high staff turnover rate in Laos (World Bank, 2012). This corresponds to my research where women occasionally moved to another factory when they were not satisfied with their current one, to Thailand to try a new experience, and to their hometown to help family during cultivating seasons. This short working life gives women less opportunity to get promoted. Another reason is, as Foo \& Lim (1987) claim, that women considered their reproductive roles a top priority and left work for marriage and childbirth, which caused the lack of females holding senior positions in the factories. 
Interestingly, I found that women with years of experience reported that they did not want to take higher positions. They preferred to earn according to their productivity. This can be seen specifically in the case of Fone, who took a very long time to accept the line manager position. She complained to me how afraid she was that her colleagues would hate her and how she lacked leadership skills and confidence in managing her colleagues. This finding is in line with the study of Ong (1988) on Malay factory workers. Ong explained that women workers in her study refused to take higher positions and continued to work as operators earning from their overtime. This is because women in higher positions found it hard to exert power over their female workers who appeared to be their friends and 'sisters.' Ong argued that, in this situation, "male authority and power were seen as necessary qualities in supervising female workers" (p.164). Male qualities such as a 'fierce' demeanour were needed for women to be listened to (Ong, 1988). From my observation, these male attributes might represent the control of a father in women's households which women have to listen to. My research shows that many women are under their father's and brother's control in almost all aspects of their life in their rural home. These women listened to, obeyed and could not challenge their fathers. The male control in the factories means that the fathers' control in households has reproduced itself as male hierarchical power in the factory. In this case, women were expected to listen to and obey orders from male bosses as well as their father's and brother's. As Sultana (2010) and Scott, Bell and Holden (2016) claimed, rural migrant women were raised with the beliefs that men are superior and belong in the top positions in their households, economic, social and religious. Also, according to WHO and LSHT (2010), women who are in positions of power and challenge the beliefs of male superiority are often disliked by society. These reasons explain why Fone felt hated by other women. Also, it explains why many experienced workers refuse offers to be promoted and prefer to work and earn from the volume they produce. In addition, this low status of women in the factory reinforces the sexual division of labour in the workplace where males hold higher positions and women are at the bottom. This is an example of how "the class hierarchy is further supported by the gender hierarchy" (Brydon \& Chant, 1989, p.183). As a result, women's status was regarded as that of secondary workers who lack power and are trapped in low paid ranks in the factory. 


\subsubsection{The reserve army of labour}

The discussion above shows the division of labour, low pay and exploitative conditions in the garment factories in this research. These conditions reflect the Marxist concept of a reserve army of labour. Marx argued that reserve army of labour is required for accumulating capital. An reserve army requires flexible workers that can be pooled into production in times of demand and fired if production drops (Beechey, 1977). These flexible workers are required to accept low wage levels and submit to increasing exploitation while producing surplus value (Beechey, 1977).

Without doubt, rural migrant women in Laos fit Marx's concept of a reserve army. However, women are not the only group that was pooled into garment production as reserve labour. As my research shows, child labour was used in the garment factories. These children could not defend themselves against exploitation. Factory B employed child labourers as young as 13 years old. The stories from Mone and Phone in the findings section explained how factories employed child workers under 18 years old and how they got away with it. Employing labourers less than 18 years old breaks the rule of the main foreign buyers and the subcontract factories might get into trouble if the main contractor finds out. According to Lao labour laws, the legal age for working starts at 14 years old, so employing people as young as 14 is not illegal, but the teen workers should be exempted from overtime work, night work and dangerous work. Many factories fail to comply since young workers entering factories follow the same conditions as adult workers.

Allowing very young labour employment can be interpreted as the Lao government playing a role in facilitating the employment of young labour in favour of industrialisation. As Beechey (1977, p.56) argued, the state plays a role in "constituting and reconstituting the industrial reserve army" through its legislation. Even though teen employment does not break the Lao labour laws, teen labourers in the garment factory lose their opportunity to gain an education, and most importantly because they entered the workforce at such young age they also lose their childhood.

Results from interviews with government officials show that the state plays an important role in perpetuating the capitalist system in Laos. This includes the perpetuation of labour exploitation as can be seen in the country's policies and legislation. A high ranking 
government official from the Lao Federation of Trade Unions explained clearly how the state plays a role in law implementation. He stated:

In Laos, we have laws that fully cover various aspects. But we fail to implement them. The implementation process is not strict enough. For example, we have trade unions and labour laws If we really enforce the laws, such as giving fines to the factories that do not have contracts with their employees, then the factories would have less money to pay their workers, production would suffer, and we would lose foreign investment. If we are too strict, the investor will move to other laces which give them a more favourable environment. Control that is too strict is not yet appropriate for our country's situation. However, our government is trying to tighten it up little by little. (Official, LFTU)

As evidenced from the official's explanation, foreign investment seems to be an important concern regarding the development of the country and Laos is willing to attract these foreign investors using its cheap labour and relaxed laws. This corresponds with Vixathep's (2011) study of how foreign investments will bring many benefits to the country such as reducing poverty, and creating jobs and income for rural poor. However, my findings revealed that the country is not gaining much from foreign investment, particularly in the garment sector. This research revealed that women were trapped doing repetitive and monotonous tasks without the opportunity for further skill development. This finding is similar to what Nolintha and Jajri (2016) argue, that the garment factory employers in Laos are not very interested in, and do not want to invest much in, upgrading human skills or research and development for workers. Also, the interview with a government official from MOIC pointed out that Laos lacks small and medium enterprises to supply materials into garment industry. It can be seen that Laos benefits only from labour wages and employment, but not human capital, which is the most important aspect of a country's development. The one who benefits the most from cheap labour, unrestricted regulation and exploitation of workers is clearly the foreign factory owner. This shows how capitalism works and raises questions about the sustainable development of the garment sector. 


\subsection{Social structure}

The previous section discussed how the economic structure and the capitalist system influenced the working life of women. This section explores how the current social structure impacts the wellbeing of women.

\subsubsection{Patriarchy in the households}

The term 'patriarchy' or the 'rule of fathers,' as defined by Walby (1990), can be seen in the rural Lao context in the form of fathers controlling daughters. All of my female participants pointed out that their father had the most power in the household, was the one who made the decisions, and controlled all aspects in the household, including finances and the personal lives. The fathers controlled their daughters' socialisation, mobility, dress and behaviours. Particularly, all of the daughter's socialisations with men was to be monitored by her parents or brothers. The strict control of a daughter can be seen as a way of keeping daughters as a "good girl" who knows how to do domestic work, remains a virgin until marriage, and can then be a good wife. In Laos, women who lose their virginity before marriage are regarded as loose and devalued by other women. My findings revealed that before coming to the city, more than half of the participants reported feeling constant pressure from their parents to get married early. GRID (2005) claims marriage is regarded as the key role of being accepted into Lao traditional society. Also, there is a lot of pressure on women to get married and to continue in the marital relationship even through hardships and controversy (GRID, 2005). Upon their daughter getting married, the father can transfer his responsibilities to his son in law. In other words, women might break free from parental control after marriage, but they are kept under patriarchal control by their husband. The "rule of fathers" as defined by Walby (1990) becomes the rule of husbands in this case.

\subsubsection{Workplace bullying and sexual harassment}

According to Haspels et al. (2001) unequal power relations between men and women intensify sexual harassment in the workplace, especially when men hold higher hierarchical positions. Unequal power relations mean that women are in lower positions and this makes them more vulnerable to bullying and harassment. Noy, a secretary for the foreign factory director, regularly received verbal and physical abuse from her male boss and did not do anything about it. Focus group in Factory $\mathrm{C}$ also reported that this foreign male boss verbally 
abused workers and disrespected Lao culture, but no one took any action against him. In this case, we can see that the director holds the highest position in the factory and uses his high level power for intimidation. According to Haspels et al. (2001), male bosses have 'obvious power' over their employees in terms of the employment decision-making, such as the ability to hire and fire employees as well as to withhold work and delay payment. As a result, no one in the factory dares to challenge this director. This male director control over employees resembles how the father controls women in his household and decides everything in his daughter's life. Even though the women do not agree with the situation, they feel powerless to challenge the patriarchal power. This example reinforces the mindset of how society operates to subordinate women in both the household and workplace.

It is not only male supervisors who harass women, but male workers also harass the female workers. In one focus group discussion in Factory B, all six women workers in this group experienced sexual harassment on a daily basis from their male colleagues. They disliked how their male co-workers harassed them both verbally and physically. However, they did not take it seriously and treated it as though it was a joke. With this attitude in mind, these women took little or no action against their male colleagues as a defence. The women in the focus group did not report it to the authority. Instead, these women coped with this situation by joking back. Women took no actions because they often were blamed for the harassment in several ways. According to Haspels et al. (2001, P.36), victims are to blame for "either 'loose' women or 'frigid' women who cannot take a joke." Haspels et al. (2001) explained that women were also to blame for the way they dressed and for their appearance as it drives male sexual desire. Sexual harassment was regarded as a normal part of life and no action should be taken except in serious cases. Likewise, Hlavka (2014) argued that women were considered as the gatekeepers for male sexuality and are the ones accepting or rejecting male harassment. These reasons might explain why women perceived sexual harassment as a joke. This is similar to the case in Cambodian garment factories where women workers coped with sexual harassment by changing their attitude towards sexual harassment as nothing serious (Lawreniuk \& Parsons, 2017). The women tolerated verbal intimidation and annoyances by developing thick skin and treating it as a joke (Lawreniuk \& Parsons, 2017).

Interestingly, Vone and Thip from Factory B regarded sexual harassment not only as a joke, but also as an acceptable way of flirting. As Vone mentioned, "they just did this to the women they adore. If they don't like us, they will not do this to us. They don't do it to the 
women they don't like". Similarly, Thip described why male workers did this to one of her friends by saying "when the men see a pretty girl, especially the one with white skin, they want to joke and flirt with her." Vone and Thip's descriptions highlight their acceptance of sexual harassment as way of flirting. This finding is supported by a report from WHO and LSHT (2010) that women accepted the harassment because they believed it shows the men that women are attractive to them. Also, Vone and Thip might have misperceptions about sexual harassment and count it as flirting. As Haspels et al. (2001, p.156) argued, "sexual harassment is harmless 'flirting' and an 'expression of men's appreciation for women."' Also, the gender stereotype which supports the idea that 'it is natural for men to flirt' complicates the situation of coping with this issue (Haspels et al., 2001).

A certain number of women in my research perceived sexual harassment as something normal and happening regularly. As Ploy from Factory B pointed out in the discussion, "this kind of harassment happens everywhere, not only here. It's not a big deal. Just turn a blind eye." After Ploy finished talking, every woman in the focus group nodded their head in agreement. From Ploy's narrative, it seemed to me that she and some other workers perceived sexual harassment as common and acceptable, not only their workplace but in Lao society as a whole. Results from this research show that sexual harassment was regarded as a joke and a way of flirting, as Vone and Thip mentioned. It was something common based as Ploy's description. These attitudes of acceptance towards sexual harassment might link to the way social norms work. As discussed in the literature review, the underlying causes of sexual harassment are patriarchal ideology and unequal gender norms which privilege males over females (Scott, Bell and Holden, 2016). These facets influence the way men and women consider certain types of behaviours to be normal practices. Women are brought up and socialised to believe that they are inferior and to be submissive to men from early childhood (Scott, Bell and Holden, 2016). Some social norms, such as sexual activity, are a symbol of masculinity which make it difficult for women to question sexual harassment (WHO \& LSHT, 2010). Sexual harassment and violence can be the men's way of expressing their masculinity as 'real men' in society (Jewkes, Flood, Lang, 2014; USAID, 2015). Both women and men might see these practices as normal, common and customary (Hlavka, 2014). These reasons might explain why rural migrant women workers in my research who grew up in patriarchal households accepted sexual harassment as normalised practices everywhere and probably see nothing wrong with it. 
My research also shows that male workers harassed their female line supervisors both verbally and physically. These line supervisors have organisational positions higher than male workers in the factory. However, these women also took no action against the harassment. In this sense, sexual harassment is not about how males use their higher status and hierarchical power in the workplace to harass female workers under their supervision, but how male individuals challenge female power. As Haspels et al. (2001, p.36) argued, "gender subordination of women in society also means that even women in positions of power can be seen and treated as 'second' by equal or lower ranking workers." Even though female line supervisors in my research held higher positions in the workplace than the male workers, their power and workplace hierarchy did not mean anything. As Scott, Bell \& Holden (2016) claimed, the patriarchal ideology and gender power hierarchy of male superiority play a role in the workplace. Female line supervisors in my research were subordinated for being a different gender despite being higher up in the organisational hierarchy. The lack of action taken by these female supervisors emphasises the tolerance of sexual harassment in their factory. This leads female workers under their line supervision to normalise sexual harassment as well. As Oy explained, " our line supervisors got the same treatment from the male mechanics and they also said nothing. No one took it seriously. We've gotten used to it. No one sulks or complains about it". Oy's comment highlights how even women within the organisational hierarchy normalised these behaviours. It also shows that men have the privilege of being the dominant gender. The status men hold in the workplace does not matter because they can assert their power through sexual harassment of their female supervisors, even in female dominated workplaces like the garment factory. At the same time, when women in power do not respond to male sexual harassment and treat it as a joke, this reinforces, maintains and intensifies the acceptance and perpetuation of patriarchy in the workplace.

There was only one young woman that challenged gender normalised behaviours by taking some actions against her harasser. Lam responded to sexual harassment from a male mechanic in the factory by assertively, by telling him to stop and also hitting him. She told me "I hit him back. I cursed him. I pointed my finger at his face and told him not to do this to me again. I told him 'I don't like it."' Lam's aggressive reaction to her harasser was surprising and impressive. It was evident that she was different from ordinary women in the factory who talked softly and behaved humbly. Lam spoke loudly with confidence and shouted at men sometimes, but was only in her late twenties. This made me curious as to why she was 
different and dared to challenge dominant accepted gender norms. From my personal observations, there are reasons that might explain why Lam broke the norms. First, she was well educated and had a diploma. This might explain her confidence and knowledge regarding sexual harassment. Secondly, she was a woman in power. She was not only a finance and recruitment officer, but also the head of the female dormitory. She lived in the same room with other women and was regarded as a big sister there. Everybody in the factory knew her. When women got into trouble, they were likely to report to her first. Since many women workers looked up to her, Lam felt that as a big sister, she needed to fight back to respond to the man's challenge to her power and reputation. Also, she was already married. In Laos, married women who are involved in sexual activity in any way with men other than their husband will be severely stigmatised. Therefore, it was important for Lam to protect her pride and reputation as a good wife. However, even though Lam acted against sexual harassment aggressively, this proved to be ineffective as these male mechanics continued to harass her. She is fighting a losing cause. In this case of harassing a female in a superior position, Haspels et al. (2001) claimed that the purpose of the harassment might not be related only to sexual pleasure, but to show the power men have over women. Scott, Bell \& Holden (2016) pointed out that men are often more highly valued in the society and often hold higher positions in the workplace. When these workers were in lower positions than women like Lam, sexual harassment might be a strategy the mechanics use to feel a sense of superiority. They can at least show other people that they are not dominated by women in power, in a female dominated workplace.

\subsubsection{Sexual violence}

The occurrence of sexual violence happens widely in Laos. My findings show that rape is likely to occur to new teenage factory workers by men from outside the factory who are introduced to them by their female senior colleagues. The sexual violence can be seen in the cases of Mone and Kim who were victims, Vone who escaped a violent incident and Noy and Mei who were involved in helping protect their colleague from a rape attempt. My findings are in line with the research of CARE International Laos (2012) which found similar patterns that in many cases of rapes had occurred to Lao women because of peer pressure from their colleague who left them alone with a stranger after going on a night out. 
Social norms and Lao culture play important roles in perpetuating sexual violence against women. In Laos, particularly in rural households, domestic sexual violence is regarded as a private matter. According to (National Commission for the Advancement of Women [NCAW], 2015), Lao women were told by their extended family members and village authorities to tolerate it and solve it among partners. There is also a notion of a 'silent culture' where women tolerate domestic violence due to the embarrassment and shame it will bring to the family (NCAW, 2015).

The culture of silence can also be applied to the case of rape. Mone, the victim of rape and violence often cried alone under her blankets and kept everything to herself. In Mone's case, she was socially isolated in the urban area. The relationships she built in the factory among colleagues could not be trusted. This left her with no support in the urban area. Mone did not tell her family back home about the incident because the promise she kept to her parents was that she would not have a husband. Having sex under any circumstances can be interpreted as having a husband, since sex before marriage is unacceptable in the Lao culture, especially in the Khmu ethnic group, which Mone belonged to. If her parents found out about this incident, they might force her to go back home which she did not want to do. It can be seen that she wanted to maintain the image of being good daughter for her family and to continue to work in the city independently. Going back home would mean she that did not accomplish what she set out to achieve, and her family and community might view her as a failure. No matter how much pain and suffering she was going through in the city, she did not want to go back home as a loser.

The story of Mone can be seen in the broader context of Laos in how some men view women as prone to being victims of sexual violence. Some men see migrant women as victims due to their young age, lack of life experience, lack of parental guidance and social isolation. This research shows that many of the sexual violence and harassment incidents are likely to occur to new employees and underage girls. The young rural migrants are more likely to be victims of men because they are perceived by society as naive, gullible, curios and unaware of how to protect themselves from or avoid risky situations. The way rural women were brought up might explain why they are often seen as being vulnerable. For example, rural migrant women from this research were kept in control by their fathers and brothers and had very limited socialisation at home. This caused them to lack the skills needed to survive in the city. 
Coming and living alone in the city without protection from male family members might make them vulnerable and men might perceive them as easy victims.

Even though this situation is prevalent among female factory workers, it is not limited to this social group. It is a nationwide issue and is accepted as a social norm. Male violence is not just an individual act, but involves social structure as Walby (1990, p.128) argued:

Male violence against women has all the characteristics one would expect of a social structure, and that it cannot be understood outside an analysis of patriarchal social structure ... Rape and wife beating, analogously and conventionally considered individual acts, are social facts best analysed in terms of patriarchal social structures.

The culture of silence stems from past instances where women were blamed and shamed for sexual violence. In Laos, the social norms and culture stigmatise the victim of rape and the victim's family tends to keep the rape incident a secret to avoid a bad reputation being bestowed on the family. It can be inferred then, that if a rape happens, the victim's family will not likely report it to the police, but will more likely try to resolve the matter domestically, within family CARE International Laos (2012). The perpetuator can avoid blame by either paying a fine to the victim and/or marrying the victim. In some cases, the perpetuator asks to continue a relationship with the victim to get away from the crime (CARE International Laos, 2012). This fits into the Lao law in that sex without consent is not considered rape in a marital relationship (Bureau of Democracy, Human Rights and Labour, 2016). Therefore, keeping an ongoing relationship negates the rape. It can be seen clearly that the Lao social norms, culture and laws oppress women.

While empirical studies focus on sexual violence of men towards women, in this research, I found that women themselves also play an important role in oppressing women. It can be seen in the case of Mone that her colleague put her in a risky situation by leaving her with strange men after a night out; in the case of Vone that she gave information about sex work to her friends; in the case of Bee who was bullied by her senior female colleague because she received a higher salary due to her high productivity; and in the case of Khaek where her friends arranged for her to meet with a married man just for the sake of some amount of money. Also, there were incidents of violence between tom (transgender men) and women as can be seen in the cases of Fone, Bobo and Khaek. The capitalist and patriarchal system explains how class hierarchy and gender subordination oppress women and how male power 
in the workplace and society exploit women. However, the exploitation of people of the same social class and sex is not addressed in the patriarchal capitalist literature. Marxist feminist literature states that women's emancipation can be achieved through removing the class, while radical feminist believes overthrowing of patriarchal structures from society is necessary. However, still unanswered is how women's emancipation can be achieved if the same working class and same sex oppression, as apparent from this research, exist. Therefore, further study regarding this matter is needed in order to understand deeply the problem of women's oppression.

\subsection{Women, new identity and empowerment}

This research indicates that rural-urban migrant women take on new identities when changing from a rural identity to a modern identity - from dependent daughters to independent wage workers in urban areas. Women often recalled their first experience coming to the city as 'bannok' (rural girls), who did not know how to behave in modern urban areas. The term 'bannok' presents rural identities as poor, uneducated and uncivilised.

To avoid being called 'bannok' and being discriminated against because of their rural identity, migrant women adapt themselves to the urban environment. Women in my research reported developing new identities through self-transformation in terms of language, manners, gestures, dress, tastes and appearances. This can be seen by the amount of money women, especially newcomers, spent on new clothes and cosmetics to dress more like urban women. Many women stated that their skin is fairer now compared to when they lived in their rural home. In Laos, fair skin implies beauty and the superior status of women. It means that women are well off and not exposed to sunlight doing agricultural work which is associated with being poor. My participants spent mainly on beauty products that made their skin fairer. The changing of identity through urban consumption in this research is similar to the research in Thailand by Mill (1997) and in Laos by Sisaleumsak (2012) and Khamphouvong \& Santasombat (2014). These studies found that urban consumption habits enable migrant women workers to construct new identities as 'modern women' and fulfil their modernization desire.

Another important element in building up a modern identity for women in this research is learning the official language (Lao) and adapting to the dialect and accent of urban people. Despite the existence of 49 ethnicities in Laos, only the Lao language of the Lao-Loum 
ethnic majority group is acknowledged as a national language (Lao Statistic Bureau, 2015). Women in my research came from a diverse range of ethnicities, but I could not distinguish their ethnicities by accent. The women spoke Lao very clearly and had no problems communicating with me. I was especially impressed with Ser, a Khmu ethnic girl who could not speak any Lao before migrating, but spoke to me clearly during the interview. Each dialect and accent reveals the region, ethnicity, origin and identity of the speaker. Being able to speak fluent Lao does not merely ease communication and survival in urban areas, but is a symbol of superior status, power and a new identity which women embrace through learning the language.

The process of acquiring language allows people to be aware of their sense of selves, subjectivities and their positions (Weedon, 1997). In this case, the process of acquiring and adjusting to Lao language makes migrant women aware of their subject position and their identity. They are conscious of the way they are different from others. The language learning journey of migrant women happens through socialisation, observation and imitation. As a result, the women transform from a rural identity to a modern identity as displayed through the new way they talk, dress and behave in order to assimilate into the urban environment.

Even though my participants changed their outside appearance and learned the Lao language for their new identity, one core value that never changed was the gratitude the women had for their parents. The desire to give something back to their parents showed through in the women sending remittances back home regularly. Through contributing to their household finances, some women gained an increased voice in their family's decisions. Importantly, they had more control over their important life choices such as marriage. These decision making in some countries link to the sense of empowerment and self-worth of women as can be seen in Vietnam in the study of Tran (2007).

Kabeer (1999) argues that power is an ability to make choices. The urban consumption of women might explain women's power. By working and living in urban areas, women have their own ability to choose their own clothes and purchase things that bring them pleasure and confidence. Women also gain access to more financial and social resources. These resources play important role "to enhance the ability to exercise choice" (Kabeer, 1999, 437). Some women in my research mentioned their economic contribution increased their voice and decision making at home. Importantly, all of my participants enjoy their mobility and 
freedom in urban areas. They also enjoy taking full control of their own life which they never had before in their home. These activities are not just an act of having power, but it is the process of empowerment. As Kabeer (1999) claims that "empowerment is a process of change... [it] refers to the process by which those who have been denied the ability to make strategic life choices acquire such an ability" (Kabeer 1999; 437). In this situation, women in my research who previously denied such abilities to make their choices can consider to be empowered in urban areas.

By learning to live and work in the city, women gradually transformed from 'bannok' rural girls into modern girls, in other words, from rural dependent daughters to independent wage workers. This transformation helped create positive self-perceptions for the women. Many women reported that they are 'Phoum jai' (prouder), 'mun jai' (more confident), 'pen phou yai' (more mature), 'kar harn' (braver) and 'keng keun' (smarter) than their rural selves were. Importantly, the women developed a stronger sense of purpose. These positive feelings reflect a personal sense of empowerment or 'power within'. As Rowland (1997) claims, the power within, or internalised individual attributes, included self-respect, self-acceptance, selfworth and dignity that exist inside each individual. Also, Kabeer (1994, p.229) points out the importance of 'power within' as important elements of empowerment that "such power cannot be given; it has to be self-generated".

In my study, the 'power within' of women might emerging through the process of embracing, negotiating and resisting changes between their rural and modern identity in shaping their new identity. New identity-making is accumulating process overtime and sometime contradicts with women's rural selves. As Pun (2005) mentioned, "to construct new industrial subjects, rural beings are constantly devalued, downgraded and forsaken" (p.20). However, it is up to women to act as subjects to embrace or resist the values on the journey of subject making. As Weedon (1997) claims, one might resist values and meaning that contradict their historical self or embrace those which fit with their interests. In this study, to build modern identity, women do embrace the change in terms of their appearance, manner and language. However, women resist the individualistic urban values which contradict with their rural family-oriented values. Women retained the rural values of gratitude to their parents. It can be seen that women have the 'power within' to choose whatever brings them a positive sense of self. 


\subsubsection{Individual agency}

Women in this study coped with the limitations of the capitalist workplace to develop their skills and used creativity to resist their managers. My research found that the women had different encounters with the system and different degrees of agency. Despite exploitation in the workplace, a number of women were able to find ways to respond to their managers by using and developing their expertise in apparel. To illustrate, I will draw on the stories of Bee in factory B and Nammok in factory A.

While the capitalist workplace system allows women to work only in repetitive and monotonous tasks, there are a number of women who find ways to change this and not get trapped in this mode of production. Nammok provides an example of this situation. She had been working in factory A for a year and half, but she was capable of sewing various part of women's suits. Her dream was to open a tailor shop in her hometown. She told me that tailor shops were quite rare there. She explained how factory work limits her chances to learn from others and how she is eager to learn. Before becoming skillful, she took the initiative to set up a group with her fellow 'sisters' to teach each other different tasks. She was often looking for an opportunity to learn from the other lines of production, such as by helping out during her lunch break or by offering help to others with their tasks when she finished her own duties.

Nammok's story suggests that although the capitalist system limits opportunities for women to develop their skills, there are always women with power to learn and who try their best to seek opportunities from this system. In the case of Nammok, she is not just a working body, but a body with a purpose. Working in the factory at least gives her the sewing skills necessary to achieve her future goals. She and her fellow 'sisters' were not just working day by day, but taking the initiative to accumulate knowledge and develop their skills as much as possible through their time in the factory. Such desire and willingness to develop themselves is important in building their reputations as qualified workers in the workplace.

Exploitation and unfair treatment in the workplace drive women to challenge those in power. During her first month at factory B, Bee was seen by her line manager as a naïve rural girl with limited knowledge. Just like other new entrants, Bee tried her best to adapt to the urban workplace. She was afraid to make a mistake because her boss scolded her with insults relating to her rural identity. She kept quiet and focused on learning all the skill sets in the packing department. In only five months, Bee surprised her colleagues by becoming one of 
the most highly productive workers. She mentioned that "I learned a lot and I know what I am doing now. I am not afraid anymore. If they criticize me for my work, I keep quiet when they are right, but do not hesitate to fight when I am right".

Bee's story shows that she was able resist the subject position of a naïve rural woman in favour of the subject position wage of a worker with expert knowledge in packing. This made her unafraid to be assertive in responding to her boss who used to exploit her or criticize her work. Bee's story reflects the experience of new entrants being oppressed while they are in the process of gaining work experiences and acquiring a new identity as urban workers. The new entrants are seen as obedient and naive because their lack of experience makes them afraid to speak out. It took some time for Bee to adjust from being a rural woman to a working woman and accumulate a sense of self. Once women get used to the system, accumulating all the skills at work and learning from their experience of living in the city, they become stronger and no longer afraid to stand up for their rights. In the case of Bee, her expertise gave her power. She embraced the constructive feedback of her superior, but did not hesitate to act against bullying or unfair treatment.

\subsubsection{Resistance}

Hard forms of resistance such as strikes and protests formed by the sisterhood in these factories are used collectively to draw public attention to the exploitation in garment factories. Aiming for public attention was seen as an effective way to bargain with employers and is likely to have good results (Tran, 2008; Zaman, 2001). Unfortunately, Lao law does not permit workers to form their own organisation or organise a political movement. Organising a protest in any form is illegal and forming an organisation needs approval from the government. Strikes are not permitted during working hours according to Lao labour law (Lao Labour Law, 2013). These laws and regulations seem to favour the capitalist system. However, it does not mean that resistance will not occur. As Foucault (1980) explained:

“as soon as there's a relation of power there's a possibility of resistance. We're never trapped by power: it's always possible to modify its hold, in determined conditions and following a precise strategy" (Foucault, 1980, p.13).

Even though the Lao system does not permit workers to resist in hard forms, women in my research seeked alternative ways of expressing their resistance in their everyday lives. 
Soft forms of defiance included talking during work hours, going to toilet without waiting for permission and sneakily using the phone when they were not allowed to. These behaviours can be seen as a form of resistance and as taking a break from the harsh working environment.

There is evidence of women resisting the exploitative conditions of work places by being assertive and claiming their rights. In this case, women positioned themselves as wage workers with knowledge of their rights. My research revealed that being assertive is an effective strategy on particular occasions but might expose women to the risk of losing their jobs and bullying from the boss in this context of ineffective laws and weak labour unions. This can be seen in the case of Joy in factory B getting fired from her previous factory for organizing a group claiming leave pay for Lao New Year. A number of women in factory $C$ received huge wage cuts by insisting on not doing overtime work. This shows how the dominant power can punish whoever challenges them.

Women have resisted the capitalist system and patriarchal control in their workplace and in everyday life, individually and collectively. Women position themselves differently at particular moments in time. Sometimes women take up a modern identity by becoming more assertive and speaking out or standing up for their rights. Other times, women resist in silence and use their rural identity or powerless position. I found that silence is a tactic used widely. Silence does not always indicate that women are complying with the regulations, but is a hidden expression of resistance, dissatisfaction and hatefulness which women harbour in themselves, waiting for the right moment to release explosively. Also, silence is the way many women react when they find that speaking out does not achieve any outcome. They resist in silence and continue tolerating the manager's attitude towards Lao rural women as naive, stupid and hard to teach.

One focus group revealed how silent resistance works. Mei and a small group of women in Factory $\mathrm{C}$ discussed the hardships they faced of doing overburdensome overtime work and decided to secretly report to the labour department to request an inspection of the factory for enforcement of late-night overtime work continuing for many consecutive days. As a result, the factory got fined after the inspection. The factory attempted to discover who reported the incident to the government officials, but they never found out.

Silent resistance could be seen in Factory $\mathrm{C}$ where the control by the foreign manager was very strict. Some women found ways to resist by aiming at production targets. 
Everything is a rush with this foreign boss who sets excessive production targets higher than our average production rate. He rushes us because he wants to continue to work here. We know that if he does not perform well, he might get demoted or moved to other places like our previous boss. He was rude and disrespected Lao culture. Everyone in the factory hated him. Our factory did not pay based on productivity. No matter how much you produce you get paid the same. Sometimes I get too tired with the "over target" so I play dumb and I can tell my friend does it too. We just work at our own pace and don't care about the production target. I think others do the same thing because if one person in the line gets slow, it affects the whole line. The foreign boss then always comes down from his office, and gets mad and angry at us regularly. He will say many things which we cannot understand. We kept quiet. Sometimes he tells some of my co-workers to get off their seat. He then displays how to sew using over exaggerated actions. We feel it's kind of funny when we see him so frustrated. (Mei, Focus group discussion, Factory C)

Women in the focus group laughed and continued to joke about this foreign manager's reaction. I felt that the women were satisfied seeing their boss getting angry and mad. They made fun of him by giving him a new name and recalled situations when he got mad at them It was like their victory. Playing dumb is how some women respond to strict control of the managers and can also be seen as they resist the manager's perspective of them as uneducated and undisciplined enough to fight back.

Such forms of silent resistance of women reflect the term 'power with'. As Rowland (1997) claims, 'power with' or power from collective actions and solidarity among the collective group greater than an individual. The solidarity of the sisterhood in Factory $\mathrm{C}$ represents what Allen (1998) called collective empowerment which aim to overthrown male domination. This collective power also challenges underlying assumptions. In this situation, women in the Factory $\mathrm{C}$ acted consciously and unconsciously together with the shared purpose of overturning the domination of their male foreign boss. Their tactics might not be aggressive. On the other hand, being quiet, submissive, and 'stupid,' under the societal norms and ideology that portray rural women as such, is the way women in Factory $\mathrm{C}$ challenged the dominant power. Despite various subject positions, women know how to switch on and off between subject positions to serve their interests. Sometimes they might take up their modern identity and be assertive and aggressive, while other times they may change to their 
rural identity and be quiet, naïve and 'stupid'. This means that women understand how to use knowledge of other discourses consciously or unconsciously to their advantage.

\subsubsection{Women's agency and relationships}

According to Weedon (1997, p.32), "forms of subjectivity are produced historically and change with shifts in a wide range of discursive fields which constitute them...the individual is always the site of conflicting forms of subjectivity." This section explores how women have conflicted subjectivity within themselves, and their strategies for survival.

The Lao public perceives migrant women in the factory as loose women. The image of men sitting on their motorbikes waiting outside the factory gate for the women, as well as the women who occupy the beer shops nearby the factory work to exacerbate this perception. My findings showed that a certain number of migrant women get involved in intimate relationships with multiple men at the same time. This conflicts with the acceptable image of Lao women, remaining a virgin until marriage and being in a monogamous relationship. Despite the public discourses, some women decided to enter a relationship on their own and viewed themselves as doing nothing wrong, which is contradictory to the public discourses. From spending time with the women, I observed that they have conflicted and fragmented subjectivity regarding this matter, but this does not make the women feel negatively towards themselves. Instead, the women exerted their agency by purposely choosing their partners and making their own decisions, free of force, to live the life they wanted. Women do have choices and they act upon them purposely.

Vone, a mother of three children who escaped her abusive husband, left her children with her parents, to migrate and work in the city. On one hand, Vone often stated that she missed her children, and showed me their picture on her phone whenever I visited her, and explained how she works hard to support them. On the other hand, Vone had taken up a modern identity as a woman in a serious relationship with one man, and a non-serious relationship with a man 10 years younger than herself. Interestingly, she criticised her friend Ploy for flirting around in the beer shop and having multiple relationships with many guys. She ignored public criticism of the women workers.

In the case of Vone, I could feel the complexity of her subjectivities. By criticising her female friend, it seems that she realised the cultural values and ideology of how respectable 
Lao women should behave and criticised those who did not follow them. However, her verbal narrative contradicted with her reality. In her real life, Vone broke the traditional Lao values of remaining married no matter what by ending her painful marital relationship and ignoring the domestic role of Lao women by leaving her children. She chose to pursue her desire and interests by beginning a new life in the city, but regarded herself as a good mother by keeping her love and responsibility through remittance. At the same time, she then chose to pursue her desire and interests by entering a new relationship. The way she disclosed this to me openly made it appear as if this is very common and acceptable and as if there is nothing wrong with it. She did not feel ashamed about her behaviour of engaging in multiple relationships at the same time.

Vone's story helped me to understand that because women were brought up with discourses and values of respectable Lao women, there is pressure on the women to follow them. Their subjectivities were constructed by history, society and culture. In reality, the desire of women to choose their own way of life is more powerful than following the discourses and values that brought them up.

By living the life women choose, it brings them a sense of self-worth and self-respect. The social structure might create tension within women's individual selves, but cannot stop them from exerting their agency as Vone did. Women act "to transform themselves in order to attain a certain state of happiness, purity, wisdom, perfection, or immortality" (Foucault, 1988, p.18).

It is clear that while these women want to keep up images as good women, they also want to survive in the urban environment mentally, physically and financially. Despite the rape and violence happening widely to factory workers in the urban environment, women need a sense of security from males who can protect them in dangerous situations. The values they were brought up with under patriarchal protection encourage them to seek a boyfriend to replace the absence of the protection of a brother and/or father in urban areas. Women were provided financial support from their boyfriends to cope with the struggle of financial hardship. Due to the exploitation in the workplace and loneliness of being far away from the family, the emotional support from boyfriends is needed.

Having a relationship is a strategy for survival, coping with loneliness and to avoid being victim in a confusing urban environment. Public discourse stigmatised the migrant 
women as low wage labourers working and living day by day without purpose. However, these women exercised their agency by maximising their choices of living and creating insurance to improve their lives and wellbeing. Outsiders might not understand and judge them for the way they choose to live and to be. Of these women, with limited social networks or education, and facing discrimination, Alisa in Factory B may have said it best regarding the negative image of the woman worker: "others will never understand because they have never been in my shoes" (Lisa, Factory B).

\subsection{Conclusion}

In conclusion, this chapter has discussed the extent to which working in the garment factories and living in the city have changed women's livelihoods and wellbeing. Also, it has examined the effects working and living in the city has had on women's agency. It argues that the women experienced oppression from their capitalist employers. Working in the garment factories reflects how capitalism works when women are exploited. Also, culture and social norms have influenced the preferences of women in the factory and created gender divisions of labour. This exploitation is intensified by sexual harassment and violence both inside and outside the workplace. Interestingly, the patriarchal ideology in the households also has had an impact on women's mindsets, often apparently accepting the male domination and leading to silence in various spheres.

Despite the challenges women faced, they have been able to develop strategies to cope with their situations. Some strategies might be seen to constitute empowerment among women. Some strategies might not result in achieving big goals, but at least they can bring about a positive sense of self to women. Although women have made attempts to improve their conditions, much attention and efforts from the government and relevant organisations are needed. It should not to be left only to women to fight to protect themselves. 


\section{Chapter 7 Conclusion}

\subsection{Introduction}

The central objective of this research was to explore the wellbeing and livelihood of the rural-urban migrant women working in the garment factories in Vientiane, Laos. It provided insights into the issues around migration, gender relations, urban livelihoods and wellbeing among these women.

With the help of feminist epistemology, the sustainable livelihood approach, and Marxist feminist, radical feminist and post structural feminist theory, the research was able to provide an in-depth analysis from the perspectives of these migrant women. It provided an inclusive understanding of how capitalism and patriarchy work, the impact of these systems on the lives of migrant women, and how women react both as objects and subjects. The points that were raised by the migrant women in this research represent a powerful image of what the women experienced, especially those from the ethnic minorities.

\subsection{Key findings}

The transition of the Lao economy from a centrally-planned to a market-oriented economy created a particular form of industrialization. This is driving people to migrate from rural to urban areas to seek employment. Garment factories are one of the industrialization strategies in the manufacturing industry. Although the economic policies pull young rural women to the city, they cannot be generalized as the only reason for their migration. This study found that all participants migrated voluntarily due to different push factors including to earn higher income, to escape domestic violence, to experience modernity, to follow religion, and to reveal their sexual identity in the case of tom (transgender men).

This research investigated the livelihoods and wellbeing of women after migrating to the city. It started with secondary questions which then led to the main research questions. The main findings of each question are below:

Sub Question one: What are the current livelihood and wellbeing conditions of migrant women working in the garment factories?

The research found that the working conditions in the garment factories were generally poor, and that the workers were vulnerable and exploited. This was evident from 
the excessive work hours, unfair payments, and sub-standard living conditions imposed on the workers.

Sub question two: To what extent has working in the garment factories and living in the city changed women's livelihood and wellbeing?

Working in the garment factory and living in a city opened up new possibilities for rural women. Women gained new opportunities to earn income in a formal wage economy, to experience city life and to enjoy their independent life. These experiences changed them from rural women to independent wage workers and breadwinners whom their families relied on.

Working and living in the city increased women's human, social and financial capital. However, upon securing these new opportunities women increased livelihood assets, these women were met with new forms of oppression. Rural migrant workers in Laos are seen as working class citizens who work for the profits of the elite garment factories owners. In reality, my findings showed that they were being exploited in several ways. Regarding human capital, women were trapped working in monotonous and repetitive jobs with no opportunity to progress further. The employers benefitted from their young bodies, women's productivity and their lack of legal knowledge. In terms of financial capital, the wages the women earned were only equal to or slightly above the minimum wage, a negligible difference in their livelihoods. Women were merely able to survive and enjoy a small taste of urban consumption. However, many women managed to send remittances back home. For physical capital, women were provided free accommodation and working facilities for living and working, however the quality of such facilities are below a suitable health and safety standard of living. Regarding social capital, the women were faced with social discrimination and were stigmatized with a bad image, often being portrayed as loose women that any man could get.

The answers to these sub-questions helped to elicit the answer to the main question: How has migration to the cities and factory work affected the livelihoods, wellbeing and development of women from rural areas in Laos?

There are positive and negative aspects, for the migrant women, of working and living in the city. This research on the livelihoods and wellbeing of women has brought me to discover some critical and emerging issues that the literature on Laos rarely pays attention to. 
These emerging issues are the sexuality of tom (transgender men), the incidence of sexual harassment and violence, and the agency of women.

The incidence of sexual harassment and violence is rooted in patriarchal ideology, social norms and the socialisation process. Women in this research were subjected to harassment in many forms. Although women were far away from their patriarchal families, they experienced patriarchy in the factories in the form of physical and verbal abuse from their male boss. These practices represent the power relations between men and women within the male-dominated hierarchy. Sexual harassment by male colleagues represents the power males have over women despite these men holding the same or a lower class position. Sexual violence experienced by women in the society revealed how males perceived women as easy targets. Despite the prevalence of these incidents, these males went unpunished for their actions and the women were found to tolerate this behaviour by keeping silent.

Although the societal and economic structure exploits and oppresses women, this does not explain the complete picture. The system cannot prevent women from resisting and exercising their agency. There are women who know how to seek alternative ways of surviving. This can be seen in the case of individual women trying to learn new skills from their peers in the factory despite the system not allowing this. Small transgressions in the factory were seen widely. This study found that women may have conflicting subjectivities, but they know how to change their subject positions and use this to their advantage. Sometimes, the women broke their rural norms and took the role of working women to claim their deserved rights. Other times, women individually and collectively took on their rural identities, as perceived by others, as slow, 'stupid,' and unsuitable for the capitalist system, resisting in silence and aiming for a slowdown of overall production targets. Importantly, this research revealed that women planned ahead and thought carefully before making any life-altering decisions such as choosing their factories, choosing to leave work and choosing to enter multiple relationships. The choices some of the women made might not make sense to other people, but for them they were acts of agency and power to control their own lives.

\subsection{Limitations}

It is worth noting here that all of my participants were able to communicate fluently in Lao-tai which is the official language of Laos. Even though the women in my research could speak Lao-tai well, this does not represent all of the migrant women in the factory, since there 
were a certain number who could not communicate and/or did not feel confident speaking Lao-tai. I was aware that these women may have felt more comfortable able to express themselves more confidently in their ethnic language. Due to the language barrier, they may have been discouraged and not wanted to be interviewed. This was a lost opportunity for them to participate in the research as well as for me to gather more information, as they may have had useful information which only their native ethnic language can provide. The findings may have provided different insights if I had been able to interview those women.

Another limitation in this research was the limited time frame that was given. It was not easy to approach and research the participants due to the need for permission to be obtained, their long working hours, and their overtime schedules. I was only permitted to interact with women after working hours. Although I was permitted to approach women in their dormitories, I was not permitted to observe a normal working day and the women's experience on the factory floor. Additionally, the majority of women finished work at 7pm and their only day off was Sunday. Naturally, after work, the women were tired, had their own personal chores to complete, and needed time to rest. I am very thankful for those who voluntary dedicated their time for me to interview them.

\subsection{Future Research Possibilities}

Through this study, several gaps in the research related to migrant women working in garment factories in Laos were identified. Below are further research areas that could contribute to the understanding of the experience of migrant women.

Several migrant women mentioned the prevalence of male sexual harassment and violence towards rural migrant women and the silent culture and accepting attitudes tolerating such practices. In-depth research of the norms, religions, customs and ideologies of what causes such a culture may be a good start to better understanding the power relations and structures that perpetuate such practices, as well as finding ways to change for women's betterment.

This study suggests that the participation of women in paid employment in the garment factories increased women's power, autonomy and agency within their patriarchal households due to their financial contributions. Still, one question that remains is the sustainability of these empowerment factors after the women had left their jobs. Whether 
the technical and life skills they obtained in the factory benefited them or if they were able to transfer these skills into their future careers and increase their bargaining power in their patriarchal households necessitates further research. Such studies will allow a researcher to examine the complexities of human capabilities and gender power relations.

The three factories in which the interviews were conducted were of medium to large size and provided a relatively good system in which they offered social security for women that worked in the factory. The condition and experience of women in the small-sized, homebased, and subcontracted factories, which were not recognized by foreign clients, might have totally different. The exploration of this particular group of factories will provide a more complete picture of the worker's experiences.

\subsection{Research contribution}

First of all, this research brings the voices of women out and provides better understanding with regard to their real life experiences, challenges and opportunities of being rural-urban migrant women working in garment factories in Vientiane.

Results and analysis of this research fill research gaps and contribute to the literature on migration, livelihoods, wellbeing, agency and empowerment of women workers in Laos. This research explores various dimensions of wellbeing - human, social, financial and physical capital - across local, national and international levels. As a result, these findings help inform policymakers, factories and relevant institutions, making them aware of what their roles are, and could be, in influencing women's working and living conditions. Furthermore, the findings help those in relevant institutions to realise what they can do to improve the wellbeing and development of women.

This research contributes to the international literature by reflecting on the cases of Laos and relates them to international issues. It provides insight into what experiences women in Laos and international have shared despite different geographical, economic and cultural context. These shared experiences of women are very important because they are not merely personal, but political matters. Particularly, the shared experiences of the exploitation and oppression happen specifically to women worldwide under the economic and social system requires global attention. 


\subsection{Final reflection}

In conclusion, this research explored the livelihoods and wellbeing of rural-urban women working in the factory in Vientiane, Laos. This research highlighted some important issues that need to be addressed to enhance the wellbeing and development of women workers in Laos. These issues range from poor conditions to the prevalence of violence inside and outside of the factories.

Surprisingly, this research uncovered violence and harassment from males to females inside and outside of the factories. Most of the time, the women were seen as victims. Some of the women put themselves in risky situations and lacked knowledge of how to pull themselves out of these situations. To cope with this issue, I would recommend having female mentors in each factory's dormitories who act as life coaches and role model to teach life skills to women, particularly newcomers who are most vulnerable to the urban environment. These life skills include knowledge of rights, consent, prevention and negotiation with men in order to make women well aware of potential risks of and how to prevent or combat sexual harassment and violence. This mentor program can come in the forms of peers to peers or 'sisters to sisters,' educating and supporting each other collectively. This kind of mentoring program will allow women to watch out and empower each other.

The most effective ways to address vulnerability issues of migrant women are through the effective role of government and involvement of civil societies. Most importantly, the government should recognize the way women workers themselves develop strategies to survive in their daily lives, and then provide support to encourage women to work out ways to control their own lives. That way women can realize their power, also women can be empowered and can empower themselves. 


\section{References}

Allen, A. (1998). Rethinking power. Hypatia, 13(1), 21-40.

Andersen, M., \& Hystock, D. (2009). Thinking about Women: Sociological perspective on Sex and Gender. United States: Pearson Education, Inc.

Anderson, E. (1995). Feminist epistemology: An interpretation and a defense. Hypatia, 10(3), 50-84.

Attanapola, C. T. (2006). Were they ever 'in place'? Sense of place and self-identities among migrant female export-processing zone workers in Sri lanka. Norsk Geografisk Tidsskrift-Norwegian Journal of Geography, 60(3), 217-226.

Barry, K. (1996). Vietnam's women in transition. New York: St. Martin's Press.

Batliwala, S. (1994). Women's empowerment in South Asia: Concepts and practices. New Delhi: Asian South Pacific Bureau of Adult Education.

Beasley, C. (1999). What is feminism?: An introduction to feminist theory. London: Sage.

Beechey, V. (1977). Some notes on female wage labour in capitalist production. Capital \& Class, 1(3), 45-66.

Bélanger, D., \& Pendakis, K. (2010). Vietnamese daughters in transition: factory work and family relations. The Asia-Pacific Journal: Japan Focus, 8(5), 1-11.

Birdsall, N., \& McGreevey, W. P. (1983). Women poverty and development. In: M. Buvinic, MA. Lycette, WP. McGreevy (Ed.), Women and poverty in the Third World (pp.3-13). Baltimore, Maryland: Johns Hopkins Univ. Press.

Brydon, L., \& Chant, S. H. (1989). Women in the Third World: Gender issues in rural and urban areas. New Brunswick, New Jersey: Rutgers University Press.

Bureau of Democracy, Human Rights and Labor. (2016). Laos 2016 Human Right Report. United States: United States Department of State, Bureau of Democracy, Human Rights and Labor. Retrieved from https://www.state.gov/documents/organization/265560.pdf 
CARE International Laos. (2012). Sewing the Line; A qualitative baseline analysis of the risks and opportunities posed for young women by migration from rural Laos to Vientiane for the purpose of employment in the garment industry. Vientiane: Care International Laos.

Carney, D. (1999). Approaches to sustainable livelihoods for the rural poor. London: Overseas Development Institute.

Carney, D., Drinkwater, M., Rusinow, T., Neefjes, K., Wanmali, S., \& Singh, N. (1999). Livelihoods approaches compared: a brief comparison of the livelihoods approaches of the United kingdom for international development (DFID), CARE, OXFAM and the United Nation Development Programme (UNDP). London: Department for International Development.

Chambers, R., \& Conway, G. (1992). Sustainable rural livelihoods: practical concepts for the 21st century. Brighton: Institute of Development Studies.

Cho, H., Zammit, A., Chung, J., \& Kang, I. (2004). Korea's miracle and crisis: What was in it for women? In Globalization, Export-oriented Employment and Social Policy (pp. 30-66). London: Palgrave Macmillan.

Cornwall, A. (2016). Women's empowerment: What works? Journal of International Development, 28(3), 342-359.

Creswell, J. W. (2009). Research design: qualitative, quantitative, and mixed methods approaches. Thousand Oaks, United States: SAGE Publications Inc: SAGE Publications Inc

DFID. (1999). Sustainable livelihoods guidance sheets. London, The Department for International Development. Retrieved from http://www.livelihoodscentre.org/documents/20720/100145/Sustainable+livelihoods+guida nce+sheets/8f35b59f-8207-43fc-8b99-df75d3000e86

Eisenstein, Z. R. (1979). Capitalist patriarchy and the case for socialist feminism. New York: Monthly Review Press.

Elmhirst, R. (2002). Daughters and displacement: migration dynamics in an Indonesian transmigration area. Journal of Development Studies, 38(5), 143-166. 
Elson, D., \& Pearson, R. (1981). “Nimble Fingers Make Cheap Workers”: An Analysis of Women's Employment in Third World Export Manufacturing. Feminist Review, (7), 87.

Fang, C., \& Dewen, W. (2008). Impacts of internal migration on economic growth and urban development in China. Beijing, China: International Organization for Migration (IOM) and Social Science Research Council (SSRC). Retrieved from http://lastradainternational.org/Isidocs/846_Migration_Development_SSRC_IOM.pdf\#page= 247.

Farrington, J., Ramasut, T., \& Walker, J. (2002). Sustainable livelihoods approaches in urban areas: General lessons, with illustrations from Indian cases. Overseas Development Institute London.

Foo, G. H., \& Lim, L. Y. (1989). Poverty, ideology and women export factory workers in South-east Asia. In Women, poverty and ideology in Asia (pp. 212-233). Springer.

Freeman, N. (2001). The Rise and Fall of Foreign Direct Investment in Laos, 1988-2000. PostCommunist Economies, 13(1), 101-119.

Gender Minorities Aotearoa. (2017). Glossary of Gender Related Terms and How to Use Them. Retrieved January 30, 2018, from https://genderminorities.com/database/glossarytransgender/

Gender Resource Information and Development Center. (2005). Lao PDR Gender Profile. Vientiane: Lao Women's Union.

Hancock, P. (2006). Violence, women, work and empowerment: Narratives from factory women in Sri Lanka's Export Processing Zones. Gender, Technology and Development, 10(2), 211-228.

Hancock, P., Carastathis, G., Georgiou, J., \& Oliveira, M. (2014). Women's economic empowerment and formal income: Sri Lankan Export Processing Zones (EPZs) and their impact on gender perceptions of empowerment. Norsk Geografisk Tidsskrift-Norwegian Journal of Geography, 68(5), 291-300.

Haspels, N. (2001). Action against sexual harassment at work in Asia and the Pacific. Bangkok, Thailand: International Labour Office. 
Hewamanne, S. (2003). Performing'Dis-respectability': New Tastes, Cultural Practices, and Identity Performances by Sri Lanka's Free Trade Zone Garment-Factory Workers. Cultural Dynamics, 15(1), 71-101.

Hlavka, H. R. (2014). Normalizing sexual violence: Young women account for harassment and abuse. Gender \& Society, 28(3), 337-358.

Jewkes, R., Flood, M., \& Lang, J. (2015). From work with men and boys to changes of social norms and reduction of inequities in gender relations: a conceptual shift in prevention of violence against women and girls. The Lancet, 385(9977), 1580-1589.

Jolly, S., \& Reeves, H. (2005). Gender and Migration (Overview Report). UK: BRIDGE. Retrieved from http://www.bridge.ids.ac.uk/sites/bridge.ids.ac.uk/files/reports/CEP-Mig-OR.pdf

Kabeer, N. (1994). Reversed realities: Gender hierarchies in development thought. London: Verso.

Kabeer, N. (1999). Resources, agency, achievements: Reflections on the measurement of women's empowerment. Development and Change, 30(3), 435-464.

Kabeer, N., Mahmud, S., \& Tasneem, S. (2011). Does paid work provide a pathway to women's empowerment? Empirical findings from Bangladesh. Retrieved from: https://core.ac.uk/download/pdf/61803081.pdf

Khamphouvong, L., \& Santasombat, Y. (2014). The Feminization of Modernity: A Case Study of Female Migrant Workers in a Garment Factory in Vientiane, Lao PDR (pp. 380-388). International Conference on Educational Reform (ICER 2014), Innovations and Good Practices in Education: Global Perspectives.

Krantz, L. (2001). The sustainable livelihood approach to poverty reduction. SIDA. Division for Policy and Socio-Economic Analysis, 44. Retrieved from:https://www.sida.se/contentassets/bd474c210163447c9a7963d77c64148a/thesustainable-livelihood-approach-to-poverty-reduction_2656.pdf

Kumar, R. (2014). Research Methodology: A Step-by-Step Guide for Beginners. SAGE.

Lao association of garment factories. (2018). Lao association of garment factories annual report 2017 (Unpublish report). Vientiane, Laos. 
Lao Statistics Bureau. (2015). Result of Population and Housing Census 2015. Vientiane, Laos: Lao Statistics Bureau, Ministry of Planning and Investment. Retrieved from https://lao.unfpa.org/sites/default/files/pub-pdf/PHC-ENG-FNAL-WEB_0.pdf

Lao Statistics Bureau. (2016). Statistic Yearbook 2016. Vientiane, Laos: Lao Statistics Bureau, Ministry of Planning nd Investment. Retrieved from https://www.lsb.gov.la/wpcontent/uploads/2018/09/final-yearbook-2016-New.pdf

Lawreniuk, S., \& Parsons, L. (2017). 'I know I cannot quit.' The Prevalence and Productivity Cost of Sexual Harassment to the Cambodian Garment Industry. Phnom Penh. Retrieved from https://insights.careinternational.org.uk/media/k2/attachments/SHCS_Full_Technical_Repor t_March_2017.pdf

Lengsavad, P., \& Vanthana, N. (2017). SEZ Developments, Industrialization and Servicification in Lao PDR (Industrialization through Servicification in Lao PDR) (pp. 104-125). JETRO Bangkok/IDEJETRO. Retrieved from http://www.ide.go.jp/library/English/Publish/Download/Brc/pdf/18.pdf

LGBTA Resource Center. (2019). Lesbian, Gay, Bisexual, Transgender, Queer, Intersex, Asexual Resource Center Glossary. Retrieved January 30, 2019, Retrieved from https://Igbtqia.ucdavis.edu/educated/glossary

Lim, L. Y. (1997). Capitalism imperialism and patriarchy: the dilemma of third-world women workers in multinational factories. In The Women Gender and Development Reader (pp. 216-229).

Malhotra, A., Schuler, S. R., \& Boender, C. (2002). Measuring women's empowerment as a variable in international development. In background paper prepared for the World Bank Workshop on Poverty and Gender: New Perspectives (pp. 1-59).

Mann, S. A. (2012). Doing feminist theory: From modernity to postmodernity. Oxford University Press New York, NY.

Massey, D. S., Arango, J., Hugo, G., Kouaouci, A., Pellegrino, A., \& Taylor, J. E. (1993). Theories of international migration: A review and appraisal. Population and Development Review, 19(3), 431-466. 
Mills, M. B. (1997). Contesting the margins of modernity: Women, migration, and consumption in Thailand. American Ethnologist, 24(1), 37-61.

Moser, C. O. (1998). The asset vulnerability framework: reassessing urban poverty reduction strategies. World Development, 26(1), 1-19.

MPI, \& UNDP. (2017). Graduation from least developed country status. The 5th National Human Development Report. Vientiane, Laos: Ministry of Planning and Investment.

National Commission for the Advancement of Women. (2015). Lao National Survey on Women's Health and Life Experiences 2014 A Study on Violence against Women. Vientiane, Laos: National Commission for the Advancement of Women, Lao PDR.

Nolintha, V., \& Jajri, I. (2016). The garment industry in Laos: technological capabilities, global production chains and competitiveness. Asia Pacific Business Review, 22(1), 110-130.

OECD. (2014). STRUCTURAL POLICY COUNTRY NOTES Lao PDR (the Economic Outlook for Southeast Asia, China and India 2014: Beyond the Middle-Income Trap). Retrieved from https://www.oecd.org/site/seao/Lao\%20PDR.pdf

Ong, A. (1988). The production of possession: spirits and the multinational corporation in Malaysia. American Ethnologist, 15(1), 28-42.

Oraboune, S. (2012). Industrial Readjustment in Lao PDR: Toward 2020. Industrial Readjustment in the Mekong River Basin Countries: Toward the AEC. BRC Research Report, (7). Retrieved from https://www.ide.go.jp/library/English/Publish/Download/Brc/pdf/07_chapter3.pdf

Phouxay, K. (2010). Patterns of migration and socio-economic change in Lao PDR. Department of Social and Economic Geography, Umeå University, Sweden. Retrieved from http://www.divaportal.org/smash/get/diva2:359288/FULLTEXT02

Phouxay, K., \& Tollefsen, A. (2011). Rural-urban migration, economic transition, and status of female industrial workers in Lao PDR. Population, Space and Place, 17(5), 421-434.

Powell, A., Sandy, L., \& Findling, J. (2015). Promising practices in workplace and organisational approaches for the prevention of violence against women. Our Watch. Melbourne: RMIT University. 
Pun, N. (2005). Made in China. Durham, North Carolina: Duke University Press.

Rigg, J. (2005). Living with transition in Laos: market integration in Southeast Asia. Routledge.

Rigg, Jonathan. (2007). An everyday geography of the global south. London: Routledge.

Rowland, J. (1997). Questioning Empowerment, Working with women in Honduras. OXFAM Print Unit, UK and Ireland.

Rowland, R., \& Klein, R. D. (1990). Radical feminism: Critique and construct. Feminist Knowledge: Critique and Construct, 271-303.

Rowlands, J. (1998). A Word of the Times, but What Does it Mean? Empowerment in the Discourse and Practice of Development. In H. Afshar (Ed.), Women and Empowerment Illustrations from the third world (pp. 11-34). London: Macmillan Press.

School of Oriental and African Studies. (n.d.). The livelihoods framework. Retrieved from https://www.soas.ac.uk/cedep-demos/000_P516_EID_K3736-Demo/unit1/page_15.htm Scoones, I. (1998). Sustainable rural livelihoods: a framework for analysis. London: Institute of Development Studies.

Scott, M., Bell, E., \& Holden, J. (2016). DFID Guidance Note: Shifting Social Norms to Tackle Violence Against Women and Girls (VAWG). London: VAWG Helpdesk.

Sene-Asa, O. (2006). The Transition of Young Women Working in Garment Factories into Prostitution Unpublish Masters' Thesis. Geneva: Graduate Institute of Development Studies.

Serrat, O. (2010). The Sustainable Livelihoods Approach. Washington, DC: Asian Development Bank.

Silverman, D. (2006). Interpreting qualitative data: Methods for analyzing talk, text and interaction. SAGE Publication.

Sisaleumsak, R. (2012). Modernity for young rural migrant women working in garment factories in Vientiane. Unpublished Thesis in Fulfilment of Masters Degree, Vientiane: National University of Laos.

Stark, O. (1991). The migration of labor. London: British Library Cataloguing.

Sultana, A. (2010). Patriarchy and women's subordination: A Theoretical Analysis. Arts Faculty Journal, 1-18. 
Sultana, F. (2007). Reflexivity, positionality and participatory ethics: Negotiating fieldwork dilemmas in international research. ACME: An International E-Journal for Critical Geographies, 6(3), $374-385$.

Tran, A. (2007). Alternatives to the "race to the bottom" in Vietnam: Minimum wage strikes and their aftermath. Labor Studies Journal, 32(4), 430-451.

United Nations. (1993). Declaration on the Elimination of Violence against Women. Retrieved October 1, 2019, from http://www.un.org/documents/ga/res/48/a48r104.htm

USAID. (2015). Working with men and boys to end violence against women and girls: approaches, challenges, and lessons. Washington, DC: United States Agency for International Development.

Vixathep, S. (2011). Efficiency and productivity change in Lao garment industry: A nonparametric approach. Journal of International Cooperation Studies, 19(1), 87-111.

Walby, S. (1990). Theorizing patriarchy / Sylvia Walby. Oxford, U.K. : B. Blackwell.

Weedon, C. (1997). Feminist practice \& poststructuralist theory. Oxford, U.K. : B. Blackwell

World Bank. (2012). Lao PDR: Labour standards and productivity in the garments export sector A survey of managers and workers. World Bank: Poverty Reduction and Economic Management Department.

World Health Organization, \& London School of Hygiene and Tropical. (2010). Preventing intimate partner and sexual violence against women Taking action and generating evidence. World Health Organization.

Zaitun, K. (2001). Action against sexual harassment in the workplace: Asian women's perspective. Paper for the ILO and the Committee for Asian Women, KualaLumpur.

Zaman, H. (2001). Paid work and socio-political consciousness of garment workers in Bangladesh. Journal of Contemporary Asia, 31(2), 145-160. 


\section{Appendices}

\section{Appendix 1.1 Information sheet for the interviews - migrant women}

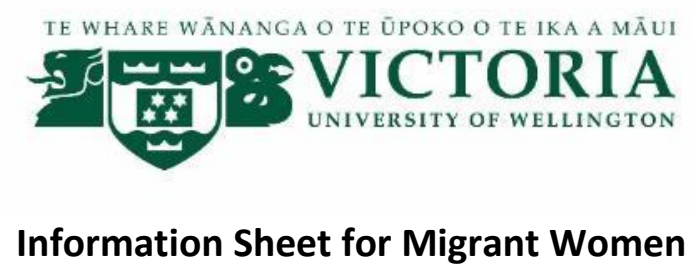

Research title: Understanding the urban livelihoods of migrant women working in factories in Vientiane, Laos

Researcher: Chanmala Homesana

supervisor: Prof John Overton

\section{Who I am?}

Sabyedee! My name is Chanmala Homesana. I am a Development Studies student completing a Master's degree at Victoria University of Wellington, New Zealand. To complete university requirements, I am undertaking a thesis titled "Understanding the urban livelihoods of migrant women working in factories in Vientiane, Laos".

The reason why I choose to conduct this research topic is that I am curious and interested to explore the experiences of rural women who migrate from their homeland to work in urban areas. I also hope the findings of this research will inform concerned authorities for better programme interventions and more holistic development policies.

This research has been approved by the Victoria University of Wellington Human Ethics Committee. The ethic approval number for this application is 26005.

\section{What is the aim of this study?}

This research aims:

- To explore the livelihood situations, challenges and opportunities of migrant women working in factories.

- To determine the existing contributions of both public and private sectors in strengthening women's livelihoods and supporting their access to livelihood assets. 
- To assess from women's perspective the effectiveness of the policies and interventions by the public and private sectors in enhancing the livelihoods of the women working in factories.

- To identify the gaps that policies and interventions have not been addressed, and find the ways to enhance them better.

\section{Why have you been invited to participate in this research?}

To achieve the objective of this research, the perspective of migrant women working in factories is the most crucial part. You have been identified as someone with a suitable level of experience who can contribute valuable insight to this study.

\section{What are the interview procedures?}

If you agree to participate in this research, a face-to-face interview will be conducted and last around 30 minutes. The interview is designed to explore your livelihood experiences as a rural-urban migrant woman working a factory in Vientiane. If you would like to know more details about the interview questions prior to the meeting, I will provide these as you request.

The location and time for the interview will depend on your convenience and availability. I will make audio recordings and take notes of discussions if you permit me to do so.

\section{How will the results be used?}

The result of this research will be published and held in the Victoria University of Wellington library. The results of this research might be used for producing journals, conference and academic reports.

\section{How will your confidentiality be protected?}

Your name and your personal details will remain confidential and will not be published or disclosed to anyone else. Your response will not be used in any way that may identify you. Also, all your responses in the form of interview transcriptions and audio tapes will be keep on password protected files, audio devices and computers. Only this thesis writer and supervisor will read the notes or transcript of your interview. Your interview data including quote will be combined, analysed and used in the thesis. 


\section{If you accept this invitation, what are your rights as a research participant?}

You are under no obligation to accept this invitation. If you decide to participate, you have the right to:

- decline to answer any particular question;

- $\quad$ withdraw from the interview any time with or without any reasons;

- $\quad$ ask for the recorder to be turned off at any time during the interview;

- $\quad$ withdraw from the study up until four weeks after conducting this interview;

- ask any questions about the study at any time;

- receive the summary of the interview within two weeks after conducting the interview and return your comments no later than two weeks after receiving the summary of the interview;

- receive summary of the research;

- $\quad$ keep your name confidential unless you give permission to the researcher to publish it.

\section{Contact points}

If you have any questions, please do not hesitate to contact either:

\section{Student:}

Name:

Course Master of Development Studies

School: School of Geography, Environment, and Earth Sciences

E-mail: homesachan@myvuw.ac.nz

\section{Supervisor:}

Name Prof. John Overton

Role: $\quad$ Course coordinator, Lecturer

School: School of Geography, Environment, and Earth Sciences

E-mail: John.overton@vuw.ac.nz

\section{Human Ethics Committee information}

If you have any concerns about the ethical conduct of the research you may contact the Victoria University HEC Convenor: Dr Judith Loveridge, email hec@vuw.ac.nz, phone 044636028 


\section{Appendix 1.2 Information sheet for the interviews - public and private sector}

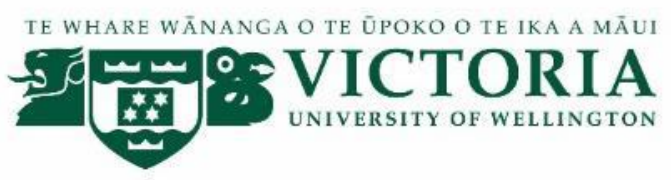

Information Sheet for public and private sector

including government officials, NGOs, civil societies, enterprises and academics

Research title: Understanding the urban livelihoods of migrant women working in factories in Vientiane, Laos

Researcher: Chanmala Homesana

supervisor: Prof John Overton

\section{Who am I?}

Sabyedee! My name is Chanmala Homesana. I am a Development Studies student completing a Master's degree at Victoria University of Wellington, New Zealand. To complete university requirements, I am undertaking a thesis titled "Understanding the urban livelihoods of migrant women working in factories in Vientiane, Laos".

The reason why I choose to conduct this research topic is that I am curious and interested to explore the experiences of women that appear to be a vulnerable group in the eyes of Lao society. I also hope the findings of this research will inform concerned authorities for better programme interventions and more holistic development policies.

This research has been approved by the Victoria University of Wellington Human Ethics Committee. The ethic approval number for this application is 26005.

\section{What is the aim of this study?}

This research aims:

- To explore the livelihood situations, challenges and opportunities of migrant women working in factories.

- To determine the existing contributions of both public and private sectors in strengthening women's livelihoods and supporting their access to livelihood assets. 
- To assess from women's perspective the effectiveness of the policies and interventions by the public and private sectors in enhancing the livelihoods of the women working in factories.

- To identify the gaps that policies and interventions have not been addressed, and find the ways to enhance them better.

\section{Why have you been invited to participate in this research?}

To achieve the objective of this research, the perspective of government officials, development practitioners, consultants, academics and enterprises are the core component of the study. You have been identified as someone with a suitable level of experience and position who can contribute valuable insight to this study.

\section{What are the interview procedures?}

If you agree to participate in this research, a face-to-face interview will be conducted and last around one hour. The interview is designed to explore your experiences and perspectives working in or contributing to the issues of rural-urban migrant women working in factories in Vientiane. If you would like to know more details about the interview questions prior to the meeting, I will provide these as you request.

The location and time for the interview will depend on your convenience and availability. I will make audio recordings and take notes of discussions if you permit me to do so. Also, with your permission, I would like to attend the meetings or conferences held by your institution to observe what is being discussed and how participants are engaged.

\section{How will the results be used?}

The result of this research or thesis will be published and held in the Victoria University of Wellington library. The results of this research might be used for producing journals, conference and academic reports.

\section{How will your confidentiality be protected?}

Your name and your personal details will remain confidential and will not be published or disclosed to anyone else. Your response will not be used in any way that may identify you. Also, all your responses in the form of interview transcriptions and audio tapes will be keep on password protected files, audio devices and computers. Only this thesis writer and 
supervisor will read the notes or transcript of your interview. Your interview data including quote will be combined, analysed and used in the thesis.

\section{If you accept this invitation, what are your rights as a research participant?}

You are under no obligation to accept this invitation. If you decide to participate, you have the right to:

- decline to answer any particular question;

- $\quad$ withdraw from the interview any time with or without any reasons;

- $\quad$ ask for the recorder to be turned off at any time during the interview;

- $\quad$ withdraw from the study up until four weeks after conducting this interview;

- $\quad$ ask any questions about the study at any time;

- receive the summary of the interview within two weeks after conducting the interview and return your comments no later than two weeks after receiving the summary of the interview;

- receive summary of the research;

- $\quad$ keep your name confidential unless you give permission to the researcher to publish it.

\section{Contact points}

If you have any questions, please do not hesitate to contact either:

\section{Student:}

Name: Chanmala Homesana

Course Master of Development Studies

School: School of Geography, Environment, and Earth Sciences

E-mail: $\quad \underline{\text { homesachan@myvuw.ac.nz }}$
Supervisor:

$\begin{array}{ll}\text { Name } & \text { Prof. John Overton } \\ \text { Role: } & \text { Course coordinator, Lecturer } \\ \text { School: } & \text { School of Geography, } \\ & \begin{array}{l}\text { Environment, and Earth Sciences } \\ \text { E-mail: }\end{array} \text { John.overton@vuw.ac.nz }\end{array}$

\section{Human Ethics Committee information}

If you have any concerns about the ethical conduct of the research you may contact the Victoria University HEC Convenor: Dr Judith Loveridge, email hec@vuw.ac.nz, phone 044636028 


\section{Appendix 1.3 Information sheet for focus groups}

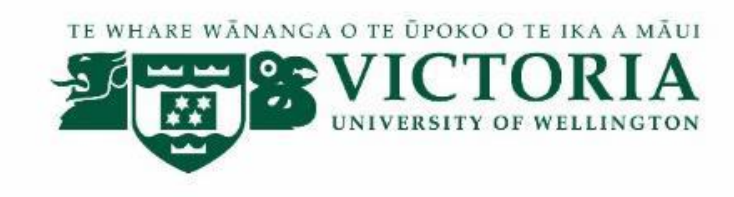

\section{Information Sheet of Women Focus Groups}

Research title: Understanding the urban livelihoods of migrant women working in factories in Vientiane, Laos

Researcher: Chanmala Homesana

supervisor: Prof John Overton

\section{Who am I?}

Sabyedee! My name is Chanmala Homesana. I am a Development Studies student completing a Master's degree at Victoria University of Wellington, New Zealand. To complete university requirements, I am undertaking a thesis titled "Understanding the urban livelihoods of migrant women working in factories in Vientiane, Laos".

The reason why I choose to conduct this research topic is that I am curious and interested to explore the experiences of women that appear to be a vulnerable group in the eyes of Lao society. I also hope the findings of this research will inform concerned authorities for better programme interventions and more holistic development policies.

This research has been approved by the Victoria University of Wellington Human Ethics Committee. The ethic approval number for this application is 26005.

\section{What is the aim of this study?}

This research aims:

- To explore the livelihood situations, challenges and opportunities of migrant women working in factories.

- To determine the existing contributions of both public and private sectors in strengthening women's livelihoods and supporting their access to livelihood assets.

- To assess from women's perspective the effectiveness of the policies and interventions by the public and private sectors in enhancing the livelihoods of the women working in factories. 
- To identify the gaps that policies and interventions have not been addressed, and find the ways to enhance them better.

\section{Why have you been invited to participate in this research?}

To achieve the objective of this research, the perspective of migrant women working in factories is the most crucial part. You have been identified as someone with a suitable level of experience who can contribute valuable insight to this study.

\section{What are the focus group discussion procedures?}

The focus group discussion will be conducted around one to two hours. There will be around 5 to 10 people in your group and the following topics will be discussed among group members.

- Your livelihood experiences, challenges and opportunities;

- The way you access to livelihood assets;

- Your views on how to improve your livelihood situations;

- Your aspiration and goal in life and how to achieve them;

- Your opinion on how can the public and private sector support you to achieve your livelihood outcome;

The location and time for the interview will depend on your convenience and availability. I will make audio recordings and take notes of discussions if you permit me to do so.

If you are agreed to participate in the focus group discussion, you will have to follow the following focus group ground rules:

- Everyone opinion and experiences are important and I encourage everyone to talk in the discussion.

- There is no right or wrong answer. It is valuable to hear all side of the story both positive and negative. Group members will not always agree with one another ideas, but each member must always show respect for one another. 
- Please be aware at all time that what share within the group by everyone is confidential. This means if you decide to participate, you agree that you will not share what was said in the group with others.

- If any participant decides to withdraw his/her contribution from the group discussion, the whole data of the group will be destroyed.

\section{How will the results be used?}

The result of this research or thesis will be published and held in the Victoria University of Wellington library. The results of this research might be used for producing journals, conference and academic reports.

\section{How will your confidentiality be protected?}

Your name and your personal details will remain confidential and will not be published or disclosed to anyone else. Your response will not be used in any way that may identify you. Also, all your responses in the form of interview transcriptions and audio tapes will be keep on password protected files, audio devices and computers. Only this thesis writer and supervisor will read the notes or transcript of your interview. Your interview data including quote will be combined, analysed and used in the thesis.

\section{If you accept this invitation, what are your rights as a research participant?}

You are under no obligation to accept this invitation. If you decide to participate, you have the right to:

- decline to answer any particular question;

- withdraw from the interview any time with or without any reasons;

- $\quad$ ask for the recorder to be turned off at any time during the discussion;

- withdraw from the study up until four weeks after conducting this discussion;

- $\quad$ ask any questions about the study at any time;

- Receive the summary of the discussion within two weeks after conducting the focus group discussion and return your comments no later than two weeks after receiving the summary of the discussion;

- Receive summary of the research; 
- Keep your name confidential unless you give permission to the researcher to publish it.

\section{Contact points}

If you have any questions, please do not hesitate to contact either:

\section{Student:}

Name: Chanmala Homesana

Course Master of Development Studies

School: School of Geography, Environment, and Earth Sciences

E-mail: homesachan@myvuw.ac.nz

\section{Supervisor:}

Name Prof. John Overton

Role: $\quad$ Course coordinator, Lecturer

School: School of Geography,

Environment, and Earth Sciences

E-mail: John.overton@vuw.ac.nz

\section{Human Ethics Committee information}

If you have any concerns about the ethical conduct of the research you may contact the Victoria University HEC Convenor: Dr Judith Loveridge, email hec@vuw.ac.nz, phone 044636028 


\section{Appendix 2.1 Participant consent form - Interviews}

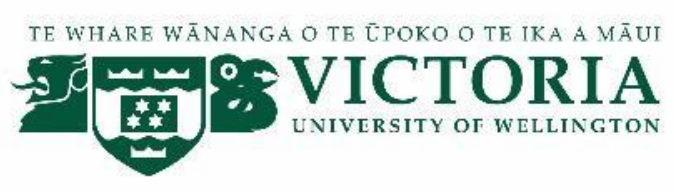

CONSENT TO INTERVIEW

Research title: Understanding urban livelihood of rural-urban migrant women working in the factory in Vientiane, Laos

Researcher: Chanmala Homesana

Supervisor: Prof John Overton

I have read the Information Sheet and the project has been explained to me. My questions have been answered to my satisfaction. I understand that I can ask further questions at any time.

\section{I understand that:}

- I may withdraw from this study at any point up until four weeks after conducting the interview, and any information that I have provided will be returned to me or destroyed.

- $\quad$ The identifiable information I have provided will be destroyed on 1 March 2023.

- Any information I provide will be kept confidential to the researcher and the supervisor.

- I understand that the results will be used for a master thesis or academic publications and/or presented to conferences.

- My name will not be used in reports, nor will any information that would identify me.

Please tick as appropriate:

- I would like to receive a summary of my interview

Yes

No

- I would like to receive a copy of the final report and have added my email Yes

No

address below

- I agree the interview being audio/ video recorded.

Yes

No

- I agree to some of my statements being quoted in the research.

Yes

No

Signature of participant: Date:

Name of participant: Contact details: 


\section{Appendix 2.2 Participant consent form - Focus groups}

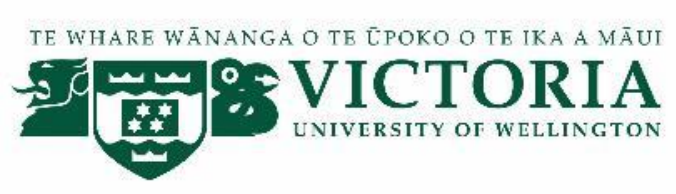

\section{CONSENT TO FOCUS GROUP DISCUSSION}

Research title: Understanding urban livelihood of rural-urban migrant women working in the factory in Vientiane, Laos

Researcher: Chanmala Homesana

Supervisor: Prof John Overton

I have read the Information Sheet and the project has been explained to me. My questions have been answered to my satisfaction. I understand that I can ask further questions at any time.

\section{I understand that:}

- I may withdraw from this study at any point up until four weeks after conducting this interview, and any information that I have provided will be returned to me or destroyed.

- The identifiable information I have provided will be destroyed on 1 March 2023.

- Any information I provide will be kept confidential to the researcher and the supervisor.

- I understand that the results will be used for a master thesis or academic publications and/or presented to conferences.

- $\quad$ My name will not be used in reports, nor will any information that would identify me.

\section{Please tick as appropriate:}

- I would like a summary of my interview

Yes $\square$

No

- I would like to receive a copy of the final report and have added my email Yes

No

address below

- I agree the focus groups being audio/video recorded.

Yes

No

- I lagree to some of my statements being quoted in the research.

Yes

No

- I agree to follow the ground rules of the focus group discussion

Yes

No

Signature of participant: Name of participant: Date: Contact details: 


\section{Appendix 3.1 Interview schedules}

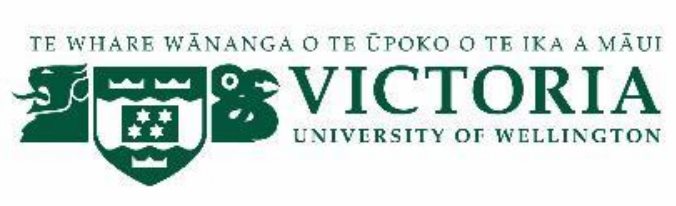

\section{Interview Schedules}

Research title: Understanding urban livelihood of rural-urban migrant women working in the factory in Vientiane, Laos.

Researcher: Chanmala Homesana

Supervisor: Prof John Overton

\section{Interview questions for migrant women working in the factories}

\section{Get to know the participant}

1. Can you give an introduction about yourself? such as who you are, which province you come from, what you did before coming here and why you migrated.

\section{Livelihood experiences in rural home area}

2. Can you describe the livelihood experiences in your home area? such as characteristics of people, traditions, culture, your challenges and opportunities.

3. Can you describe the livelihood assets such as financial, natural and social resources in your home area? And how do you access them?

4. How do you feel about your home area?

\section{Livelihood experiences after migrating to the urban areas}

5. Can you discuss your livelihood experiences of working and living in the city?

6. What kind of livelihood assets and resources are available for you here? And can you access those resources? If no, what prevents you from accessing them? Have the resources been adequate for your livelihood?

7. How is the social network here? Are you aware of, know of or participate in the existing networks such as Lao women union and Lao youth union?

8. What skills, knowledge and capabilities have you gained after living and working in urban areas? 
9. How do you feel about urban areas? Do you perceive yourself differently?

\section{Livelihood strategies}

10. What kind of shocks, difficulties and changes do you experience after moving to, establishing your life, working and living in urban areas?

11. Please discuss how do you cope and adapt to the challenges you experiences?

\section{Supporting services, expectation and motivation}

12. Please discuss the supports provided to you by the public and private sectors, such as their availabilities, effectiveness and the improvement of these services.

13. How do you want your current livelihood to be improved?

14. What are your goals in life? What do you want to achieve in the short term and long term? What do you want your future career to be?

15. What skills and knowledge have you gain so far to pursue your career?

16. Can you discuss about the supports from public and private sector? How do these supports help you to achieve your career and goals?

\section{Focus group Factory women}

\section{Livelihood challenges}

1. What are challenges and opportunities do you encounter being rural-urban migrant factory women at workplace and public place?

2. Please discuss how did you establish your life in urban areas?

\section{Livelihood assets}

3. What kind of natural resources, infrastructure and services are available for you here? And can you access those resources? If not, what prevents you from accessing them? If yes, have the resources been adequate for your livelihood?

4. What social networks or groups exist here? How do you participate or keep contact with such groups? How does the participation and access to these networks influence your livelihood opportunities?

5. How do you manage your savings? Can you access any financial resources and financial service organisations? 
6. What kind of knowledge, information, technologies and skills are important to you to establish your life in urban areas? Can you access to those resources?

\section{Livelihood strategies and adaptation}

7. How can you as a collective group cope and adapt to challenges at workplace and daily life?

8. Please discuss how can you make your voice heard? How do you empower your group?

9. Please discuss about right issues such as your knowledge and awareness of rules, laws, rights and legislation that important for living in urban areas.

10. What will you suggest to related institutions regarding to your livelihood?

11. How would you like your livelihood to be improved?

\section{Interview questions for the public and private sector}

\section{Getting to know participants}

1. Can you describe about yourself such as your position, your experiences in dealing with industrial or labour policies development in Laos?

2. What is your perspective on the issues that Lao factories and factory workers especially women face today? Do you think there is any difference between male and female workers in terms of livelihood condition?

The institutional policies, strategies and interventions

3. What policies, strategies and interventions have your institutions implemented to enhance/improve the factory sector and the livelihood of factory workers especially female workers?

4. How have your policies, strategies, interventions and resources improve factory workers' access to livelihood assets?

5. What are the strengths and challenges in using these policies, strategies and intervention?

The impact of policies, strategies and interventions

6. To what extent or how effective do you think your policies and interventions in addressing livelihood challenges, enhancing livelihood opportunities and supporting livelihood expectation of factory women? 
7. Please discuss how do other organisations or key stakeholders engage in the development process of factory workers related policy?

8. Please discuss how does the ASEAN economic community integration affect Lao factories in terms of policies and worker livelihoods?

\section{The lessons learned}

9. In your previous experience, please discuss what are your lessons learned in improving factory women living and working condition? what do you think the public and private sector could have done better?

10. This is the end of our interview; please feel free to add or give comments. 


\section{Appendix 4.1 Human ethics approval}

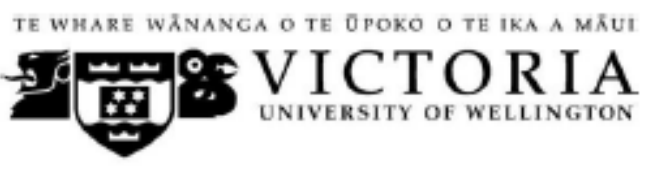

MEMORANDUM

\begin{tabular}{l|l}
\hline TO & Chanmala Homesana \\
\hline FROM & Dr Judith Loveridge, Convenor, Human Ethics Committee \\
\hline DATE & 20 May 2018 \\
\hline PAGES & 1 \\
\hline \multicolumn{2}{|l|}{} \\
\hline SUBJECT & $\begin{array}{l}\text { Ethics Approval: 26005 } \\
\text { Understanding urban livelihoods of rural-urban migrant women } \\
\text { working in factories in Laos }\end{array}$ \\
\hline
\end{tabular}

Thank you for your application for ethical approval, which has now been considered by the Human Ethics Committee.

Your application has been approved from the above date and this approval is valid for three years. If your data collection is not completed by this date you should apply to the Human Ethics Committee for an extension to this approval.

Best wishes with the research.

Kind regards

Judith Loveridge

Convenor, Victoria University Human Ethics Committee 


\section{Appendix 5.1 Support letter from supervisor for data collection}

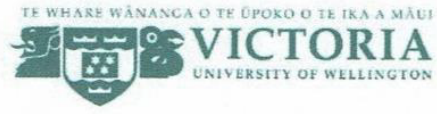

School of Geography, Environment and Earth Science Victoria University of Wellington, Kelburn parade,

Wellington 6012 New Zealand

Email: geo-enquiries@vuw.ac.nz Phone: +64 44635337

Date: 10 May 2018

\section{To Whom It May Concern}

I am writing this letter as the supervisor of Ms. Chanmala Homesana to support her in collecting data for her master thesis in her home country, Laos.

Chanmala was awarded New Zealand ASEAN Scholarship to study a Master of Development Studies at Victoria University of Wellington, New Zealand. In order to complete her master degree, Chanmala needs to conduct research and write a thesis based on the fieldwork in her home country, Laos.

Chanmala proposes to conduct a research on "understanding the livelihood of rural-urban migrant women working in the factories" in Vientiane, Laos from 4 June to 20 August 2018.

Therefore, I am writing this letter to support her and urge related organisations to cooperate and assist her in providing necessary information to complete her thesis.

If you require any further information please contact me on John.overton@vuw.ac.nz

Your sincèrely,

Prof. John Overton

Course coordinator, Lecturer

School of Geography,

Environment, and Earth Sciences

John.overton@vuw.ac.nz 